\title{
Las TIC y la \\ Ingeniería Gráfica
}

Oscar Farrerons Vidal, Noelia Olmedo Torre

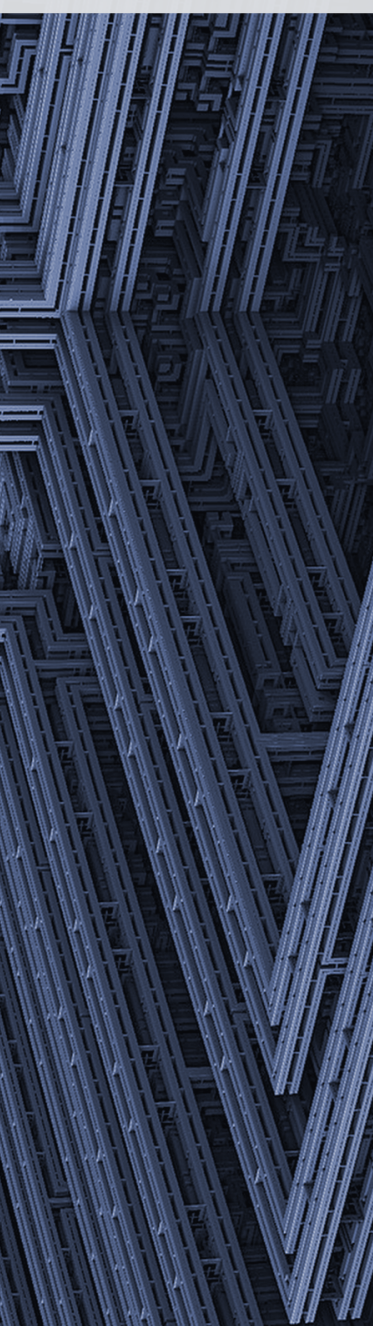

Omniascience


- 


\section{Las TIC y la Ingeniería Gráfica}

Oscar Farrerons Vidal Doctor en Ingeniería Multimedia y Arquitecto

Noelia Olmedo Torre Doctora en Ingeniería Multimedia e Ingeniera de Telecomunicaciones 
LAS TIC Y LA INGENIERÍA GRÁFICA

Autores:

Oscar Farrerons Vidal

Noelia Olmedo Torre

Universitat Politècnica de Catalunya

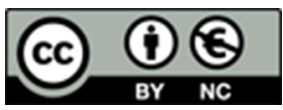

ISBN: 978-84-944673-4-9

DOI: http://dx.doi.org/10.3926/oms.306

(C) OmniaScience (Omnia Publisher SL) 2016

(C) Diseño de cubierta: OmniaScience

OmniaScience no se hace responsable de la información contenida en este libro y no aceptará ninguna responsabilidad legal por los errores u omisiones que puedan existir. 


\section{ÍNDICE}

Índice de llustraciones $\ldots \ldots \ldots \ldots \ldots \ldots \ldots \ldots \ldots \ldots \ldots \ldots \ldots \ldots \ldots \ldots$

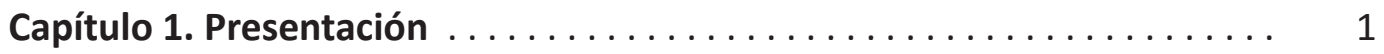

Capítulo 2. Introducción. ......................... 5

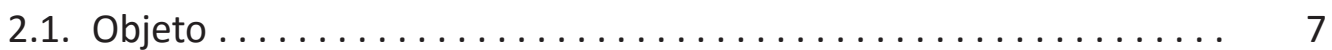

2.2. Metodología de trabajo $\ldots \ldots \ldots \ldots \ldots \ldots \ldots \ldots \ldots \ldots \ldots, 7$

2.3. Universo de la investigación $\ldots \ldots \ldots \ldots \ldots \ldots \ldots \ldots \ldots \ldots \ldots$

2.4. Delimitación cronológica ...................... 9

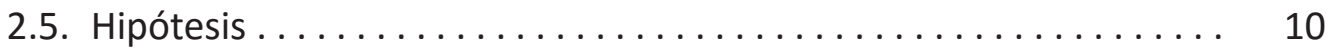

Capítulo 3. Antecedentes.......................... 11

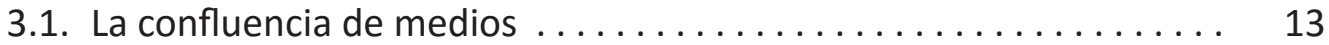

3.2. Evolución de la universidad española.................. 24

3.3. La ingeniería industrial en España. ................. 35

3.4. Enseñanzas históricas de la Ingeniería Gráfica en España . . . . . . 43

3.5. Estudio comparativo del área en Europa y USA ............. 61

3.6. Estudio conceptual y semántico ................... 67

3.7. Las TIC, evolución informática en el Área Gráfica . . . . . . . . . . 80

3.8. Herramientas tecnológicas basadas en las TIC ............ 94

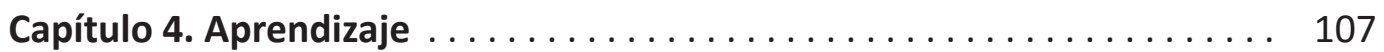

4.1. Modelos de Aprendizaje ......................... 109 
4.2. Aprendizaje Virtual. ........................ 112

Capítulo 5. Docencia............................. 117

5.1. El profesor no enseña; el alumno aprende ............. 119

5.2. Docencia semipresencial ...................... 122

5.3. Informatización de la docencia .................... 123

5.4. Evaluación continuada............................ 125

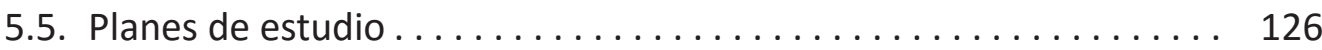

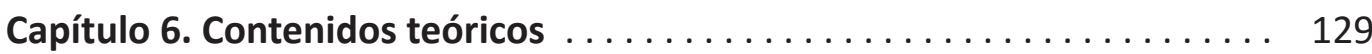

6.1. Geometría Descriptiva ...................... 131

6.2. Normalización industrial ........................ 132

6.3. Multimedia ........................... 133

6.4. Lenguaje de Modelado de Realidad Virtual (VRML) . . . . . . . . 135

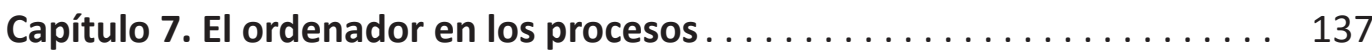

7.1. Animación por ordenador ....................... 139

7.2. Enseñanza Asistida por Ordenador (EAO) . . . . . . . . . . . 139

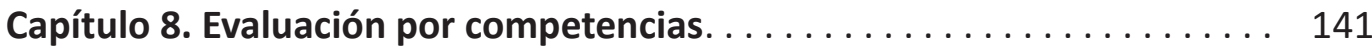

8.1. Estudios sobre competencias en Ingeniería . . . . . . . . . . . . 144

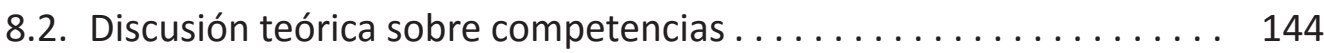

8.3. Competencias transversales en Ingeniería Gráfica . . . . . . . . . . 146

Capítulo 9. Conclusiones . . . . . . . . . . . . . . . . . . . . . . . 149

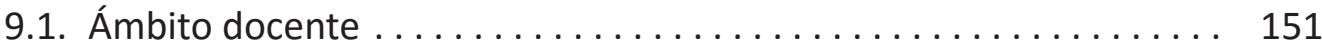

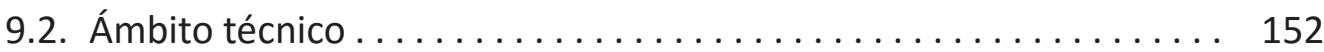

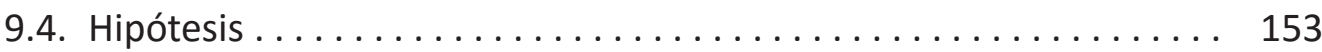

Bibliografía..................................... 155

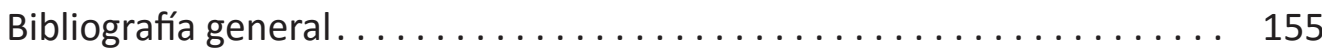

Bibliografía congresos. ........................... 162

Bibliografía referenciada ......................... 173

Acrónimos ......................................... 175 


\section{ÍNDICE DE ILUSTRACIONES}

Ilustración 1. Universidad pública/privada $\ldots \ldots \ldots \ldots \ldots \ldots \ldots \ldots \ldots$

Ilustración 2. Presencialidad universitaria $\ldots \ldots \ldots \ldots \ldots \ldots \ldots \ldots \ldots \ldots$

Ilustración 3. Universidad pública/privada (por no estudiantes) . . . . . 37

Ilustración 4. Presencialidad universitaria (por no estudiantes) . . . . . . 37

Ilustración 5. Categorías profesorado universitario ............ 50

Ilustración 6. Doctores universitarios. .................... 50

Ilustración 7. Evolución categorías profesorado universitario .......... 51

Ilustración 8. Departamentos de Ingeniería Gráfica + Proyectos. ....... 52

Ilustración 9. Tipo de asignatura en Ingeniería Gráfica ........... 53

Ilustración 10. Tipos de créditos en las asignaturas de IG . . . . . . . . . 54

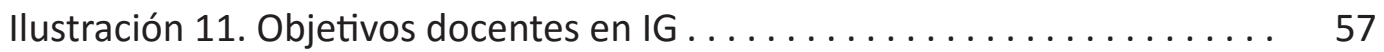

Ilustración 12. Autores más recomendados en bibliografía IG . . . . . . . 59

Ilustración 13. Universidades con más bibliografía IG . ........... 60

Ilustración 14. Acceso a las TIC en la OCDE ..................... 62

Ilustración 15. Tabla Universidades CLUSTER 2002-2011 . . . . . . . . . . 63

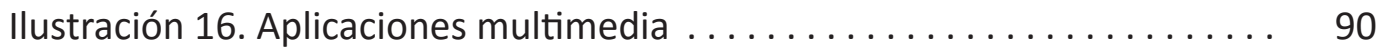

Ilustración 17. Relación inversa costes/usuarios en Internet. . . . . . . . . 92

Ilustración 18. Aprendizaje y motivación . . . . . . . . . . . . . . . . 109

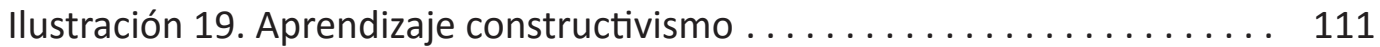

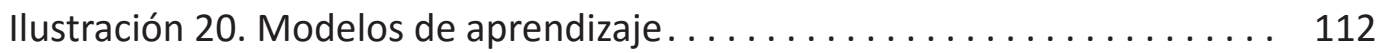

Ilustración 21. Entornos de aprendizaje virtual. . . . . . . . . . . . . 113

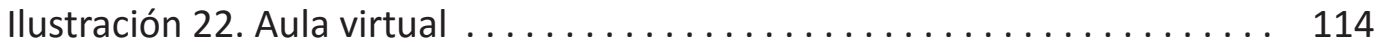

Ilustración 23. Modelo docente clásico . . . . . . . . . . . . . . . . . 120 
Ilustración 24. Nuevo paradigma docente. . . . . . . . . . . . . . 121

Ilustración 25. Evolución docencia . . . . . . . . . . . . . . . . . . . . 123

Ilustración 26. Ventajas docencia semipresencial. . . . . . . . . . . 123

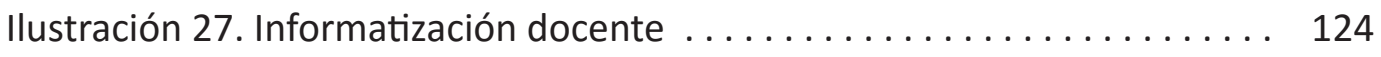

Ilustración 28. Evaluación Continuada . . . . . . . . . . . . . . . . . . 125

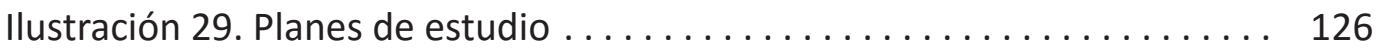

Ilustración 30. Geometría descriptiva ..................... 132

Ilustración 31. Pros y contras tecnología multimedia............... 134

Ilustración 32. Competencias en la empresa (Llorens, ACET) . . . . . . . . . 145

Ilustración 33. Competencias IG (Ortega, Rojas, García-García) . . . . . . . . 147 
CAPítulo 1

\section{Presentación}



El libro que tienen en sus manos es un trabajo de investigación que tiene por objeto estudiar las técnicas docentes de Ingeniería Gráfica en los estudios de ingeniería industrial en España, y analizar de forma empírica la planificación docente del área en la Universidad Politécnica de Catalunya (UPC).

El trabajo está centrado en el estudio de las aportaciones teóricas llevadas a cabo por parte de diferentes autores y presentadas públicamente en congresos relevantes en nuestro ámbito de investigación, referentes a:

- Innovación Educativa en las Enseñanzas Técnicas

- Docencia Universitaria e Innovación

- Ingeniería Gráfica

Se han repasado las aportaciones presentadas en los congresos CUIEET, CIDUI e INGEGRAF desde finales de los años 90, teniendo en cuenta los cambios más importantes producidos en el entorno universitario español, y su influencia en la docencia de la Ingeniería Gráfica:

- Aceleración en los cambios de los planes docentes desde los antiguos planes de estudio de 1964 y 1972.

- Nacimiento, muerte y modificación de asignaturas implementadas en el área de conocimiento de la ingeniería gráfica.

- Progresiva e imparable reducción de horas lectivas en las asignaturas del área gráfica.

- Incorporación del Dibujo Asistido por Ordenador (DAO) como herramienta fundamental en el cambio de la ingeniería gráfica partir de 1993. Y posterior 
expansión del CAD paramétrico a raíz de la migración de estaciones de trabajo tradicionales a ordenadores personales.

- Incorporación imparable de las nuevas Tecnologías de la Información y la Comunicación (TIC) en las aulas universitarias en general, y en las de la Ingeniería Gráfica muy en particular.

- Nuevos formatos aularios: las aulas informáticas con acceso a Internet.

- Nuevas metodologías docentes basadas en Aplicaciones Didácticas Interactivas (ADI)

- Implantación completa de los nuevos planes docentes basados en el Espacio Europeo de Educación Superior (EEES)

Todos estos cambios han propiciado una revisión continua de objetivos, contenidos y métodos docentes, adaptado a las transformaciones en el marco de la enseñanza universitaria. 
CAPítulo 2

\section{Introducción}





\subsection{Objeto}

Este libro tiene por objeto aportar el mayor número de elementos de juicio posibles que permitan interpretar la posición del área de conocimiento de Ingeniería Gráfica en el marco del conjunto de la docencia universitaria española en general, y de la docencia en ingeniería en particular. Para ello, se ha observado la práctica desaparición de los sistemas de representación sobre soporte papel, desplazados por herramientas digitales de modelado geométrico 3D paramétrico. Por otro lado, y como consecuencia del modelo de enseñanza-aprendizaje promovido por la consolidación del EEES, se ha modificado el esquema formativo clásico basado en primeros y segundos ciclos, unificando los nuevos grados (de 4 años de duración) con contenidos y objetivos homogéneos para permitir la movilidad, y especializando los nuevos máster.

\subsection{Metodología de trabajo}

Para el trabajo de análisis teórico, el método seguido se ha basado en cuatro fases claramente diferenciadas, aunque en varios casos se ha trabajado de forma simultánea en varias de las citadas fases.

La primera fase ha consistido en la búsqueda de la información. Dos tipos de información: una de tipo teórico general, a partir de actas de los congresos de referencia; y otra de particular, a partir de las guías docentes de las escuelas donde se imparte docencia el departamento EGE UPC. Conseguir las actas de los congresos de los últimos tres lustros se ha convertido en un trabajo de variada sistemática: en algunos casos (pocos) de fácil acceso a través de Internet, en otros buscando los formatos 
digitales en las bibliotecas (principalmente de la UPC, pero no sólo), en otros gracias a la inestimable ayuda de compañeros del departamento EGE de la UPC y de la EUETIB, que guardan como oro en paño este valioso material para la investigación. De algún congreso sólo existe material en soporte papel, difícil de encontrar. Sólo en uno de los 34 congresos ha sido imposible acceder a esta información.

La segunda fase ha sido más mecánica, tan sólo se trataba de bucear entre las actas de los congresos y buscar a través de palabras clave los temas presentados acorde a nuestro interés, ayudados por el abstract de las presentaciones. Bien predispuesto a la lectura, el trabajo ha consistido en una mirada rápida, un breve resumen del tema planteado, y si el artículo prometía, una segunda lectura obligada con el análisis pertinente. La selección de los más de 200 artículos ha sido un poco variada. Se ha procurado tener una visión amplia de los temas de interés, con autores con exposiciones divergentes, con una presencia geográfica y cronológica variada.

La tercera ha residido en intentar agrupar las opiniones de los aproximadamente 300 autores para presentar unas trazas identificables de como ha evolucionado la docencia universitaria en general, y la del área de ingeniería gráfica en particular. Con el análisis teórico realizado se ha podido desarrollar una síntesis teórica en base a las palabras claves de esta investigación.

Con todo ello se pueden afirmar las conclusiones que se presentan en el capítulo pertinente, junto con una propuesta metodológica para la impartición de la Ingeniería Gráfica.

\subsection{Universo de la investigación}

El universo de la investigación para el análisis y la discusión teórica se ha circunscrito al estudio de las actas de los congresos que se aproximan a las palabras clave de nuestra investigación: docencia universitaria, innovación docente, ingeniería gráfica.

Los CUIEET (Congreso Universitario de Innovación Educativa en las Enseñanzas Técnicas) organizados por la CDITI (Conferencia de Directores de Escuelas de Ingeniería Técnica Industrial) ${ }^{1}$, han sido estudiados porque reúnen experiencias inno-

\footnotetext{
1 www.cditi.es
} 
vadoras en el campo de la formación técnica universitaria y son un foro de debate permanente en el marco de las enseñanzas técnicas, en áreas temáticas de mejora e innovación educativa, docencia, investigación y sociedad, nuevas tecnologías y formación, influencia de los marcos legislativos en la acción docente, y aspectos organizativos de la docencia. Aunque su ámbito geográfico preferente es España, se presentan también aportaciones foráneas, sobretodo de otros países hispanos.

Los CIDUI (Congreso Internacional Docencia Universitaria e Innovación) analizan la necesidad de desarrollar habilidades acordes a las demandas económicas y productivas de la sociedad, introducir cambios cualitativos en los procesos de aprendizaje, nuevos modelos de adquisición de conocimientos, nuevas aplicaciones de la tecnología, Fomentar el intercambio de experiencias docentes, contribuir a la mejora de la actividad docente en las universidades, y favorecer la cooperación entre universidades. Aunque el origen de los CIDUI era Catalunya, en las últimas ediciones el abanico se abre al conjunto universitario español en general.

Los INGEGRAF² (Asociación Española de Ingeniería Gráfica) tienen por objeto la promoción del área de conocimiento de la Ingeniería Gráfica en la ingeniería industrial en general, y en particular en las universidades existentes en España. Estos congresos, que tienen un ámbito marcadamente hispano-italiano, puesto que se organizan de forma conjunta con los de "Asociación Nacional de Diseño y Métodos de Ingeniería Industrial de Italia (ADM)", pretenden ser un foro de encuentro que propicie el intercambio de experiencias de carácter científico y profesional en el ámbito de la Ingeniería Gráfica. Las áreas generales de interés de los congresos se refieren a simulación, técnicas de representación, herramientas de diseño, realidad virtual, docencia del diseño y el dibujo, procesamiento digital de imagen, modelado en el ámbito industrial, diseño industrial, ingeniería inversa, técnicas de prototipado, intercambio de datos, historia de la tecnología, tecnología gráfica, artes gráficas, y topografía y cartografía.

\subsection{Delimitación cronológica}

El análisis teórico empieza a partir de 1993, con la incorporación a la docencia del Dibujo Asistido por Ordenador en aplicación de los descriptores del Boletín Oficial del Estado 3 (BOE).

2 www.ingegraf.es

${ }^{3}$ BOE no 206 de 27.08.92 para el plan de estudios 1993. 
La discusión teórica empieza poco después, cuando se promueven de forma intensiva los programas de diseño por ordenador en la docencia de la Ingeniería Gráfica, justo cuando las TIC empiezan tímidamente a emerger en las universidades. 1997 es el año del primer congreso INGEGRAF del que existe libro de actas en formato electrónico. Son los años de la introducción de nuevas herramientas basadas en las TIC en la docencia.

Las palabras clave que van apareciendo de forma progresiva en los diferentes congresos son: aprendizaje, aprendizaje virtual, geometría descriptiva autoformación, evaluación continuada, comunicación multimedia, Virtual Reality Modeling Language (Lenguaje de Modelado de Realidad Virtual), docencia, animación por ordenador, dibujo industrial, enseñanza asistida por ordenador, Internet, planes de estudio, informatización de la docencia, competencias docentes.

El estudio teórico termina con la plena aplicación de nuevos criterios docentes, expresados a grandes rasgos en el EEES.

\subsection{Hipótesis}

En relación con el objeto de estudio, se plantean las tres siguientes hipótesis, cuestiones que se corroboran a lo largo del libro con el análisis, la discusión teórica y la síntesis que se aporta en el desarrollo del trabajo.

El empleo de sistemas informáticos en la docencia de la Ingeniería Gráfica implica nueva formas de enseñanza de la materia clásica de la geometría del espacio, pero también la desaparición de ciertos contenidos que estaban fuertemente relacionados con las metodologías basadas en el soporte papel.

El Diseño Asistido por Ordenador supone nuevas oportunidades para el desarrollo del área de Ingeniería Gráfica. Los nuevos contenidos existentes más allá de los clásicos exclusivamente geométricos, son una oportunidad para el área para compensar la disminución de carga académica acaecida en los últimos planes de estudio.

Las Tecnologías de la Información y la Comunicación favorecen el nuevo paradigma de enseñanza-aprendizaje impulsado por la plena implantación del Espacio Europeo de Educación Superior. 
CAPítulo 3

\section{Antecedentes}





\subsection{La confluencia de medios}

Al inicio de esta investigación nos encontramos ante un panorama de confluencia de medios. Tal como expone Agustín Olmos «los aproximadamente 75 años de desarrollo de la radio y la televisión se han acompasado a los cerca de $55 \mathrm{del}$ ordenador, y los apenas 10 de Internet para provocar una transformación vertiginosa en todo el mundo, confluyendo en lo que llamamos Nuevas Tecnologías de la Información »" Y esta es una transformación que va más allá de la mera innovación tecnológica, pues como señala Gutiérrez Martín se han producido «cambios en sistemas económicos, sociales y culturales, e incluso en los individuos que han de ajustarse a los nuevos sistemas» ${ }^{5}$. Podemos intuir que nos encontramos dentro de un nuevo marco de relaciones.

Las compañías telefónicas han cambiado su nombre por el de compañías de telecomunicaciones o de servicios. Este cambio no es casual ni aleatorio, sino una muestra del proceso de convergencia que se ha llevado a cabo. Las operadoras telefónicas están empezando a facturar cada vez más por servicios de datos en vez del tradicional servicio de voz. Hasta mediados de los ‘90 el núcleo económico de las compañías lo constituían las llamadas telefónicas, esto ha cambiado y aún cambiará más en el futuro.

\footnotetext{
${ }^{4}$ NUEVAS TECNOLOGÍAS Y EDUCACIÓN EN ANDALUCIA. Agustín Olmos. Quadernsdigitals.net/ articles/monográfico/mononuevas

${ }^{5}$ EDUCACIÓN MULTIMEDIA Y NUEVAS TECNOLOGIAS. Alfonso Gutiérrez Martín. Madrid. Ediciones la Torre. 1997.
} 
La confluencia de medios lleva aparejada una nueva configuración de los canales de distribución de información. Tradicionalmente el sistema telefónico era básicamente una red en estrella. Con la aparición del cable, y de su mayor valedor, la televisión por cable, aparece una nueva configuración, basada en un bucle. En el primer caso, cada hogar dispone de una línea de bajo ancho de banda. En el segundo, un gran número de hogares comparten el servicio de un ancho de banda superior. La configuración entre estrellas y bucles depende del contenido de las comunicaciones. En la red telefónica cada conversación es diferente, los bits de una casa no tienen que ver en nada con los de su vecino. Por el contrario, en el caso de la televisión, los vecinos comparten la información. Esta situación está empezando a cambiar. La confluencia de medios también se llevará a cabo en las redes. "Puede que dentro de veinticinco años no exista ninguna diferencia entre el cable y el teléfono, no sólo en términos corporativos sino en el sentido de la configuración de redes» ${ }^{6}$.

Para el profesor Negroponte, en el futuro sólo existirán ordenadores «El aparato receptor será como una tarjeta de crédito que al introducirla en nuestro PC lo convertirá en una puerta electrónica para la recepción de información y entretenimiento por cable, teléfono o satélite. En otras palabras, no existirá una industria de aparatos de televisión en el futuro, sino sólo fábricas de ordenadores, es decir pantallas alimentadas con toneladas de memoria y un enorme poder de procesamiento» ${ }^{7}$. En el futuro lo único que existirá será la información. No será importante si llega por cable, cobre, satélite ni cualquier otro nuevo medio. No será importante que leamos esta información en el ordenador, la televisión, en el teléfono móvil, o en un display incrustado en el microondas. Es cierto que la información podrá circular por diferentes redes y que nosotros podremos disponer de ellas en diferentes pantallas, pero lo único importante será el hecho de poder disponer de la información en cualquier momento, en cualquier lugar y de cualquier manera.

Los laboratorios virtuales son un buen ejemplo de esta confluencia de medios, donde la combinación de diversas tecnologías permite a los usuarios interactuar en tiempo real con un entorno dinámico tridimensional generado por ordenador, llamado Realidad Virtual.

\footnotetext{
6 «EL MUNDO DIGITAL» N. Negroponte. Ediciones B. Barcelona 1995. Pag 52. ISBN-84-406-5925-3.

7 «EL MUNDO DIGITAL» N. Negroponte. Ediciones B. Barcelona 1995. Pag 66. ISBN-84-406-5925-3.
} 
Las TIC son el resultado de la confluencia de una tecnología que avanza a marchas forzadas haciendo converger en un único punto elementos hasta hace poco tiempo distanciados: la informática, las comunicaciones y la tecnología audiovisual. Todas las redes de telecomunicaciones tienden a converger hacia una única red: Internet, puesto que al fin y al cabo lo único que están transportando estas redes es información digital. Pero además de la confluencia tecnológica se está produciendo una convergencia en los servicios que antes eran independientes por tener diferente infraestructura tecnológica, pero no ahora que comparten un mismo espacio y una única forma de comunicación.

Estos, y otros elementos definidores de las TIC rápidamente cambiantes hacen difícil la previsión de un futuro indiscutible. Para poder intuir como se desarrollará este futuro es necesario observar aquellas organizaciones que están a la cabeza del desarrollo tecnológico, y que están sabiendo adaptarse a los cambios del futuro. En el caso español las organizaciones que han destacado en este ámbito han sido los grandes grupos industriales y sobretodo financieros ${ }^{8}$.

En el mundo de los negocios "los directivos han asumido riesgos presintiendo que el paso de la sociedad industrial a la sociedad de la información se materializaba con estas nuevas tecnologías y ningún gran grupo financiero o industrial ha querido quedarse al margen de esa carrera hacia el futuro, realizando para ello inversiones multimillonarias con rentabilidad a largo plazo" mientras que "han tardado en implantarse en el mundo educativo ${ }^{9}$. Sin embargo el profesor Castells nos dice que "la educación es la base de la creación de la riqueza en la sociedad de la información".... "hay que educar individuos autónomos y creativos, capaces de gestionar el cambio continuo y buscar y generar información $»^{10}$. Para paliar esta situación muchos pensadores nos proponen redefinir el sistema educativo de arriba a abajo, desmantelando la formación orientada a la calificación requerida a corto plazo (y por lo tanto rápidamente obsoleta) y sustituyéndola por una enseñanza que integre educación y trabajo a lo largo de toda la vida profesional.

\footnotetext{
${ }^{8}$ BBVA y Santander son dos de los grupos financieros más analizados en Europa, ya que con la aplicación de las nuevas tecnologías han conseguido aumentar sus márgenes financieros en un momento en el que la banca europea los estaba bajando.

${ }^{9}$ NUEVAS TECNOLOGÍAS Y EDUCACIÓN EN ANDALUCIA. Agustín Olmos. Quadernsdigitals.net/ articles/monográfico/mononuevas

${ }^{10}$ MANUEL CASTELLS. Entrevista en EL PAIS, 19-07-98. Suplemento Domingo. Páginas 6 y 7.
} 
Para Joan Batlle: "hasta ahora, la palabra educación era prácticamente concebida como sinónimo de escuela"...»hoy por hoy, este reduccionismo es imposible y no funciona ${ }^{11}$. El modelo de educación "clásico» no puede funcionar, pues era unidireccional, basado en el profesor que «descargaba» unos conocimientos sobre unos alumnos que escuchaban. Las TIC no son sólo un recurso didáctico, una ayuda tecnológica para seguir explicando lo mismo. Hay que educar «en» y «con» las TIC, una transformación en la forma de enseñar que debemos asumir los profesores. Pero para eso los profesores primero tenemos que trabajar «en" y «con» las TIC, porque no se puede enseñar algo que se desconoce, sino el fracaso estará servido como nos explica el profesor Terceiro «...dada la malicia de los escolares viéndose más sabios que sus profesores delante del ordenador, es comprensible que en muchas escuelas el principal obstáculo para la entrada de las TIC sean los profesores ${ }^{12}$. En este mismo sentido ahonda la ponencia presentada por la AEIC "la facilidad de adaptación de los jóvenes con las TIC nos puede llevar, si no se toman las medidas adecuadas, a una situación que no se había producido nunca: que los alumnos dominen las nuevas herramientas de trabajo y que los educadores no las dominen ${ }^{13}$.

\subsubsection{El marco social}

Tradicionalmente el tiempo libre, el tiempo para aprender y el tiempo para trabajar estaban separados. Uno primero jugaba, luego estudiaba y después trabajaba. Hoy en día esto no es, ni puede ser así. Jugar, aprender y trabajar se superponen. Los niños aprenden jugando en la escuela. Los alumnos aprenden y trabajan en las empresas en prácticas simultáneas. $Y$ todos nosotros trabajamos y no podemos de dejar de aprender en ningún momento, para no perder el tren de la tecnología.

Tal como afirmaba en 1996 el profesor Terceiro, ya estamos en la Sociedad Digital "la Era Electrónica duró veinticinco años, y la era de la Información ya tiene 20, evolucionando rápidamente desde lo que podríamos llamar Infolítico Inferior al

\footnotetext{
${ }^{11}$ EL TIEMPO LIBRE INFANTIL Y JUVENIL. Joan Batlle. Revista La Factoría no 3.

12 JOSE B. TERCEIRO. Entrevista en Ciberp@is de 3-08-2000 página 9.

${ }^{13}$ EDUCACION E INFORMATICA. Asociación de Enseñantes de Informatica de Catalunya. Editorial. 11-08-2001. www.aeic.es
} 
Infolítico Superior ${ }^{14}$, e incluso para otros como Sartori el habitante de nuestro actual mundo es el Homo Videns ${ }^{15}$. La cultura digital se ha extendido por toda la comunidad, la actividad artesana ha evolucionado hacia la actividad industrial, y de ella a la postindustrial, ha aparecido un nuevo lenguaje de comunicación multimedia, etc...No son sólo cambios tecnológicos, sino cambios conceptuales. Para el doctor Monguet Fierro y Fernández Sánchez en algunos entornos «los cambios conceptuales ya han tenido lugar, las TIC lo que harán es potenciar» ${ }^{16}$. De la misma manera podemos ver como las predicciones llevadas a cabo en el año 1995 para el futuro más o menos próximo, se materializaban en un breve espacio de tiempo "La próxima década será testigo de un sinnúmero de casos de abusos de los derechos de propiedad intelectual y de invasión de nuestra intimidad. Habrá vandalismo digital, piratería de software y robo de información. Y lo peor de todo, mucha gente se quedará sin trabajo debido a los sistemas automatizados y las oficinas cambiarán tanto como lo han hecho las fábricas. La noción de tener el mismo trabajo toda la vida ha empezado a desaparecer ${ }^{17}$. A pesar que estos comentarios están centrados en la sociedad norteamericana, el profesor Negroponte hace hincapié en el hecho de que la cultura digital se extiende internacionalmente más deprisa que cualquier cambio geopolítico mundial.

Según los indicadores de la Unión Europea, España parte desde el furgón de cola de la innovación europea, tanto en el terreno público como en el privado: "respecto a la sociedad de la información, España permanece hoy en la cola en acceso a Internet, penetración de ordenadores e infraestructura de banda ancha. El plan Info XXI de desarrollo de la sociedad de la Información del Gobierno, presentado ostentosamente por el presidente Aznar en enero (de 2001) recoge (...) en su mayor parte (600.000 millones de 825.000) los gastos de la administración en tecnología, y no se ha ejecutado ni la mitad de lo presupuestado en 2000 ». "La Situación en España es más preocupante por dos motivos. Por una parte por la especial magnitud que tiene nuestra brecha tecnológica en todos los ámbitos y más específicamente en las TIC (...) Y por otra parte, por las notorias limitaciones en la implementación

\footnotetext{
${ }^{14}$ SOCIEDAD DIGITAL. DEL HOMO SAPIENS AL HOMO DIGITALIS. José B. Terceiro. Madrid. Alianza Editorial. 1996.

${ }^{15}$ HOMO VIDENS. LA SOCIEDAD TELEDIRIGIDA. Giovani Sartori. Madrid. Taurus. 1998.

${ }^{16}$ LAS COMUNICACIONES MULTIMEDIA ¿CONSTITUYEN NUEVOS AMBITOS CIENTIFICOS Y TECNICOS DE INTERES PARA EL AREA DE EXPRESION GRÁFICA EN LA INGENIERÍA. J.M. Monguet Fierro y J. Fernández Sánchez. Ponencia presentada en Ingegraf 1998.

17 «EL MUNDO DIGITAL» N. Negroponte. Ediciones B. Barcelona 1995. Página 269. ISBN-84-4065925-3.
} 
de la política científica y tecnológica que no está llevando a la realidad las prometedoras acciones programadas en el plan $1+D+\mid 11^{18}$. Para muchos estudiosos, como el profesor Lafuerte Pérez "ello permite sospechar que las políticas de apoyo a la $1+D$ empresarial no son adecuadas o que su gestión es deficiente ${ }^{19}$. Existe diferencia entre decir que un país es digital y serlo.

\subsubsection{El marco económico}

La actual revolución de la información es en realidad la cuarta de la historia humana. La primera fue hace 6.000 años con la invención de la escritura en Mesopotamia ${ }^{20}$. La segunda fue provocada por la invención del libro escrito en China hacia 1.300 a.C. ${ }^{21}$. La tercera por la invención de la imprenta por Gutemberg en 1450-1455. Cada una estas revoluciones supusieron un enorme salto cualitativo para el hombre a un coste increíblemente bajo respecto a la etapa anterior. Antes de 1450, 10.000 monjes repartidos por monasterios de toda Europa se dedicaban a copiar a mano unos pocos miles libros muy caros e inaccesibles a la población; a partir de 1500, los aproximadamente 800 impresores europeos podían imprimir unos 25.000 libros al año. Todo ello tuvo importantes connotaciones no sólo económicas sino también políticas, culturales y religiosas. Es en este contexto que algunos pensadores sitúan la actual revolución de la información: «el efecto que tuvo la revolución de la imprenta en la sociedad, la educación, la cultura- por no hablar de la religión- fue por lo menos tan importante y con certeza tan rápido


con otros nos encontramos en un momento de cambio de paradigma.

En la sociedad digital la economía no está basada en un uso intensivo de la mano de obra (como en el siglo XIX) o en un uso intensivo de la energía (siglo XX), sino que la Economía Digital es una economía intensiva en Información. Ello comporta una serie de efectos positivos en nuestra sociedad, pero también otros más discutibles. Entre

\footnotetext{
18 «EL FRACASO DE LA POLÍTICA TECNOLÓGICA». Carmela Martín. El País. Negocios. 21 octubre de2001. Pág. 5.

${ }^{19}$ Alberto Lafuerte Pérez. Catedrático de la Universidad de Zaragoza. El País Negocios. 24 de febrero de 2002. Pág. 20.

${ }^{20} 2.000$ años después y de forma independiente en China.

${ }^{21} 800$ años después y también de forma independiente en Grecia.

22 «EL MANAGEMENT DEL SIGLO XXI» Peter Drucker. Pág. 155. Edhasa. Barcelona 2000. 1a edición. ISBN-84-350-1452-5.
} 
los primeros podemos destacar el crecimiento de la productividad, la reducción de costes, el mantenimiento a raya de la inflación, la eliminación de las barreras de entrada y salida, la multiplicación de las posibilidades de internacionalización y la aceleración del crecimiento económico. De los efectos más discutibles (no todos los autores están de acuerdo en que sean más o menos importantes) se pueden enumerar la dispersión salarial (dentro de una misma sociedad pero también entre diferentes sociedades), el paro tecnológico (efectos de sustitución de empleo) y la desaceleración de precios. Para algunos autores esta economía digital intensiva en información conlleva un cambio de paradigma en el marco económico "en la economía digital se producen una serie de cambios respecto al anterior marco económico: cobran mayor importancia los bienes públicos que en la economía tradicional, genera mayores externalidades de red (mayores economías de escala), los mercados tienden a ser más "perfectos», y los cambios de las TIC son tan bruscos que no permiten su regulación, lo que provoca sobreinversion (1990-2000) y burbujas financieras (2001-?) „23.

Este nuevo paradigma supone la aparición de la virtualidad. Así lo expresa el Dr. Mario Aguer: "Las nuevas Tecnologías de la Información y la Comunicación constituyen el nuevo paradigma técnico-económico, basado en un conjunto interconectado de innovaciones tecnológicas que permiten a la empresa desenvolverse en un entorno cada vez más dinámico e incierto. Tales progresos hacen que los empleados no tengan necesidad de estar cerca unos de otros y permiten que individuos lejanos en el espacio trabajen conjuntamente. Esta situación ha dado lugar a la creación de empresas virtuales, fábricas virtuales, oficinas virtuales y corporaciones virtuales» ${ }^{24}$. La economía virtual permite a las organizaciones eliminar las barreras del espacio y el tiempo para ser más eficaces y poder competir internacionalmente en un mundo cada vez más global.

Para que este nuevo paradigma basado en las Tecnologías de la Información pueda llegar a buen puerto hace falta invertir dinero. Las sociedades modernas ya no son aquellas que invierten en protección de la agricultura o industria nacional. Hay que invertir en la sociedad de la información. A pesar de la crisis, España es considerada una economía importante del mundo, pero en cambio en todos los

\footnotetext{
${ }^{23}$ Dra. Susana Gordillo. Conferencia el 17/3/03 en la ETSEIB en el programa de doctorado «Enginyeria Multimedia».

24 "LA EMPRESA VIRTUAL EN EL MARCO DE LA SOCIEDAD DE LA INFORMACIÓN» discurso de ingreso del académico numerario electo Dr. Don Mario Aguer Hortal. Página 66. Publicaciones de la Real Academias de Ciencias Económicas y Financieras. Barcelona 2000.
} 
indicadores de la sociedad de la información está por debajo del puesto número 20 , lo que lastra su competitividad actual, pero sobretodo futura. El plan Info XXI fue un fracaso. Cualquier plan volverá a fracasar si el gobierno español no invierte el dinero suficiente en la sociedad de la información. España no sólo invierte poco, si no que en la última década su porcentaje inversor en las TIC ha decrecido respecto a los principales países industriales.

\subsubsection{Escenarios}

Si podemos pues presumir que es fundamental incorporar las TIC a todos los niveles de la enseñanza, parece lógico que sea aún más imprescindible incorporarlas en el ámbito de la expresión gráfica en la ingeniería, en tanto que disciplina instrumental, significativamente afectada por las Tecnologías de la Información y de la Comunicación.

La universidad actual es (se supone que es) una institución canalizadora de conocimientos y de valores. Por otra parte, debe tener la suficiente capacidad como para transmitir adecuadamente y mantener sus contenidos actualizados al día, ya sea mediante sus actividades de investigación y/o de formación permanente. Actualmente, se puede decir que la universidad realiza sus funciones de una forma esencialmente artesanal. Un profesor en clase imparte su docencia a un grupo de alumnos. La aplicación de las TIC conlleva implícito un modelo más «industrial», o si se prefiere «postindustrial» de aprendizaje.

Por otro lado las herramientas tecnológicas permiten más funcionalidades que los tradicionales libros y documentos impresos. A medida que vayamos ganando experiencia en estas nuevas tecnologías crearemos mejores "clases», más interactividad, podremos favorecer que los estudiantes aprendan por su cuenta.

Las TIC hacen posibles nuevas actividades y nuevas formas de organización del tiempo y del espacio de la docencia. Aparecen nuevos modelos de aprendizaje diferentes al meramente presencial: modelos enteramente virtuales, y también modelos híbridos, están empezando a desarrollarse y a estudiarse teóricamente ${ }^{25}$.

\footnotetext{
${ }^{25}$ MODELO DE FORMACION HIBRIDO PARA EL DISEÑO, PRODUCCION E INTEGRACCIÓN DE CONTENIDOS FORMATIVOS Y ENTORNOS VIRTUALES DE APRENDIZAJE. Tesis doctoral de FrancesC Alpiste. 2002.
} 
Todas las clases no tienen por qué ser meramente expositivas por parte del profesor. Pueden organizarse diversas actividades docentes, en las que intervienen los alumnos y el profesor actúa de moderador. En los laboratorios de DAO de los departamentos de expresión gráfica en la ingeniería se puede avanzar mucho en este sentido. El profesor ya no sólo es un expositor de contenidos y de instrucciones, sino un facilitador y guía del proceso de aprendizaje, incrementando la atención personalizada al estudiante. Los ordenadores en si no cambian nada, somos los profesores los que podemos cambiar la enseñanza para adaptarla a los retos del nuevo modelo que las TIC propician. Podemos ofrecer contenidos a través de Internet, compartirlos de una manera horizonta ${ }^{26}$, ofrecer docencia de otra manera. En el fondo eso es ofrecer libertad de aprendizaje.

Las TIC permitirán la sustitución de algunas clases presenciales por otras virtuales tal y como ya se lleva a cabo en algunas universidades ${ }^{27}$. Este proceso requiere un cierto tiempo para la adecuación de los profesores a las nuevas herramientas pero también para una nueva organización de la universidad.

Parece lógico pues que la Universidad está llamada no sólo a cambiar, sino incluso a liderar el cambio que se debe producir con las TIC. A modo de ejemplo podemos citar al programa ABET $2000^{28}$ del Acredition Board for Engineering and Technology que propugna una profunda reforma de la enseñanza de la ingeniería en Estados Unidos, sobre la base de tres puntos: I- Diferenciación, II- Auto evaluación y III- Criterio ABET 3, que propone 11 capacidades fundamentales de los futuros ingenieros, entre la que destaca el reconocimiento de la necesidad de aprendizaje de por vida, y la capacidad para conocer y utilizar las técnicas y herramientas modernas.

En Catalunya el número de universitarios prácticamente se ha duplicada entre 1985 y 2012. El número de estudios universitarios que pueden cursarse ha aumentado de 30 en 1985 (las antiguas carreras) a casi 500 grados. En el conjunto de España el número de universitarios ha subido hasta casi dos millones de estudiantes. Pero ¿en qué marco se ha producido este incremento de la oferta universitaria? Pueden considerarse dos escenarios posibles para el próximo lustro en el ámbito universitario.

\footnotetext{
${ }^{26}$ El profesor ya no es un personaje inaccesible, sino un ayudante en el proceso de aprendizaje.

${ }^{27}$ En la EUETIB, el $20 \%$ de los créditos de cada asignatura son de tipo «no presencial» desde el curso 2002-2003.

${ }^{28}$ ACREDITION BOARD FOR ENGINEERING AND TECHNOLOGY. http://www.abet.org
} 
Actualmente el escenario de la enseñanza reglada universitaria aun es claramente local (y por lo tanto también el de la expresión gráfica en la ingeniería). Los alumnos se agrupan en universidades no por la calidad de sus profesores, ni por los programas de las diferentes escuelas, sino simplemente por proximidad física. Mecanismos como el distrito único universitario podemos considerarlos como claramente fracasados o como mínimo numéricamente poco importantes. Sólo algunas universidades de prestigio consiguen atraer alumnos más allá de nuestras fronteras locales, suele tratarse de alumnos de segundos y sobretodo de terceros ciclos universitarios.

Podemos constatar estas afirmaciones al comprobar que la mayoría de los alumnos que superan la selectividad piden en las primeras posiciones de sus preferencias siempre facultades de su ámbito local, independientemente del área de estudio. Aunque con la Ley Orgánica 6/2001, de 21 de diciembre, de Universidades (la LOU) limitaba las consecuencias de la selectividad, y la nueva ley Wert desaparezca la selectividad, siempre existirán mecanismos de selección.

Si tenemos en cuenta que en los últimos diez años se ha doblado el número de universidades en España, y que en la mayoría de los casos estas son de carácter poco más que provincial, el escenario local parece tomar cuerpo. A modo de ejemplo podemos fijarnos que en la Catalunya de 1990 sólo existían 3 universidades y en 2002 ya se habían convertido en 11. Además hay que tener en cuenta que este escenario no es fortuito sino reforzado políticamente tal como nos indica J. Benedito "l'important efecte, pel que fa a l'equilibri territorial, de l'opció adoptada per a la Generalitat en crear les universitats de Girona, de Lleida i la Rovira i Virgili» (de Tarragona) ${ }^{29}$. En el ámbito español ocurre algo similar.

Frente al anterior escenario local se puede prever un escenario de tipo multinacional, sobre todo para la enseñanza continua, en Posgrados y Master, debido a una producción descentralizada de materiales multimedia, a un gran número de profesores de otras latitudes, a los diversos países de procedencia de los estudiantes, a la importancia de las economías de escala para poder amortizar las inversiones tecnológicas necesarias y a la obligatoria diferenciación de la oferta en un marco de competencia abierta. El mercado ya no es España, es como mínimo el mundo hispano, o todo el mundo. Ya estamos viendo como tienen lugar gradualmente

\footnotetext{
${ }^{29}$ LA ARQUITECTURA EN LA UNIVERSITAT I EL TERRITORI. Josep Benedito. Articulo en la revista INDE. Pagina 7. Julio 2001.
} 
procesos de concentración, alianzas y fusiones, no sólo entre universidades sino con la participación de empresas privadas. Monguet Fierro y Fernández Sánchez son de esta opinión al afirmar que «iremos viendo como tienen lugar gradualmente procesos de concentración, estrategias de alianzas y fusiones, incremento de la función comercial de las universidades...» ${ }^{30}$.

Este escenario global tiene especial importancia para la enseñanza continua, que es la que la mayoría de los pensadores actuales piensa que más se va a desarrollar, hasta el punto de superar a la mera enseñanza puntual en edad de aprendizaje, sobre todo para los "trabajadores del saber»: "el sector de más rápido crecimiento de cualquier país desarrollado puede resultar ser el de la educación continua para adultos con un alto nivel de educación " $^{31}$ "el saber queda rápidamente desfasado y los trabajadores del saber tienen que volver a la escuela regularmente. Por todo ello, la educación continua de unos adultos que tienen ya un alto nivel de educación será un sector de rápido crecimiento en la sociedad que viene» ${ }^{32}$.

¿Cuál de los dos escenarios será el más próximo dentro de 10 años? Seguramente el escenario que nos encontraremos no será ninguno de los dos extremos. Por un lado, los grados, donde se enmarca una parte significativa de la enseñanza de la expresión gráfica en la ingeniería no son susceptibles de una carrera competitiva para ganarse al estudiante. Pero por otro lado, sí es verdad que el pleno uso de las TIC sólo será posible con la colaboración de grupos de profesores de una misma universidad, sino con la colaboración de departamentos de varias universidades. Desde este punto de vista es compatible el crecimiento del número de universidades por toda la geografía española con su coordinación a efectos de alcanzar la masa crítica necesaria. Un ejemplo claro de relación entre universidad y empresa es el consorcio andaluz Fernando de los Ríos (para la enseñanza abierta y a distancia), participado por las 10 universidades andaluzas, la Radio y Televisión de Andalucía y ADM (Andalucía Digital Multimedia), que cuenta con estudios universitarios, formación continuada y formación corporativa de em-

\footnotetext{
${ }^{30}$ LAS COMUNICACIONES MULTIMEDIA ¿CONSTITUYEN NUEVOS AMBITOS CIENTIFICOS Y TECNICOS DE INTERES PARA EL AREA DE EXPRESION GRÁFICA EN LA INGENIERÍA. J.M. Monguet Fierro y J. Fernández Sánchez. Ponencia presentada en el Ingegraf 1998.

31 «LA EMPRESA EN LA SOCIEDAD QUE VIENE». P. Drucker. Pág. 198. Empresa Activa / Nuevos Paradigmas. Ediciones Urano. Barcelona 2003. ISBN 84-95787-43-1.

32 "LA EMPRESA EN LA SOCIEDAD QUE VIENE». P. Drucker. Pág. 206. Empresa Activa / Nuevos Paradigmas. Ediciones Urano. Barcelona 2003. ISBN 84-95787-43-1.
} 
presas. El mercado natural de la Fernando de los Ríos no es sólo Andalucía es en realidad todo el mundo.

\subsection{Evolución de la universidad española}

\subsubsection{La academia platónica}

En el 387 AC Platón funda una escuela de pensamiento dedicada al héroe Akademos. La academia platónica no pretendía formar profesionales de ningún tipo, sino educar a los futuros gobernantes de las polis griegas. A pesar que muchas veces se cita la academia platónica como el origen de nuestra universidad esto es sólo una verdad a medias. Es cierto que el deseo de conocimiento y descubrimiento de la actual universidad procede de la antigua Grecia, pero completado con la formación científica, técnica y profesional actual. La academia platónica tendrá 800 años de vida dedicada al goce del saber hasta que el emperador Justiniano ordena cerrarla en el año 529, iniciando una oscura época para el conocimiento hasta la aparición de las primeras universidades medievales.

\subsubsection{El origen de la universidad}

Desde el siglo XI se forman en Europa centros de estudios en monasterios y catedrales que tratan sobre la reforma de la Iglesia y la formación cultural de los religiosos. Estas escuelas monacales se acaban desarrollando de forma más ambiciosa en las universitas magistroruim et scholarium, estructurando una enseñanza en latín basada en los grados de bachiller, licenciado, maestro y doctor. «Tanto la irrupción del racionalismo aristotélico como el temor del Papado a la expansión de las nuevas herejías, así como el deseo de la Iglesia de mantener bajo control la enseñanza, propician la fundación de las Universidades: centros culturales sometidos a la disciplina de la Santa Sede y dirigidos por las ordenes mendicantes» ${ }^{33}$.

La palabra Universidad procede del latín universitas, término jurídico que significa corporación social de cualquier tipo. Hoy en día el término sólo se usa en la acepción de las universitates litterariae constituidas por maestros y escolares desde

\footnotetext{
${ }_{33}$ «Atlas Histórico Mundial». Hermann Kinder. Ediciones Istmo. 10ạ edición. Madrid 1980. pag 187. ISBN 84-7090-005-6.
} 
finales del siglo XII en Europa. En el París de 1264 aparece por primera vez el término universidad. Desde Europa las Universidades se expandieron por el mundo «occidental», primero por la América española y después Norteamérica. En 1538 una bula papal funda la Universidad de Santo Domingo. En 1551 Carlos V firma las cedulas reales para la constitución de las universidades de México y Lima.

\subsubsection{La esencia de la universidad}

Para el profesor Rodrigo Fernández-Carvajal existen cinco puntos fundamentales en la esencia de la universidad actual que datan de los orígenes de las universidades europeas de finales del siglo XII y son de plena vigencia aún hoy.

\subsubsection{Una institución dedicada a captar y transmitir la verdad del ser}

En los orígenes sólo existían las facultades de Teología, Derecho y Medicina donde se impartían los conocimientos para ejercer las «profesiones mayores» de la Edad Media: Clérigo, Abogado o Médico. Pero por encima de estos conocimientos específicos sobresalía el espontáneo deseo de saber y conocer la verdad, una cierta actitud académica que les unía al origen clásico de Platón. A medida que se van sumando más Facultades y Escuelas Técnicas a la Universidad mantienen esa actitud académica conjunta con los estudios técnico-profesionales.

Estas premisas aún son de actualidad, como podemos leer en el Documento-Marco «La integración del sistema Universitario Español en el Espacio Europeo de Enseñanza Superior» del Ministerio de Educación, Cultura y Deporte de febrero de 2003: "la formación científica, humanística, artística y técnica adquiere una relevancia social fundamental no sólo como soporte del itinerario del aprendizaje para la actividad profesional, sino también como fundamento para el proceso de construcción de una comunidad europea de ciudadanos». Los conocimientos que imparte la universidad no son sólo técnicos, sino que pretende introducir el deseo del saber y del conocer la verdad.

\subsubsection{Studium Generale}

Los orígenes de la universidad se sitúan entre el cabildo catedralicio y la sociedad civil. Puesto que la cristiandad es universal, los «studia» también tienen que ser 
generales. La lengua franca es el latín ${ }^{34}$, lengua viva de uso docente para toda la comunidad científica. "La endogamia o política de puertas cerradas atenta mortalmente contra la idea misma de Universidad $»^{35}$. Esta cita es igualmente cierta para las universidades de principios del siglo XIII que para las de principios del XXI. Si se cierra el paso al mérito y a la experiencia el fracaso está servido. No sólo es necesario movimiento de docentes, sino que también es preciso que los estudiantes conozcan otras universidades de su ámbito geográfico para generalizar el conocimiento ${ }^{36}$.

\subsubsection{Las universidades se organizan corporativamente}

Las universidades adoptan los moldes gremiales propios de la Edad Media para conseguir privilegios que aseguren su autonomía de los poderes políticos de la época. El primero, el de conceder el título para enseñar pasando por encima de la autoridad del canciller. El segundo el del autogobierno, bajo el manto del Papa o el Emperador, únicos autorizados para dar licencia para impartir conocimiento en cualquier parte de la Cristiandad. Las universidades devienen organismos autónomos de la «política» del momento, y sólo así pueden desarrollarse plenamente para cumplir los objetivos que se han marcado. Esta autonomía universitaria es uno de los rasgos más reconocidos y apreciados desde la época medieval hasta nuestros días: «las Universidades son las instituciones más antiguas de Europa. (...) La autonomía (de las universidades) es medieval» ${ }^{37}$.

\subsubsection{La convivencia en las universidades}

Los «hospitia» son el germen de los futuros «collegia». Como en los colegios convivían alumnos y profesores de diferentes partes de la cristiandad, se convierten en pequeñas ciudades que funcionan como hogares de formación general. En Ingla-

\footnotetext{
${ }^{34}$ El quartier latin de Paris recibe este nombre debido al antiguo barrio de los estudiantes parisinos. ${ }^{35}$ RETORNO DE LA UNIVERSIDAD A SU ESENCIA. Rodrigo Fernández-Carvajal. Secretariado de Publicaciones. Universidad de Murcia. 1994. pág 50. ISBN-84-7684-493-X.

${ }^{36}$ La UE fomenta este movimiento con programas como el ERASMUS y el SOCRATES, que han conseguido desplazar aproximadamente a un $1 \%$ de la masa estudiantil en el quinquenio 1995-2000. 37 "LA UNIVERSIDAD, AL FINAL DEL MILENIO». Josep Ma Bricall Masip. Ponencia presentada en la Conferencia "Los objetivos de la Universidad ante el nuevo siglo». Universidad de Salamanca, noviembre 1997. www.crue.org
} 
terra los Colegios absorben a las Universidades ${ }^{38}$, mientras que en la Europa continental, las Universidades absorben a los Colegios. Las universidades no pueden ser sólo meras expendedoras de conocimiento, sino que es necesario la existencia de una vida universitaria, que debe estar compuesta por todos sus actores.

\subsubsection{De las históricas universidades a los departamentos}

En la segunda mitad del siglo XIX se produjo la división entre la Facultad de Filosofía y Letras y la de Ciencias. Pero esta división era poco drástica porque existía un Preparatorio que establecía un cierto solapamiento entre las Facultades, de tal modo que los estudiantes cursaban no sólo las asignaturas de su carrera sino que estaban obligados a asistir a algunas de las demás. El Artículo 124 del Estatuto de la Universidad de Madrid de 1918 así lo explica: "para reforzar los lazos que han de fundir los conocimientos de las Facultades en un saber universal, el estudiante, de cualquier Facultad que sea, estará obligado a cursar, en uno o varios de los períodos de estudio, durante su carrera, dos enseñanzas, por lo menos, libremente elegidas por él, de las Facultades de Filosofía y Letras y de Ciencias, cuyos alumnos tendrán la misma obligación respecto a les demás Facultades». Cuando las diferentes Facultades estaban juntas físicamente en los viejos caserones eclesiásticos vaciados por la desamortización, los estudiantes convivían codo con codo en los mismo edificios y podían entrar en el aula de al lado a asistir a clases de filosofía y después a ciencias. Pero esto sólo fue posible mientras existió una cierta idea universal de conocimiento universitario. Hasta ese momento la Universidad tenía un contenido propio como un todo, que se deslizó hacia las nuevas Facultades a partir de la desaparición del Preparatorio a principio de los años 50 . Este hecho se volvió a repetir desde los años 70 y sobre todo desde 1983, migrando la función universitaria desde las Facultades y Escuelas a los Departamentos.

\subsubsection{La disgregación del saber}

La génesis del conocimiento universitario cada vez se está desmenuzando más, desde grandes unidades docentes a más pequeñas. El conocimiento universal está desapareciendo, las Escuelas se están convirtiendo en elementos de coor-

\footnotetext{
${ }^{38}$ Que pasan a ser confederaciones de estos.
} 
dinación en materia financiera, de infraestructuras, editorial, laboral, etc... pero perdiendo este carácter universitario universal. Así lo describe el profesor Rodrigo Fernández-Carvajal: "la Universidad y las Facultades han venido a reducirse a servicios administrativos, útiles sin duda (... ) pero ajenos a la vida propiamente académica. Y la cosa irá a más: lo más seguro es que nuestros Departamentos sean víctimas del mismo destino. Pasará entonces la sabia cultural a las llamadas "áreas», integradas ahora en magnífico ciempiés dentro de unos departamentos generalmente heteróclitos ${ }^{39}$. La aplicación de las TIC a la enseñanza universitaria acrecentará este proceso disgregador «El resultado final de las tecnologías distribuidas será la creación, dentro de una institución mayor, de unidades docentes y administrativas relativamente pequeñas, autónomas, integradas y autosuficientes $»^{40}$. La función de la universidad en este entorno desmenuzador es aún más importante, puesto que a sus tareas administrativas, se suma el procurar que la disgregación de conocimientos no nos aleje de la visión global imprescindible de cualquier universitario.

\subsubsection{La masificación de los años 70 y 80}

El 4 de agosto de 1970, se aprobó la Ley General de Educación y de Financiación de la Reforma Educativa. Esta Ley abarcaba todo el sistema educativo, desde la enseñanza básica hasta la enseñanza universitaria. La Ley establecía que las universidades dispondrían de autonomía y determinarían ellas mismas sus procedimientos de control y de verificación de conocimientos, su sistema de enseñanza y su régimen de docencia y de investigación. Según esta misma Ley, las universidades, asumirían, también, la gestión y la administración de sus centros y de sus servicios. La Ley preveía, también, la incorporación de las escuelas universitarias de Ingeniería Técnica y de Arquitectura Técnica a la estructura universitaria.

En los años 70 la universidad española fue dejando de ser un reducto de la sociedad privilegiada. Todos los españoles comprendieron que la única vía de progreso personal estaba en el aprendizaje y empezaron a mandar a sus hijos a la universidad. Este flujo se acrecentó en los años 80 a raíz de una cierta recuperación

\footnotetext{
39 RETORNO DE LA UNIVERSIDAD A SU ESENCIA. Rodrigo Fernández-Carvajal. Secretariado de Publicaciones. Universidad de Murcia. 1994. pág 88. ISBN-84-7684-493-X.

40 «COMO GESTIONAR EL CAMBIO TECNOLÓGICO. Estrategias para los responsables de centros universitarios.» A.W. Bates. Pág 23. Ediuoc. Gedisa Editorial. Barcelona 2001. ISBN 84-8429-400-5.
} 
económica y de la política de los socialistas españoles ${ }^{41}$ en la «popularización» de la universidad. Este fenómeno junto con la llegada del baby-boom a las edades universitarias llevó aparejado una masificación de la enseñanza universitaria, difícilmente compatible con la calidad requerida. A pesar que a partir de la segunda mitad de los años 80 se incrementaron las plazas universitarias, primero en ampliaciones de facultades y escuelas existentes, y después con la creación de nuevas facultades, existió una grave masificación, donde se primaba más la cantidad que la calidad de los alumnos.

\subsubsection{Ley de Reforma Universitaria}

El 25 de agosto de 1983 se aprobó la Ley de Reforma Universitaria (LRU) con un doble imperativo. Por un lado el funcional había que sustituir a la Ley General de Educación que hacia aguas por todas partes. El crecimiento de la Universidad española en los años 70 hizo estallar unas estructuras demasiado rígidas. Y el otro imperativo, el constitucional. La Constitución Española contiene algunos artículos que tienen que ver con la organización de nuestras Universidades: el Artículo 20.1 C establece la libertad de cátedra, el Artículo 27 está dedicado a la educación, con un apartado específico, el 10, donde se establece que la autonomía universitaria se regulará por sus propias leyes. Había también que organizar de forma distinta la distribución de poderes, en lo que a política universitaria se refiere. Una distribución que, después de la Constitución, exigía un reparto de las competencias entre Estado y Comunidades Autónomas, estas últimas responsables en materia de educación, de acuerdo con sus Estatutos y el Estado con competencias residuales establecidas en los Artículos 54, 149.1, 18 y 30 de la Constitución Española.

Además de las competencias de las autonomías la LRU introdujo competencias propias de las universidades, al introducir una cierta autonomía universitaria respecto a las administraciones públicas.

La LRU es heredera del pacto constitucional. Es una ley que desarrolla el pacto al que llegaron los partidos políticos en la redacción de la Constitución Española. Es la primera ley en España que reconoce con carácter general la creación de Universidades privadas, casi 100 años después de la promulgación de la primera normativa

\footnotetext{
${ }^{41}$ En 1982 Felipe González consiguió mayoría absoluta en las Elecciones Generales a las Cortes Españolas.
} 
universitaria española. Es una ley que deriva de un pacto constitucional, que se mantiene y que se configura en torno a valores consensuados. Es una transacción jurídica-política en la medida en que hace una distribución competencial diversificada y equilibrada.

La LRU intentó conciliar las competencias educativas del Estado con las de las Comunidades Autónomas, conciliar la autonomía universitaria con los intereses sociales, coordinar la prestación por las Universidades de un servicio público con la libertad de creación de las Universidades privadas o conciliar la libertad académica con el control necesario de las titulaciones, que corresponde al Estado. A todos estos equilibrios intentó responder la LRU, tratando de encontrar una solución integradora y equilibrada.

Es una ley que pretendió reformar la estructura de la Universidad. El $80 \%$ de los artículos están dedicados a restablecer la arquitectura institucional en el seno de la Universidad y muy pocos a lo que son propiamente las funciones de la Universidad, al estudio y la investigación. Hay ocho artículos en toda la ley, y algunas referencias indirectas a la investigación, a lo largo de todo el articulado lo que, sin duda, es fruto de una determinada estrategia del Gobierno socialista que la aprobó. "La LRU es una ley para la reforma de la Universidad no de reforma universitaria, es una ley que confía en el cambio de estructuras de la Universidad como fuente y origen de una reforma en su funcionamiento, es decir, en la docencia y la investigación que realiza $»^{42}$.

\subsubsection{Transferencia a las Comunidades Autónomas}

A mediados de los años 80 se inició un proceso de transferencia de competencias desde el estado central español hacia las florecientes autonomías. Las universidades también fueron transferidas poco a poco. El 19 de diciembre de 1984, el Parlamento de Cataluña aprobó la Ley de Coordinación Universitaria y de Creación de Consejos Sociales. La Ley 11/1989 de 20 de julio, de Ordenación del Sistema Universitario de Galicia, supuso la transferencia de las universidades gallegas. Poco a poco, todas las comunidades autónomas fueron promulgando leyes de ordenación de sus sistemas universitarios.

\footnotetext{
42 «LRU. UNIVERSIDAD Y PODERES PÚBLICOS». Alfredo Pérez Rubalcaba. Ponencia presentada en la Conferencia "Los objetivos de la Universidad ante el nuevo siglo». Universidad de Salamanca, noviembre 1997.
} 
Con la transferencia a las comunidades autónomas se cierra el capítulo de la masificación de los años 80. Continuará existiendo una gran demanda de formación universitaria en toda España, pero los gobiernos autonómicos invertirán cada vez mayores cantidades de dinero para crear nuevas facultades, escuelas e incluso nuevas universidades de base no sólo autonómica sino provincial y local, permitiendo una de las más altas tasas de escolarización universitaria de los países europeos.

En diciembre de 1994 se constituye la Conferencia de Rectores de las Universidades Españolas (CRUE), que se define como una Asociación sin ánimo de lucro de ámbito estatal, formada por las Universidades públicas y privadas españolas que se asocian a tenor de la Ley 191/64, de 24 de diciembre, y normas complementarias del Decreto 1440/65, de 20 de mayo.

La CRUE, tal y como refleja el Preámbulo de sus Estatutos, dentro del máximo respeto a la autonomía universitaria y en el marco de los principios emanados de la Constitución Española y de los contenidos en la Carta Magna de la Universidad, promueve la reflexión sobre las finalidades y problemas universitarios, orientando sus planteamientos con criterios que van más allá de los intereses de sectores o grupos particulares. La CRUE pretende ser un cauce ágil, efectivo y representativo de las Instituciones españolas que facilite la cooperación mutua y con otras Conferencias de Rectores europeas. Los fines vienen reflejados en el Artículo 3 de los Estatutos:

- Promover cuantas funciones y actividades afectan a la promoción, gestión y desarrollo de la Educación Superior y la Investigación Universitaria.

- Fomentar en esos ámbitos la cooperación de las Universidades españolas entre sí y con instituciones análogas extranjeras.

- Intercambiar información, promover estudios, que redunden en una mayor y más eficaz cooperación con las Administraciones públicas.

- Otros de naturaleza análoga.

\subsubsection{El futuro europeo de la universidad española}

Las primeras intervenciones de la UE (Unión Europea) para fomentar la «europeización» de la universidad europea, fueron los programas ERASMUS y SOCRATES para fomentar la movilidad de los estudiantes (97.041 en 1999-2000) y profesores (9.837 en 1999-2000). Fueron los primeros en indicar la necesidad de cohesionar la estructura académica europea, demasiada fragmentada e inconexa hasta 
el momento. "Estos programas generaron la necesidad de encontrar un sistema adecuado de equivalencias y reconocimiento de estudios. De aquí se creó el Sistema Europeo de Transferencia de Créditos o ECTS» ${ }^{43}$. SÓCRATES y ERASMUS son el germen de los ECTS, pero también del programa TUNING (para la armonización de las estructuras educativas europeas) y la red ENQA (para difundir experiencias, buenas prácticas y sistemas de evaluación y garantía de la calidad).

Pero todos estos programas europeos (junto con alguno más como por ejemplo el LEONARDO) no pueden romper la inercia de sistemas universitarios enclaustrados, donde la movilidad de los estudiantes apenas llega al $1 \%$. Por este motivo en 1998, en París, se presentó la Declaración de la Sorbona, firmada por cuatro ministros de educación europeos (Francia, Italia, Alemania y Reino Unido). Esta declaración significó el compromiso decidido de impulsar la creación de un nuevo Espacio Europeo para la Educación Superior, a la vez que constituía un llamamiento a las otras naciones europeas para confluir en los objetivos contenidos en la declaración.

\subsubsection{La declaración de Bolonia}

El 19 de junio de 1999, en Bolonia, expertos universitarios de 29 países europeos sentaron las bases de la futura universidad europea, que fue firmada posteriormente por los 29 ministros de sus respectivos países, entre ellos España. En la declaración de Bolonia, los estados firmantes se comprometieron a coordinar sus políticas universitarias para conseguir en el plazo más corto posible los siguientes objetivos:

- Adoptar un sistema de titulaciones fácilmente comprensibles y comparables, para facilitar la integración de los ciudadanos europeos al mercado de trabajo.

- Establecer un sistema de titulaciones basado en dos niveles principales. La titulación del primer nivel, el grado, de una duración mínima de 3 años, sería pertinente para el mercado europeo de trabajo, ofreciendo el nivel de titulación apropiada. El segundo nivel, que requerirá haber superado el primero, ha de conducir a titulaciones de postgrado.

- Adoptar un sistema común de créditos ECTS para fomentar la comparabilidad de los estudios y promover la movilidad de estudiantes y titulados.

\footnotetext{
${ }^{43}$ HACIA UN ESPACIO EUROPEO DE ENSEÑANZA SUPERIOR. Documento CRUE no 25. www.crue.org
} 
- Promover la movilidad con especial atención al acceso a los estudios de otras universidades europeas.

- Impulsar la cooperación interna europea para garantizar la calidad de las universidades.

- Ayudar a promover la dimensión europea de la educación superior.

La declaración de Bolonia fue completada posteriormente en la Republica Checa en 2001. En el Comunicado de Praga se introducen líneas adicionales:

- El aprendizaje a lo largo de la vida, como elemento esencial para conseguir una mayor competitividad europea y mejorar la cohesión social.

- El rol activo de las universidades, de las instituciones de educación superior y de los estudiantes en el desarrollo del proceso de convergencia.

- La promoción del EES mediante el desarrollo de sistemas de garantía de claridad y de mecanismos de certificación y acreditación.

\subsubsection{El espacio europeo del conocimiento}

El "Informe sobre las universidades y la enseñanza superior en el espacio europeo del conocimiento" de 24 de mayo de 2002 de la Comisión de Cultura, Juventud, Educación, Medios de Comunicación y Deporte del Parlamento Europeo, plantea la necesidad de articular una política institucional para favorecer un Espacio Europeo de Educación Superior, abordando a las universidades como instituciones públicas y no sólo con programas sectoriales para favorecer el trabajo docente y/o la movilidad de los estudiantes y profesores. Este Informe manifiesta la necesidad de:

- Elaborar un Libro Verde sobre el EES en el que se considere con un enfoque integral el estado actual de la universidad como institución pública.

- Creación de una sede de las universidades europeas, con representación de los estados de la UE, el Parlamento Europeo y la EUA.

- Fundación de una universidad europea de la cultura, consagrada a las disciplinas artísticas, literarias y filosóficas, y las ciencias de la comunicación.

\subsubsection{La integración del sistema universitario español en el EEES}

La ley Orgánica 6/2001 de Universidades (LOU) de 21 de diciembre de 2001 prevé que el gobierno introduzca las reformas necesarias para la convergencia hacia el 
EEES. En febrero de 2003, el Ministerio de Educación, Cultura y Deporte publicó el Documento-Marco "La integración del sistema universitario español en el EES» en el que el gobierno anuncia las medidas para la aproximación europea:

- Dar a conocer el proyecto de normativa jurídica para la cual se establece el crédito europeo como unidad de medida académica.

- El primer nivel, el de grado, dará lugar a las titulaciones de licenciado, ingeniero o arquitecto.

- Someter a consulta dos propuestas alternativas para conseguir el grado: Será necesario haber obtenido en los estudios correspondientes: a) 240 créditos ECTS; b) entre 180 y 240 créditos ECTS ${ }^{44}$.

- Dar a conocer el proyecto de normativa jurídica de carácter general que definirá y regulará las nuevas modalidades cíclicas de las enseñanzas oficiales.

- Presentar el proyecto de RD. sobre los estudios de postgrado.

- Dar a conocer el proyecto de RD. sobre el Suplemento Europeo al Título.

En este Documento-Marco se llega a la conclusión que es imprescindible la incorporación de las TIC en el sistema universitario español para poder integrarnos adecuadamente al nuevo EES, con las siguientes recomendaciones:

- Es esencial incorporar las TIC a los cursos de postgrado.

- Es imprescindible desarrollar oferta universitaria no presencial.

- El funcionamiento de los cursos aconseja el desarrollo de no presencial.

- Propiciar el cambio conceptual a una enseñanza más centrada en el alumno.

- Formación de unidades técnicas centrales de ayuda al profesorado.

- Tiene que existir un núcleo de apoyo formado por pedagogos y técnicos para la estructuración de los materiales docentes.

- Es más aconsejable crear cursos nuevos que remodelar los antiguos diseñados de manera tradicional.

- Hay que ofertar cursos de formación al profesorado.

- Fijar estándares mínimos de calidad para los cursos no presenciales.

- Evaluar los cursos no presenciales en igual medida que los presenciales.

\footnotetext{
${ }^{44}$ Abril 2003: las titulaciones de grado del área de la INGENIERÍA INDUSTRIAL serán de 240 créditos ECTS, es decir, estudios de 4 años.
} 


\subsubsection{El Suplemento Europeo al Título (SET)}

El SET es una iniciativa europea como elemento de transparencia en el Espacio de Enseñanza Superior Europeo. Está auspiciado no sólo por la UE, sino por todo el Consejo de Europa, la AEU (Association of European Universities), y por otros organismos no sólo europeos sino internacionales como la UNESCO. El objetivo fundamental del SET es hacer comprensibles y comparables los títulos universitarios en Europa por medio de una información académica y profesional relevante para la sociedad, la universidad y las organizaciones que contraten a los nuevos titulados europeos. EI SET es un modelo de información unificado para el titulado universitario, sobre los estudios cursados, su contexto nacional y las competencias y capacidades profesionales adquiridas. Será un documento fácilmente comprensible, y pretende estar abierto para incorporar el necesario aprendizaje a lo largo de toda la vida, acreditando los conocimientos adquiridos por cada persona en diferentes instituciones europeas de educación superior.

\subsection{La Ingeniería Industrial en España}

\subsubsection{La universidad española}

Hasta la aprobación de la LRU en 1983 no existían en España las universidades privadas. Podían existir facultades de propiedad privada pero siempre tenían que figurar adscritas a alguna universidad pública, si pretendían impartir títulos reconocidos. La LRU permitió la aparición de estas universidades privadas que se comportan de manera diferente en cuanto al número de alumnos, relación con las empresas, contactos internacionales, etc... A pesar de tener un mismo marco normativo las instituciones privadas se comportan de diferente manera respecto a sus alumnos, y el "peaje» de entrada no es ajeno a ello. El precio de un curso en una universidad privada española bien puede ser 10 veces del de una pública (a pesar de las becas y ayudas que casi todas las universidades privadas tienen concertadas con importantes entidades financieras).

En 1973 se fundó la UNED para permitir un acceso universal de todos los españoles a la enseñanza universitaria, independientemente de lugar de residencia y del tiempo que pudiesen disponer para ello. Con la UNED no existía excusa para nadie, habían desaparecido las barreras espacio-tiempo, y teóricamente de democratizaba el acceso universitario. Fue la primera universidad no presencial española, basada en la tecnología hábil en el momento. A principios de la década de los 90 
apareció la UOC, segunda y hasta el momento única universidad no presencial española. A pesar de la existencia de muchos proyectos de carácter no presencial (o también semi-presencial), no se han llevado a cabo más entidades completamente no presenciales.

Hasta julio 2002 existían en España 66 universidades; 45 públicas (68 \% del total), 10 privadas (15\%), a las que se pueden sumar 7 confesionales (15\%), 2 universidades internacionales (o «de verano», que sólo imparten cursos de verano) (3\%) y 2 de carácter no presencial (3\%), una privada y una pública.

Así, si analizamos el número de universidades respecto al binomio privada/públi$c a, y$ al tipo de estudio que realizan, presencial o no presencial podemos descubrir los porcentajes reflejados en las llustraciones 1 y 2 :

Pero si analizamos estos mismos datos no respecto al número de universidades si no respecto al número de estudiantes obtendremos unos resultados claramente diferentes (Ilustraciones 3 y 4 ).

A pesar de que las universidades privadas representan el $28 \%$ del total español, sólo ofrecen docencia al $8 \%$ de los estudiantes (un total de 117.197). Por el contrario, en las dos únicas universidades de carácter no presencial, que representan un $3 \%$ de las instituciones, estudian el $10 \%$ del total de los universitarios españo-

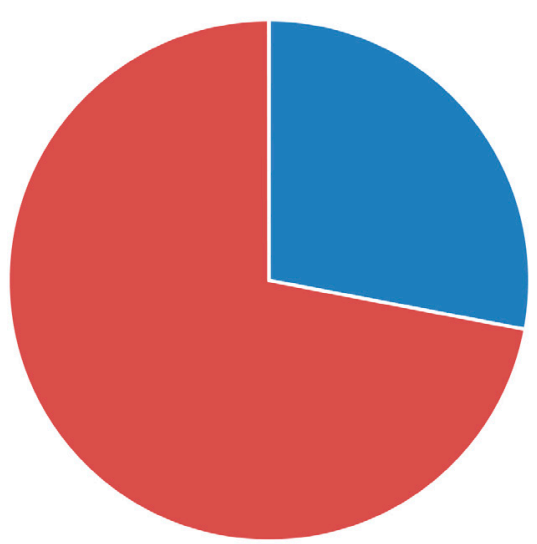

privadas $28 \%$ públicas $72 \%$

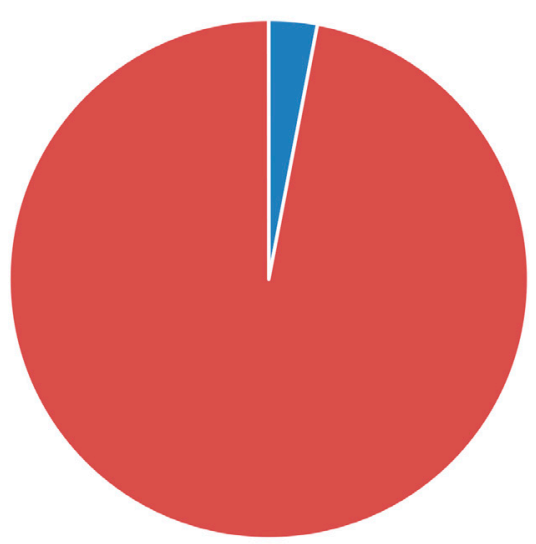

no presencial $3 \%$ presencial $97 \%$ 


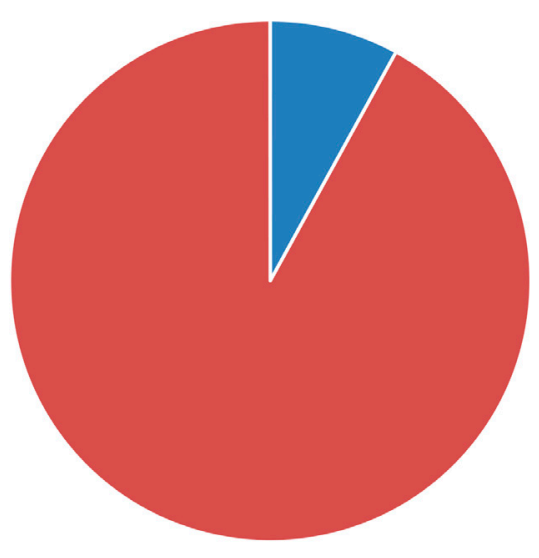

privadas $8 \%$ públicas $92 \%$

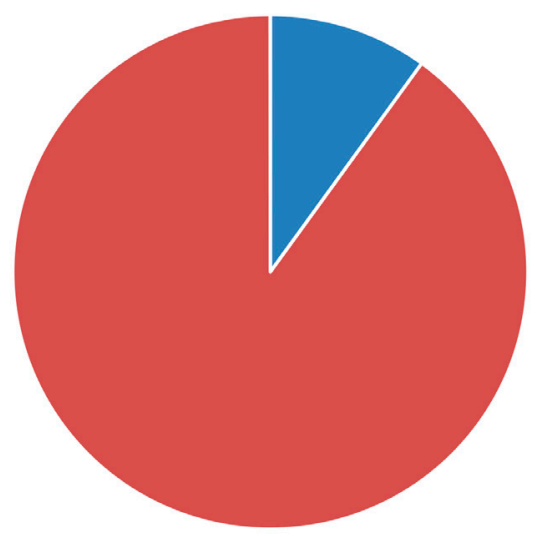

no presencial $10 \%$ presencial $90 \%$
Ilustración 3. Universidad pública/privada (por no estudiantes)
Ilustración 4. Presencialidad universitaria (por no estudiantes)

les (gracias sobre todo a la UNED, que con sus 133.591 estudiantes, es la de más alumnos matriculados).

Concluimos que la universidad española es básicamente una universidad pública de carácter marcadamente presencial. En los siguientes capítulos se citan experiencias de estudios semipresenciales e incluso completamente virtuales en las universidades presenciales actuales pero su aplicación es aún hoy en día relativamente testimonial ${ }^{45}$. Las universidades privadas son reducidas en número, pero aunque se prevé que aumenten en el próximo quinquenio (a diferencia de las públicas) seguirán teniendo un bajo porcentaje de alumnos. Podemos intuir que en un futuro bastante próximo (en algunas escuelas esto ya se puede estar produciendo) existirá una feroz competencia para captar a los estudiantes, que pasaran a ser vistos como clientes potenciales de unos servicios universitarios que tendrán que adaptarse a las nuevas circunstancias si quieren sobrevivir. Las instituciones no presenciales partirán de la ventaja de tener unos costes más ajustados por el número de estudiantes, y además podrán adaptarse mejor a un tipo de estudiante diferente al tradicional que dedicaba unos años de su

\footnotetext{
${ }^{45}$ Este hecho puede cambiar si se generalizan los créditos y las actividades no presenciales en la mayoría de las asignaturas, como se pretende en algunas instituciones universitarias.
} 
vida sólo a formarse. El nuevo estudiante del siglo XXI es una persona que está en permanente proceso de aprendizaje durante toda su vida, que compagina trabajo y estudios, y que demandará cada vez con más insistencia estudios no presenciales.

\subsubsection{Las escuelas de Ingeniería Industrial}

\subsubsection{Origen catalán}

Josep Ma de la Poza i Lleida considera probado que el origen de la carrera de ingeniero industrial en España procede de la "Il/lustre Junta de Comerç de Barcelona» que fundó las enseñanzas técnicas de aplicación a la industria en el siglo XIII por privilegio del rey Jaume I. A medida que avanza la Edad Media, las ciudades toman más protagonismo y los burgueses engendran el nacimiento de un nuevo comercio. Cuando la burguesía se aproxima a la cultura se presenta un nuevo hombre práctico que debe su desarrollo al propio esfuerzo, antítesis del Santo y el Héroe, figuras de la clerecía y la aristocracia. El imperio mediterráneo catalán de la edad media desparramó por todo el mediterráneo occidental estas escuelas dedicadas a los estudios técnicos, especialmente en los territorios de la Corona de Aragón: Valencia y el Reino de Mallorca.

Los cambios producidos por la guerra de Sucesión, con la derrota en 1714 de Barcelona a las tropas de Felipe $V$ truncan este desarrollo incipiente de la vida cultural y técnica catalana. El "Decreto de Nueva Planta» de las potencias vencedoras obligará a cerrar todos los centros de enseñanza catalanes y creará una nueva universidad en Cervera, bajo el dominio del rey borbón.

En 1735 la «Il/Iustre Junta de Comerç de Barcelona» es reformada y enriquecida con donaciones y privilegios para reactivar la economía catalana. Hasta principios del siglo XIX llevará a cabo una política de protección e impulso a la industria, con la fundación por todo el territorio de los «Centros de Enseñanza Profesional Obrera», cuya finalidad era la de formar a profesionales de determinadas oficios industriales y artísticos. Estos Centros son el germen de las actuales escuelas de ingeniería industriales.

La «II/lustre Corporació de Barcelona» se instalará primero en el antiguo convento de "Sant Sebastià», de ahí a la "La Llotja», después en los sótanos de la "Universitat Central de Barcelona» y finalmente, a principios de siglo Xx, a la antigua fábrica 
"Can Batlló», que es ampliamente reformada y rebautizada como "Universitat Industrial» ${ }^{46}$. Hasta 1850 las enseñanzas técnicas se producían sin ninguna tutela estatal, confiadas exclusivamente a la iniciativa de la sociedad que coordinaba las necesidades de la producción con los avances pedagógicos. Por esa razón, en esta época sólo existen escuelas de ingeniería industrial en las zonas desarrolladas industrialmente.

\subsubsection{Estudios «reglados» de Ingeniería Técnica Industrial}

En el mes de agosto de 1824 se funda en Madrid el «Real Conservatorio de las Artes», base oficial de las enseñanzas de mecánica, física, química y delineación, hasta 1850. En 1845 el Ministerio de Comercio, Instrucción y Obras Públicas, publica un Plan de Estudios, que ni tan siquiera mencionaba a los estudios de base industrial. Ante esta enorme laguna, la "Il/lustre Corporació de Barcelona», junto con otros organismos, evidenció esta falta y pidió al gobierno que fuera corregida, cosa que no sucedió hasta el Real Decreto de 1850.

El Real Decreto de 4 de septiembre de 1850 fija los motivos del porque de la organización de los estudios de Ingeniería Técnica e Industrial en España: "Ocupado el gobierno, desde hace algunos años, en la organización general de la instrucción pública, para poner en armonía con las necesidades del nuevo siglo, no podía olvidar unos de los ramos más interesantes y el que más influencia puede ejercer en la prosperidad y riqueza de nuestra patria. No era suficiente con dar impulso a la enseñanza clásica y mejorar los estudios literarios o científicos. Para completar la obra era preciso, entre otros establecimientos importantes, crear escuelas donde los que se dedican a las carreras industriales puedan encontrar toda la instrucción que han de necesitar para destacar en las artes o llegar a ser químicos perfectos, o hábiles mecánicos. De esta manera se abrirán nuevos caminos a la juventud deseosa de enseñanzas, (...) se dedicarán a la ciencia de aplicación a propósito de profesiones para las que hay que buscar en las naciones extranjeras personas que sepan ejercerlas

\footnotetext{
${ }^{46}$ Actualmente aún es conocida popularmente como "Universitat Industrial», y siguen impartiéndose las enseñanzas técnicas industriales, puesto que en ella está ubicada la EUETIB. En los años 70 la UPB (posteriormente UPC) se expandió a la Zona Universitaria, trasladando a un edificio de nuevo cuño la nueva ETSEIB.
} 
con el pleno conocimiento que exigen ${ }^{47}$. En la declaración de intenciones del Real Decreto ofrecida a la reina Isabel II queda patente dos cosas. Primero, el gobierno del estado se da cuenta que la ingeniería industrial es imprescindible para el desarrollo de España como país moderno. Segundo, no se confía este desarrollo a la sociedad civil, como había ocurrido en Catalunya mediante los primeros establecimientos preindustriales y los pioneros «Centros de Enseñanza Profesional Obrera».

El Real Decreto de 1850 establece las enseñanzas técnicas en tres grados: un grado superior, formado por los denominados ingenieros de primera, o ingenieros mecánicos y eléctricos (los actuales ingenieros industriales); un segundo grado formado por los ingenieros de segunda (los actuales ingenieros técnicos industriales); y un grado elemental, los maestros industriales. En 1856 se cambia el nombre de ingenieros mecánicos por el actual de ingenieros industriales. Y el de ingenieros de segunda por el de peritos industriales, posteriormente ingenieros técnicos industriales.

Existieron tres escuelas superiores para cursar ingeniería industrial: Barcelona (1851), Madrid (1857) y Bilbao (1897). En 1867, el Real Instituto Industrial de Madrid se extinguió, de manera que como la escuela de Bilbao no se fundó hasta 1897, Barcelona fue durante 30 años la única escuela donde se podía cursar cualquiera de los niveles de ingeniería industrial.

\subsubsection{Ingenieros, técnicos y peritos}

La LIP de 1857 determinó que la carrera de ingeniero se dividiera en dos secciones: ingenieros mecánicos e ingenieros químicos. Posteriormente se añadió la sección eléctrica. El 14 de septiembre de 1902 se aprobó el reglamento de la Escuela de Ingenieros Industriales y se implantó el plan de estudios de esta carrera.

El plan de estudios de 1902 fue vigente hasta el nuevo plan del 6 de agosto de 1907 , en el que por primera vez se considera el título de ingeniero como el com-

\footnotetext{
47 «UN TOMB DE 150 ANYS D'HISTORIA. CORPORACIÓ D'ENGINYERS TECNICS INDUSTRIALS DE CATALUNYA (1850-1995)». Pág 29. Josep Mạ de la Poza i Lleida. Edita COETIC. Barcelona 1995. ISBN-b-14376-95.
} 
pendio de un conjunto de estudio teóricos, prácticos y de relación que reconocen al estudiante una formación completa para el ejercicio profesional en el campo industrial. Algunos autores defienden que es a partir de 1907 cuando realmente nacen las carreras de ingeniería industrial, no limitadas a un conjunto de conocimientos de la técnica mecánica, química y eléctrica, sino con el complemento de otros de carácter económico.

El plan de estudio fijó como objetivos de las escuelas de ingeniería industrial: formar buenos ingenieros directores de las ramas mecánica, química y eléctrica; adquirir conocimiento exacto de los inventos de mayor utilidad relacionados con estas industrias en los países extranjeros más desarrollados para poderlos implantar en España; verificar ensayos y reconocimientos que requiriesen las corporaciones y los particulares; promover exposiciones industriales de carácter general y específico; expender certificados de aptitud de los estudios que impartían.

El Real Decreto de 16 de diciembre de 1910 establece la enseñanza de perito textil, y la de perito manufacturero. El Real Decreto-Ley de 31 de octubre de 1924 establece el estatuto de Enseñanza Industrial, dependiente del ministerio del Trabajo. En el Artículo 3으 y 350 establece las diferencias de capacitación entre los ingenieros industriales y los peritos.

La Real Orden de 21 de enero de 1929 cambia la denominación de los Peritos Industriales por el de Técnicos Industriales, redefiniendo sus atribuciones. El decreto de julio de 1942 vuelve a cambiar las relaciones laborales entre las dos familias de la ingeniería industrial.

El Proyecto de Ley de Reforma de las enseñanzas Técnicas de 1945 promovió un interesante debate, que no llegó a fructificar después de más de 5 años de discusiones sobre los planes de estudios, las asignaturas, los años de docencia y el sempiterno problema de atribuciones profesionales entre los diferentes grados. La Ley 12/1986 de 1 de abril es una de las más importantes y claras respecto a las atribuciones profesionales de arquitectos e ingenieros y entre ellos y sus grados técnicos.

Parece ser que la vieja polémica entre ingenieros industriales e ingenieros técnicos industriales ha llegado a su fin, en el marco del Espacio Europeo de Enseñanza superior, que aboga por un nuevo planteamiento a nivel europeo lejos de los dos ciclos universitarios españoles clásicos. 


\subsubsection{Escuelas de ingeniería industrial en España en 2001-02}

Hasta 2002-2003, del total de las 66 universidades españolas, 47 (el $71 \%$ ) imparten ingeniería industrial, superior o técnica, en cualquiera de sus especialidades.

Estas 47 universidades tienen adscritas un total de 76 escuelas de ingeniería industrial, lo que representa que el número de escuelas por universidad es de 1,62. Este es un valor medio indicativo de que la mayoría de las universidades poseen más de una escuela de ingeniería industrial, ya sea por razones geográficas (en diferentes campus) o en menor medida, separando las EUITI de las ETSII ${ }^{48}$. Casos sobresalientes son la Politécnica de Catalunya con 8 escuelas (fruto de la combinación las dos circunstancias anteriormente explicadas) o la Euskal Herriko Unibertsitatea con 5 escuelas. Tampoco la distribución por comunidades autónomas es homogénea.

Las 17 universidades privadas tienen 12 escuelas, a razón de sólo una escuela por universidad. Esto significa que las universidades privadas mantienen el mismo porcentaje ( $70.5 \%$ ) en cuanto a estudios de ingeniería industrial, pero concentrados en un único centro universitario. Las universidades privadas, imparten docencia en ingeniería, pero la concentran en menos escuelas. De las 76 escuelas de ingeniería industrial, sólo el $16 \%$ son privadas (12), cuando el porcentaje de universidades privadas era del $26 \%$. Esta es una primera diferencia entre públicas y privadas en la ingeniería industrial.

Otro aspecto interesante a tener en cuenta es la antigüedad de la escuela. 1945 es la antigüedad media de las escuelas de Ingeniería Industrial de España. En este dato está computado el origen de la escuela, aunque a posteriori haya existido cambio de nombre oficial, o de emplazamiento (como en el caso de la ETSI ICAI de Comillas a Madrid). Sólo se ha considerado la fecha desde que la escuela ha empezado con estudios de ingeniería industrial, no antes si la escuela tenía otros estudios de ingeniería ${ }^{49}$.

Las escuelas más antiguas son lógicamente las pertenecientes a universidades públicas, repartidas por la geografía más industrial de la última mitad de siglo XIX y principios del $\mathrm{xx}$ :

\footnotetext{
${ }^{48}$ Aunque actualmente esta separación carece claramente de sentido si nos atenemos al documento marco aprobado en febrero de 2003 sobre Integración del Sistema Universitario Español en el Espacio Europeo de Enseñanza Superior del Ministerio de Educación, Cultura y Deporte.

${ }^{49}$ Por ejemplo, la E.U. Politècnica de Mataró, 1982, primera promoción de ingeniería industrial.
} 
- ETSEl de Barcelona, 1851

- ETSII de Madrid, 1857

- EUETI de Oviedo, 1887

- ESI de Bilbao, 1897

- ETSII de Cartagena, 1901

- EUP de Vilanova, 1901

- ETSEl de Terrassa, 1902

- EUETI de Terrassa, 1902

- EUITI de Zaragoza, 1902

- EUETI de Barcelona, 1904

- ETSI ICAI Comillas, de Madrid, 1908

España, a pesar de no ser una gran potencia industrial ni pertenecer al G-7, si es un país con una cierta tradición industrial en algunas regiones. Las escuelas de ingeniería tradicionalmente han sido la locomotora de las universidades españolas. De las escuelas de ingeniería industrial han nacido otras ingenierías, telecomunicaciones, informática, etc... Regiones poco industrializadas han comprendido la necesidad de poseer una escuela de ingeniería industrial en su entorno para poder desarrollarse industrialmente, incluso antes de tener sus propias universidades, adscritas a otras instituciones foráneas. En este sentido las escuelas de ingeniería están bien asentadas en el entorno socioeconómico en la que se ubican.

\subsection{Enseñanzas históricas de la Ingeniería Gráfica en España}

\subsubsection{Bibliografía básica desde 1940}

\subsubsection{1. "Perspectiva Elemental», 1940}

Publicado por Edelvives en Zaragoza se subtitula «Método sencillo y práctico para dibujar con corrección». Es una edición muy sencilla de tan sólo 36 páginas y de papel de poca calidad. Es un repaso elemental de los conceptos básicos de perspectiva, pero consigue introducir al lector en las ideas básicas que le permiten seguir la resolución de los problemas propuestos. Es una edición casi de emergencia, en una época de gran escasez en España. Como dato curioso, el libro además de los dibujos "a mano» también está escrito "a mano». 


\subsubsection{2. "Geometría Descriptiva y sus aplicaciones», 1943}

Ángel Taibo trata sobre los cuatro sistemas de representación explicándolos a la vez: Cuando trata un tema explica como se resuelve en todos los sistemas, lo que da una visión clara de las semejanzas y diferencias entre ellos. A pesar de su pequeño tamaño abarca los aspectos fundamentales de todos los sistemas. A juicio de algunos críticos los dibujos son un poco confusos. También se objeta la existencia de un tema dedicado a la homología y las cónicas, muy típico en los libros de esa época. En este primer tomo sólo llega hasta la representación de figuras planas. Posteriormente se editó un segundo donde se trataba el tema del dibujo de cuerpos. Es un libro completamente original tanto en exposición como dibujos. Editorial original Blass. Editorial actual Tebar Flores. Madrid. ISBN 84- 7360-041-X.

\subsubsection{3. "Geometría Descriptiva aplicada al dibujo», 1950}

Obra de Leopoldo Crusat Prats y Manuel Daurella Rull. Editorial Bosch. Barcelona. Crusat, profesor de la Escuela de Ingenieros, publicó anteriormente otros libros de relación entre matemáticas y geometría: «Apuntes de Geometría con arreglo al programa de Complemento de Algebra, Geometría y Trigonometría» (1901), «Curso de ampliación de matemáticas» (1928), «Álgebra Superior» (1928), «Concepto de número» (1941), «Aritmética general y aplicada» (1946).

\subsubsection{4. "Manual práctico de Dibujo Técnico», 1956}

Schneider, W. Otra obra fundamental de la editorial Reverté. La historia de editorial se inicia en el Castillo de Montjuïc, habilitado durante años como cárcel para presos políticos de la guerra civil española, en la que Pedro Reverté Gil, Ingeniero Industrial y Artillero, permaneció encarcelado por un periodo de casi cuatro años. Fue durante su estancia en la prisión donde se fraguó la idea de crear una editorial de libros científicos y técnicos. La Editorial Reverté se fundó en el año 1947. Inicialmente establecida en la calle Rosellón 224, de Barcelona.

\subsubsection{5. "Dibujo Geométrico Acotado», 1957}

Obra de Carreras Soto, editado en Sevilla por su propia editorial: Ediciones Carreras Soto. Es una Segunda Parte que completa un primer tomo. En la portada 
interior de este libro se destaca «Obra aprobada por la comisión dictaminadora de libros de texto para la segunda enseñanza. Boletín Oficial no 202 fecha 20-7-1940. Nueva aprobación B.O. no 21 fecha 31-5-1955». Como se puede comprobar este fue un libro de texto recomendado desde el Boletín Oficial del Estado, destinado sobre todo a los cursos de ingreso a la universidad fue "especialmente recomendada para los alumnos de institutos, escuelas de comercio y de bellas artes». Carreras Soto publicó otras colecciones de libros para la enseñanza de lo que él llamó Dibujo Técnico Moderno: «Dibujo industrial», «Dibujo de Máquinas», «Dibujo de croquis», "Dibujo Geométrico Industrial», «Dibujo Geométrico», «Construcción de escalas», "Engranajes», "Dibujo Axonométrico Industrial» (5 tomos), "Caligrafía industrial», "Dibujo lineal y arquitectónico», «Dibujo lineal apulso», «Arquitectura: trazado de los cinco órdenes», etc...

\subsubsection{6. "Lecciones de Geometría Descriptiva», 1961}

Libro compuesto de dos tomos de Luis Mateo Díaz (arquitecto y licenciado en ciencias exactas) y editado en Barcelona por A. Gimeno Sorolla forma parte de la colección «Matemáticas para las enseñanzas Técnicas». Sus 300 páginas comprenden un vasto tratado de geometría descriptiva donde priman las matemáticas sobre los dibujos, pequeños y en limitada cantidad. También fue "Obra declarada de texto para las escuelas de Enseñanza Media Técnica. B.O. del Ministerio de Educación Nacional de 31 de mayo de 1955)». B-490-61.

\subsubsection{7. "Manual DIN. Normas Fundamentales para Técnica Mecánica», 1963}

Este manual casi de bolsillo a pesar de sus 368 páginas es la 7ạ edición española, traducción autorizada por el Comité de Normas Alemán (DNA). Fue editado en Bilbao por Editorial Balzola. Desde la edición de 1954 no se había actualizado, con la incorporación de las nuevas normas alemanas. Fue manual imprescindible en cualquier clase de normalización. Bi-1733-1963.

\subsubsection{8. "Dibujo», 1965}

Obra del catedrático Javier Rodríguez de Abajo, publicado por la editorial Vasco Americana en Bilbao, tiene una primera hoja titulada "Cuestionario Oficial» que marca el temario típico de la expresión gráfica en la ingeniería de la época en dos 
grandes bloques: 1-Proyección ortogonal: proyecciones de la recta, posiciones relativas de dos planos, cambios de planos, giros y abatimientos, ángulos de recta y plano, triedros, poliedros, representación de cilindro, cono y esfera. 2-Normalización: signos de trabajo, sistemas de roscas, representación simbólica y consignación de medidas, muelles, representación normalizada de engranajes, soldadura UNE y DIN, remaches, acotación y roblonados, pasadores de fijación. BI 1.100-65.

\subsubsection{9. "Tratado de Dibujo», 1968}

Sola Torrella, J. Se trata en verdad de dos libros fundamentales. El primero subtitulado «Cuarto Curso. Perspectiva axonométrica. Excéntricas. Levas. Engranajes. Diferentes clases de dibujos», ISBN 84-400-0975-5. Y el segundo subtitulado "Quinto Curso. Sombras. Coordenadas triangulares. Calderería. Nomografía. Estampación. Ficha de fabricación. Utillajes». Depósito legal B-649-1961. Ambos editados por G. Suñol.

\subsubsection{0. "Dibujando en Perspectiva», 1968}

Emilio Freixas es el autor de este tratado de perspectiva de 96 páginas perfectamente encuadernado y editado en Barcelona por Editorial Sucesor de E. Meseguer. Este prolijo autor plantea un artístico tratado de la perspectiva siempre recordando las bases matemáticas en que se sustenta. En la introducción del libro queda de manifiesto que no está especialmente dedicado a los ingenieros (a pesar que fue libro de consulta en muchos cursos) al decir: "lo verdaderamente importante para un artista no es operar prolijamente la perspectiva, sino comprender sus leyes básicas y obrar de acuerdo con ellas». Emilio Freixas, junto con su hermano Carlos, fueron unos grandes dibujantes que publicaron varias colecciones de libros dibujos. ISBN 84-7106-049-3.

\subsubsection{1. "Geometría Descriptiva», 1980}

Este libro de Fernando Izquierdo Asensi interesa a aquellos alumnos que, sin tener grandes conocimientos de geometría métrica inician el estudio de la Geometría Descriptiva. El autor expone de forma clara las proyecciones de un cuerpo en los cuatro sistemas de representación, la perspectiva caballera y cónica, las intersecciones de superficies, sombras, etc. Declarada de Utilidad Pública, de Utilidad para 
el Ejército y de texto para el ingreso en el Cuerpo de Ayudantes de Ingenieros de Armamento y Construcción. Recomendada en gran número de Escuelas Técnicas de Ingeniería de España y en diversos Centros y Universidades de Hispano América. Su gran valor didáctico se refleja en las 26 ediciones publicadas hasta la actualidad. ISBN 84-237-0151-4.

\subsubsection{2. "Normalización del Dibujo Industrial», 1981}

Libro de Rodríguez de Abajo y Galarraga Astibia de múltiples reediciones, aun la venta en la actualidad, de 307 páginas, donde se estudia escalas, formatos, plegado para archivadores, perspectiva caballera y axonométrica, principios generales de representación, dibujos técnicos, cuadro de rotulación, indicaciones de los estados superficiales en los dibujos, dibujo industrial, acotación, signos convencionales para los resortes, etc.. ISBN 84-706-181-0.

\subsubsection{Reducción de horas en los planes de estudio}

A partir de mediados de los años 80 en algunas Escuelas de Ingeniería se empezó a reducir las horas dedicadas a la IG. Primero de forma casi testimonial, pero a mitad de los noventa de forma más abrupta.

En el plan 72 de la EUETIB se impartían las asignaturas de «Dibujo |» y «Dibujo II» de duración anual, con una carga lectiva de 6 horas semanales cada una. El plan 95 supuso la sustitución de estas asignaturas por la de "Expresión Gráfica y DAO» también de 4 horas semanales pero sólo durante un cuadrimestre. En el caso de la especialidad mecánica, se completaba con otra asignatura obligatoria en el segundo cuadrimestre «Expresión Gráfica y DAO Il». Del plan 72 al plan 95 la mayoría de las especialidades de ingeniería técnica de la EUETIB pasaron a disponer de sólo un $33 \%$ de las horas. En el caso de la especialidad mecánica, esta reducción fue «sólo» del $66 \%$. El plan de estudio vigente actual 2002 no ha supuesto ninguna reducción de horas, pero si una distribución interna, dando lugar a un incremento interno de las horas dedicadas al laboratorio y la aparición de un $20 \%$ de créditos de no presencialidad.

De la misma manera, en la ETSEIB durante el curso 1886-87 se impartieron por última vez las asignaturas obligatorias «Dibujo |» y «Dibujo II» de duración anual con una carga lectiva de cuatro horas semanales, que fueron sustituidas por las 
materias «Técnicas de Expresión Gráfica |» y «Técnicas de Expresión Gráfica I|» de duración cuatrimestral con una carga lectiva de 5 horas. En el año 94 estas asignaturas fueron sustituidas por una sola materia obligatoria «Técnicas de Representación Gráfica (TGR)» de duración cuatrimestral con 5 horas lectivas a la semana. En total una reducción de 24 a 7.5 créditos.

¿Cómo se ha podido llevar a cabo esta drástica reducción de las horas dedicada a la asignatura sin mermar su capacidad? Básicamente por dos motivos. Por un lado la reducción y concentración de contenidos; y por otro por la incorporación de nuevas metodologías educativas en base a los nuevos programas de Diseño Asistido por Ordenador. A finales de los 80 y principios de los 90 empezaron a aparecer asignaturas optativas de «dibujo por ordenador». En los nuevos planes, estas materias penetraron dentro de los objetivos de las asignaturas obligatorias de dibujo, permitiendo un ahorro sustancial de tiempo, a la vez que algunos de los conceptos que se explicaban hasta ese momento dejaron de tener sentido. Se puede afirmar sin lugar a dudas que la implementación de nuevas metodologías basadas en las nuevas herramientas tecnológicas permitió un ahorro de horas semana del alumno sin perder ni un ápice de la importancia de la asignatura, más bien al contrario. Así lo explica el profesor Ignasi Garcia Almirall: «la gran capacidad del programa propició importantes cambios conceptuales y procedimentales y demostró que podían resolverse los mismo ejercicios que antes, pero de forma más ágil y con menos tiempo. Al trabajar en 3-D se potencia la visión espacial al tiempo que se eliminan las complejidades aportadas por los sistemas de representación clásicos. El estudiante, que suele llegar de secundaria con buenos conocimientos de diédrico directo y axonométrico, se introduce sin demasiadas dificultades en el 3-D, especialmente motivado por la manera más ágil de obtener aquellas vistas y verdaderas magnitudes que tanto le costaban sobre el papel, a cambio, tendrá que incorporar a sus conocimientos, además de los contenidos propios de la asignatura, la manipulación de un programa de CAD y todo sólo en 15 semanas. A pesar de todo, la experiencia de estos dos últimos cursos permite asegurar que el estudiante se ve recompensado por los resultados y no oculta su atractivo por la nueva forma de impartir TGR. $\|^{50}$.

\footnotetext{
50 «PROYECTO DE INFORMATIZACIÓN DE LA DOCENCIA DE TÉCNICAS DE REPRESENTACIÓN GRÁFICA (TGR) EN LA ESCUELA TÉCNICA SUPERIOR DE INGENIEROS INDUSTRIALES DE BARCELONA». Ignasi García Almirall. XI INGEGRAF. Volumen I. Pág.342. ISBN 84-699-0473-6. Ed. Secretaría del XI CIIG. Logroño-Pamplona 1999.
} 


\subsubsection{La Ingeniería Gráfica en España en 2001-2002}

\subsubsection{Los departamentos de Expresión Gráfica en la Ingeniería}

¿Cómo organizan las universidades españolas la docencia de la expresión gráfica? En las 47 universidades con estudios de ingeniería industrial existen 14 departamentos específicos de expresión gráfica (30\%), mientras que otras 33 universidades (un $70 \%$ ) incorporan esta área de conocimiento en otros departamentos, principalmente departamentos de proyectos e ingeniería mecánica, aunque no faltan casos curiosos como la Universitat de Girona, con el departamento de «Organización, gestión de empresas y distribución de producto» o el departamento de «Matemáticas e informática» de la Universitat de les Illes Balears.

Existe una gran diferencia si se trata de una universidad pública o privada. Lo anteriormente explicado sólo es válido para las públicas, puesto que en ninguna de las 12 privadas ha sido posible discernir la organización departamental. Las universidades privadas más que organizadas por departamentos horizontales, que afectan a varias escuelas, están organizadas por escuelas que parecen funcionar de forma bastante autónoma.

Así pues nos encontramos con que el área de ingeniería gráfica está nulamente representada en las universidades privadas y discretamente en las públicas. No es de extrañar que se trate de un área con poca influencia, con poca capacidad para la innovación tecnológica y con una limitada aplicación de las nuevas herramientas de la tecnología de la información.

¿Qué profesores imparten la docencia de la expresión gráfica en España? Nuestra investigación ha llegado a contabilizar a un total 515 profesores en el área. Si tenemos en cuenta que sólo existía información pública de un 51 \% de los departamentos, podemos deducir que si el resto de los departamentos de los que no tenemos información tuvieran un número similar, el total de profesores de esta área de conocimiento superaría el millar ${ }^{51}$. Deducido de nuestro estudio, el porcentaje de categorías de profesorado en el área de Expresión Gráfica en la Ingeniería es: 3.3 \% Catedráticos de Universidad, 2.0 \% Catedráticos de Escuela Universitaria, 8.6 \% Titulares de Universidad, 38.5 \% Titulares de Escuela Universitaria, 39.3 \% Asociados

\footnotetext{
${ }^{51}$ Según el MECD a enero 2003, hay contabilizados 440 funcionarios adscritos al área 305 Expresión Gráfica en la Ingeniería: 23 CU, 77 TU, 27 CEU y 313 TEU.
} 
(en diferentes modalidades) y un $8.3 \%$ otras categorías (ayudantes, visitantes, ad honorem,...$)^{52}$. Si resumimos todas estas categorías entre doctores y no doctores es resultado es parecido ${ }^{53}$.

Si comparamos estos gráficos, que hacen referencia a las categorías del profesorado en el área de Expresión Gráfica en la Ingeniería, respecto al conjunto de toda la universidad española podemos ver que esta es una área con pocos doctores (14 \% respecto $42 \%$ del conjunto de universidades españolas) y en general con pocos catedráticos de universidad (3\% respecto al $9 \%$ del conjunto de universidades españolas) ${ }^{54}$ (ver llustraciones 5 y 6 ).

¿Es posible, con un $78 \%$ de profesorado TEU-Asociado, provocar los cambios docentes en dirección a la aplicación de las TIC en la docencia? Parece difícil, cuando muchos

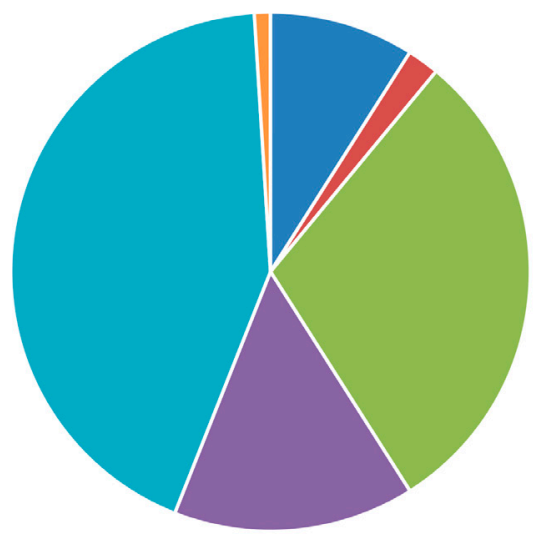

$\square$ CU $\square$ CEU $\square$ TU $\square$ TEU $\square$ Asociados $\square$ Otros

Ilustración 5. Categorías profesorado universitario.

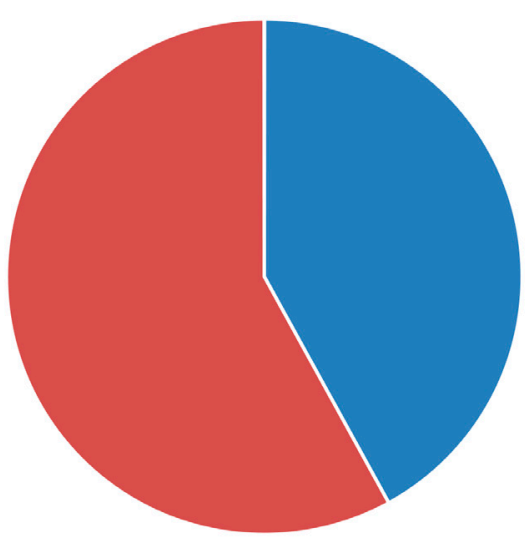

doctor $42 \%$ no doctor $58 \%$

Ilustración 6. Doctores universitarios.

\footnotetext{
52 Según investigación propia.

${ }^{53}$ Estos resultados sólo en consideración a las universidades públicas, porque en ninguno de los servidores de Internet de las privadas existe esta información.

${ }^{54}$ PROFESORADO UNIVERSITARIO: SITUACIÓN EN ESPAÑA Y TENDECIAS INTERNACIONALES. Cuadernos del Consejo de Universidades. Ministerio de Educación, Cultura y Deporte. M-24.631. Madrid 2000.
} 
de estos profesores tienen a menudo una dedicación limitada. ¿Será capaz ese escaso $14 \%$ de doctores de arrastrar a los departamentos hacia las medidas necesarias para una mejora de la docencia y de la investigación en nuestra área de conocimiento? Un número apreciable de universidades ni siquiera tienen un CU en expresión gráfica en la ingeniería. ¿Es posible, con sólo un $14 \%$ de doctores implementar los cambios necesarios para que la aplicación de las TIC en nuestra docencia sea exitosa?

Es lógico pensar que la estructura cualitativa del profesorado de nuestros departamentos obedezca al hecho de que la mayoría de nuestra docencia se imparte en primeros ciclos, en escuelas universitarias y son asignaturas de carácter troncal y con grupos de gran cantidad de alumnos.

Si estudiamos la evolución del profesorado en el último decenio en el conjunto de las universidades españolas (ver Ilustración 7), podremos observar como existe un significativo incremento en los TU, pero también en la categoría de «otros» (especialmente asociados ${ }^{55}$ ). Seguramente nuestra área de conocimiento a pesar

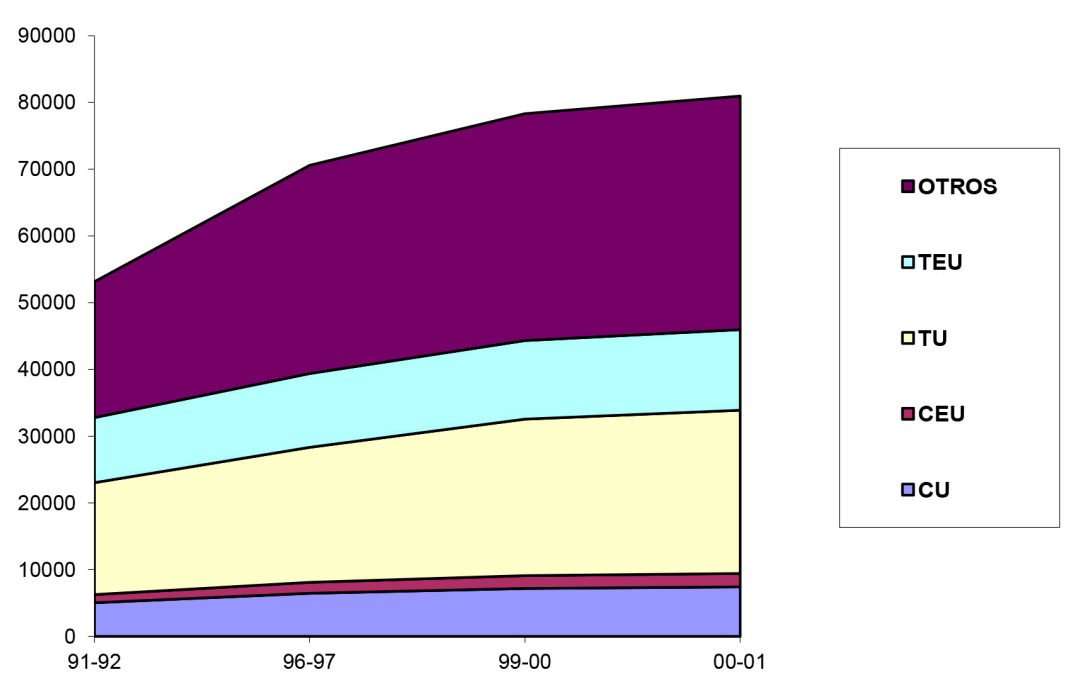

Ilustración 7. Evolución categorías profesorado universitario.

\footnotetext{
${ }^{55}$ Según el profesor Ginés Mora el número de profesores asociados puede llegar hasta los 33.000, según ponencia presentada en el encuentro PROFESORADO UNIVERSITARIO: SITUACIÓN EN ESPAÑA Y TENDECIAS INTERNACIONALES. Cuadernos del Consejo de Universidades. Ministerio de Educación, Cultura y Deporte. M-24.631. Madrid 2000.
} 
de partir de un retraso histórico en estas categorías, tampoco ha incrementado lo suficiente en el último decenio su cuota de doctores entre el profesorado ${ }^{56}$.

\subsubsection{Los departamentos de proyectos}

Se ha visto, hasta ahora, que sólo existen 14 departamentos de Expresión Gráfica constituidos como tales. Es una cifra extraordinariamente baja para toda un área de conocimiento como es la de nuestra investigación.

¿A qué obedece este bajo número de departamentos? Una primera explicación está en los departamentos de Proyectos. Si contabilizamos el número de departamentos de Proyectos (también llamados de Ingeniería de Proyectos, o de Diseño de Proyectos) llegamos hasta un número de 11 departamentos que imparten asignaturas de expresión gráfica. Pero es que además, de los 14 departamentos de Expresión gráfica antes referidos, 2 de ellos son mixtos con el de Proyectos y así lo referencia el nombre del departamento ${ }^{57}$. De manera que si contamos los departamentos de Expresión Gráfica y Proyectos de forma conjunta (ver llustración 8) nos

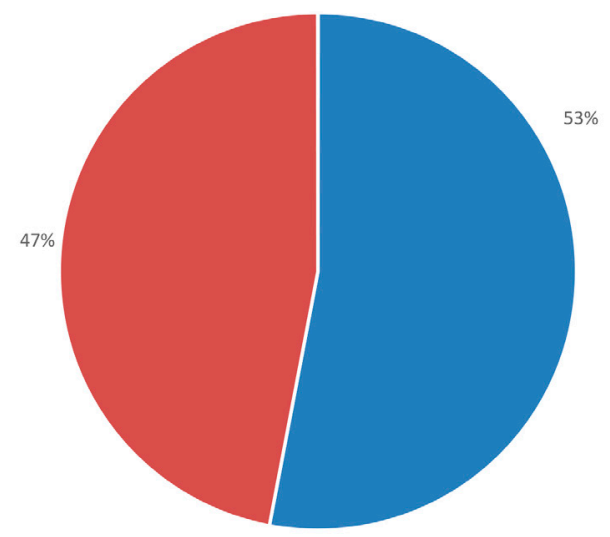

Ingeniería Gráfica + Proyectos D Otros

Ilustración 8. Departamentos de Ingeniería Gráfica + Proyectos.

\footnotetext{
${ }^{56}$ PROFESORADO UNIVERSITARIO: SITUACIÓN EN ESPAÑA Y TENDECIAS INTERNACIONALES. Cuadernos del Consejo de Universidades. Ministerio de Educación, Cultura y Deporte. M-24.631. Madrid 2000.

57 Euskal Herriko Unibersitatea, Universidad de Jaén.
} 
encontramos con que suman un total de 25 en las 47 universidades con estudios de ingeniería industrial

Este gráfico permite aventurar la relación entre el área de Proyectos y el de Expresión Gráfica. De hecho, la mayoría de departamentos de Expresión Gráfica incluyen entre sus asignaturas, para las EUITI's, la de Oficina Técnica, mientras que estas asignaturas, en las ETSII's, están explicadas por profesores del departamento de Proyectos principalmente. Otros autores por el contrario sostienen que aunque tradicionalmente estos dos departamentos han estado muy relacionados, en la actualidad (y aún más en el futuro) tenderán a crear sus propias áreas de saber. Así opina el profesor Federico Fernández Díaz ${ }^{58}$, para el cual el futuro de los departamentos de Proyectos está en el seguimiento del proceso de diseño del proyecto, y no en el «dibujo» del proyecto como había estado tradicionalmente.

\subsubsection{Las asignaturas de Ingeniería Gráfica}

En este estudio se han recogido un total de 106 asignaturas, de las cuales 63 (60\%) son troncales, 20 (19\%) obligatorias y 23 (22\%) optativas (ver llustración 9).

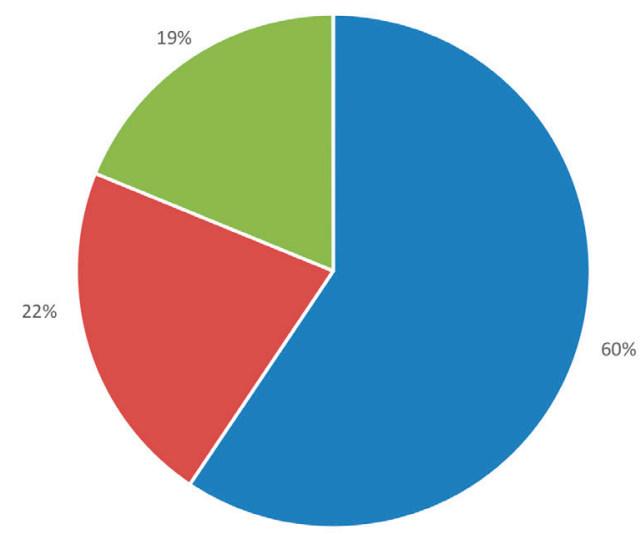

Ilustración 9. Tipo de asignatura en Ingeniería Gráfica.

${ }^{58}$ Profesor del departamento de Proyectos de la UPC. 
El modelo más estandarizado para la docencia de la expresión gráfica se basa en dos asignaturas, que se suelen repartir entre el 1er y el 2 o cuadrimestre. Estas asignaturas son casi siempre troncales $u$ obligatorias. Existe otra versión con una única asignatura, también troncal, pero de duración anual. Como ampliación de la materia, las dos terceras partes de las escuelas proponen asignaturas optativas del tipo «Diseño Asistido por Ordenador» o «Ampliación de Dibujo».

Este modelo curricular puede inducir a pensar que el dibujo por ordenador es un añadido a la expresión gráfica, cuando debería ser herramienta básica para profundizar en los contenidos de la asignatura. Al menos en una primera etapa parece que el DAO se explica como parte de los contenidos, en lugar de como herramienta genérica. Por otra parte no podemos reducir las TIC como instrumento de comunicación en la ingeniería al DAO.

Las asignaturas del área analizadas suman un total de 653 créditos, 148 prácticos (o de laboratorio) y 115 de teóricos. Esto significa que la media de créditos por asignatura es de $6,66^{59}, 3,03$ créditos de teoría y 3,88 de laboratorio (ver llustración 10).

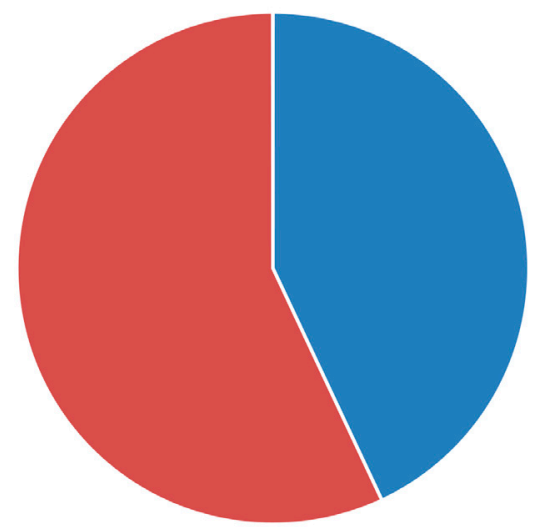

$43 \%$ créditos teóricos $\square 57 \%$ créditos prácticos

Ilustración 10. Tipos de créditos en las asignaturas de IG.

\footnotetext{
${ }^{59}$ Esta es una media, pero existen casos extremos como los 18 créditos totales de la asignatura de expresión gráfica de la Universidad de Oviedo, los 15 de la Universidad de León, o los 12 de las universidades de Burgos, Cardenal Herrena, de Lleida, Pública de Navarra y la de Zaragoza.
} 
Se trata en principio de asignaturas con un gran peso en horas de estudio, y esto es positivo, puesto que indica que las universidades comprenden el potencial de estudio del área. También podemos hacer una lectura positiva de la relación entre teoría y práctica. En las asignaturas de expresión gráfica parece razonable que se impartan más horas de laboratorio que de teoría. Pero aún la relación entre teoría y práctica esté quizá demasiado desajustada hacia la teoría. Pocas horas de teoría, en modalidad de clase magistral, juntando todos los grupos, y bastantes más horas de prácticas de laboratorio, donde no sólo se debería explicar «el DAO», sino «en el DAO». Podemos aplicar las TIC dentro de nuestra docencia, pero esto implica incorporar los contenidos teóricos dentro de nuestros laboratorios, y modificar las relaciones crediticias.

Se han conseguido 46 programas de asignaturas vía Internet, 2 vía fax y 4 vía personal. En esta primera fase de estudio sólo se ha analizado los programas colgados en la Red, lo que supone un $43 \%$ de las asignaturas de expresión gráfica detectadas.

\subsubsection{El programa}

En general, todos los programas recogen los tres descriptores que el Ministerio publica para la asignatura de expresión gráfica: sistemas de representación, normalización del dibujo industrial y dibujo asistido por ordenador. El que sigue podría considerarse un temario tipo, bastante parecido en las diferentes universidades:

- Introducción al dibujo industrial

- Introducción a los sistemas CAD

- Conceptos básicos de normalización

- Los sistemas de representación

- Geometría computacional. Primitivas geométricas

- Geometría constructiva de cuerpos y superficies

A pesar de que todos los programas encontrados conducen a pensar que la materia es la misma, los índices inducen a pensar que el tratamiento que se da a las diferentes asignaturas es diferente ${ }^{60}$.

${ }^{60}$ De hecho, es interesante investigar la relación que se establece entre los programas expuestos al público, y los exámenes a los que se somete a los estudiantes. 
En general hay que concluir que este temario se cumple en gran medida tanto si la asignatura es única, como si existen 2 asignaturas troncales (Dibujo I y Dibujo II, por ejemplo), en cuyo caso suele dividirse a mitades, asignando la parte del DAO en el $2^{\circ}$ cuadrimestre.

\subsubsection{El plan de estudio}

Es lógico que en asignaturas tan instrumentales y por tanto condicionadas tecnológicamente como las de nuestra área de conocimiento, los planes de estudio estén en constante evolución. Si calculamos la antigüedad media de los planes de estudio, descubrimos que se remonta a 1998. Un dato que puede parecer positivo, se ha de valorar junto al hecho que en los últimos 4 años la evolución tecnológica ha sido bastante significativa. No usamos los mismos programas de DAO de hace 4 años, y sobre todo, tenemos a nuestro alcance Internet. Aunque también es cierto que los planes de estudio no tienen por qué especificar el tipo de tecnología que usaremos en nuestra docencia, sino los descriptores de lo que queremos enseñar.

Los planes de estudio más antiguos (siempre de los conseguidos vía Internet) datan de 1994. Y los más modernos son del 2000, en la Universidad Ramón Llull, la Politécnica de Madrid, la de Oviedo, la de Navarra, la Católica Santa Teresa de Ávila y la Carlos III de Madrid; la mitad de ellas privadas. Las universidades privadas tienden a actualizar sus contenidos antes que las públicas ${ }^{61}$.

\subsubsection{El objetivo docente}

De los 47 departamentos que imparten Expresión Gráfica en España sólo 18 tienen los objetivos que pretenden explicar publicados en Internet. Parece un porcentaje bastante bajo. El objetivo enunciado en este $39 \%$ de los departamentos, es bastante heterogéneo, desde los departamentos que resumen sus objetivos en una sola línea, hasta los que desglosan en varios puntos.

Pero es que además, si distinguimos entre objetivos de tipo informativo o de tipo formativo, los 18 son informativos, pero sólo 6 de estos son además objetivos de

\footnotetext{
${ }^{61} \mathrm{O}$ al menos, tienden a actualizar en sus programas antes.
} 
marcado carácter formativo. Entre los objetivos de carácter informativo se encuentran la transmisión de conocimientos de los Sistemas de Representación principales y de las técnicas básicas en dichos sistemas, el conocimiento de las formas, generación y propiedades de los entes geométricos más frecuentes en la técnica, la Normalización básica del Dibujo Técnico, y las aplicaciones de todo lo anterior a la Ingeniería. Entre los formativos o de capacitación están la adquisición de visión y comprensión espacial, dominio de los automatismos de razonamiento geométrico de inducción y deducción, preparación para el uso del Dibujo Técnico como lenguaje en sentido emisor y receptor, fomentar la creatividad y adiestramiento imprescindible para el dibujo de croquización manual o con instrumentos informáticos (ver llustración 11).

\subsubsection{La bibliografía}

Otra variable muy interesante a estudiar es la bibliografía recomendada por cada área de Expresión Gráfica, si consideramos que los libros recomendados permiten deducir el tipo de enseñanza que se da.

De las 47 universidades españolas con estudios de ingeniería sólo 20 tienen publicada vía Internet bibliografía del área ingeniería gráfica. De otras 2 se ha conseguido vía fax y personalmente. Esto representa un $43 \%$ de los departamentos de Expresión Gráfica en la Ingeniería de España. Fruto de esta investigación se ha

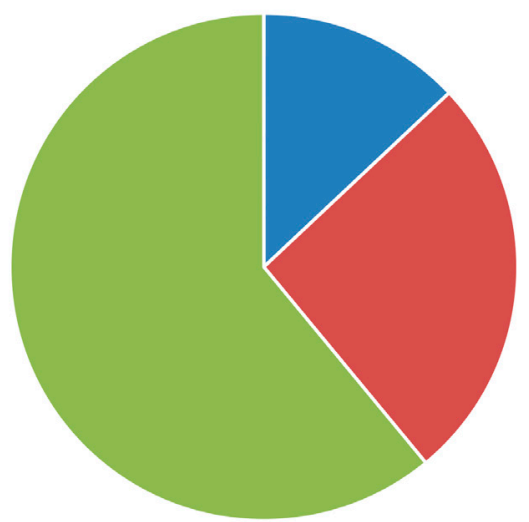

$13 \%$ formativos

$26 \%$ solo informativos

$61 \%$ sin objetivos

Ilustración 11. Objetivos docentes en IG. 
logrado identificar hasta 166 libros de 131 autores diferentes. Algunas de estas referencias bibliográficas agrupan diferentes tomos de una misma colección. En el caso que algún departamento recomendara 2 tomos se ha contabilizado dos menciones para esta referencia. Algunas universidades han separado entre bibliografía fundamental y complementaria. En este caso la bibliografía complementaria se ha contabilizado como 0,5 menciones.

Los libros más mencionados han sido:

- 11 menciones. AENOR, Normas UNE sobre Dibujo Técnico. Tomo 3. Normas Fundamentales. 1997 Madrid AENOR.

- 11 menciones. FÉLEZ, MARTínEZ, Dibujo industrial, Madrid, Síntesis, 1995.

- 11 menciones. IZQUIERDO ASENSI. «Geometría Descriptiva». Madrid: Ed. Dossat. 1990.

- 9,5 menciones. RODRÍGUEZ DE ABAJO. Geometría Descriptiva: tomos 1, 2, 3 y 4. Ed. Marfil

- 8,5 menciones. RODRíGUEZ DE ABAJO, GALARRAGA ASTIBIA. Normalización del dibujo industrial. Donostiarra, San Sebastián 1993.

- 8 menciones. RODRÍGUEZ DE ABAJO, ÁlVAREZ BENGOA, Dibujo técnico, San Sebastián, Ed. Donostiarra, 1996.

Si esta bibliografía la analizamos porcentualmente respecto al total de datos bibliográficos de que disponemos en este momento aún es más reveladora:

- 55 \% AENOR, Normas UNE sobre Dibujo Técnico. Tomo 3. Normas Fundamentales. 1997 Madrid AENOR.

- 55 \% FÉLEZ, MARTínEZ, Dibujo industrial, Madrid, Síntesis, 1995.

- 55 \% IZQUIERDO ASENSI, F. «Geometría Descriptiva». Madrid: Dossat. 1990.

- 48 \% RODRÍGUEZ DE ABAJO. Geometría Descriptiva: tomos 1, 2, 3 y 4 . Ed Marfil

- 43 \% RODRÍGUEZ DE ABAJO, GALARRAGA ASTIBIA. Normalización del dibujo industrial. Donostiarra, San Sebastián 1993.

- 40 \% RODRíGUeZ DE ABAJO, ÁlVAREZ BENGOA, Dibujo técnico, San Sebastián, Donostiarra, 1996.

Se aprecia que la mitad de los departamentos de Expresión Gráfica recomiendan bibliografía clásica, que existía 10 años atrás, y además específicamente españo- 
$1 a^{62}$. Existen diferentes referencias a libros de DAO (en su mayor parte manuales de Autocad) pero dispersos y poco mencionados.

Si analizamos los libros citados y los autores más recomendados (ver llustración 12), este estudio aún acrecienta lo anteriormente destacado. Así la lista de los «top-ten» sería:

- Con 35 menciones RODRÍGUEZ dE ABAJO

- Con 13 menciones Jesús FELEZ

- Con 12,5 menciones, IZQUIERDO ASENSI

- Con 11 menciones, AENOR

- Con 8 menciones, David CORBELLA BARRIOS

- Con 7 menciones, LEICEAGA

- Con 5 menciones, BARTOLOMÉ RAMírez (todos de la U. de la Rioja)

- Con 5 menciones, el servicio de publicaciones de la UPNA

- Con 4,5 menciones, GONZALEZ MONSALVE, PALENCIA

- Con 4,5 menciones, HIDALGO DE CAVIEDES

- Con 4,5 menciones, PUIG ADAM.

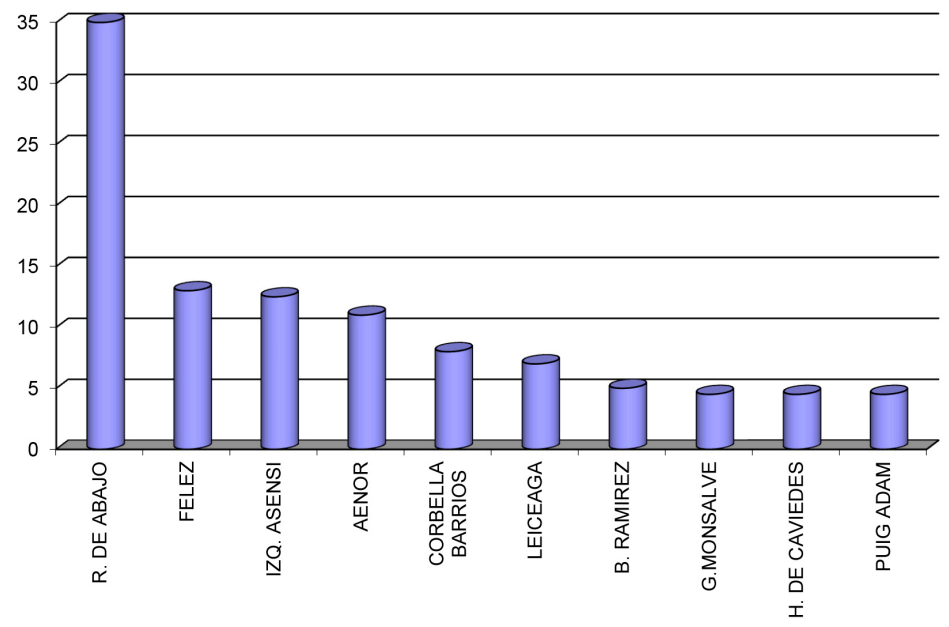

Ilustración 12. Autores más recomendados en bibliografía IG.

62 También se cita bibliografía internacional, como el libro de Mortenson, pero sin suficientes menciones como para aparecer en este listado. 
Los diez autores más citados suman un total de 105.5 menciones, un $40 \%$ del total, con un claro destacado gracias a sus 6 libros.

Otro efecto detectado, además de enumerar siempre la misma bibliografía "consagrada", consiste en citar los libros editados desde el departamento, por los profesores. La mayor parte de estos libros tan sólo son citados por su departamento. De hecho, si contamos los libros con una sola mención veremos que son 113. El $68 \%$ de la bibliografía sólo es citada por una sola de las 21 Universidades.

También podemos analizar la bibliografía desde el punto de vista de los emisores, las universidades (ver Ilustración 13). Estas 166 referencias aportadas por las 21 universidades se han repartido de la siguiente manera:

- Universidad de Málaga, 48 libros, (un $18 \%$ del total de menciones)

- Universidad de Castilla-la Mancha, 29 libros, (11\% del total)

- Universidad de Zaragoza, 20 libros, (un $7 \%$ del total de menciones)

- Universidad Europea de Madrid, 19 libros, (un $7 \%$ del total de menciones)

- Euskal Herriko Unibertsitatea, 16 libros, (un $6 \%$ del total de menciones)

- Universidad Pública de Navarra, 16 libros, (un $6 \%$ del total de menciones)

- Universidad de Vigo, 15 libros, (un $6 \%$ del total de menciones)

- Universidad Politécnica de Catalunya, 13 libros, (un $5 \%$ del total de menciones)

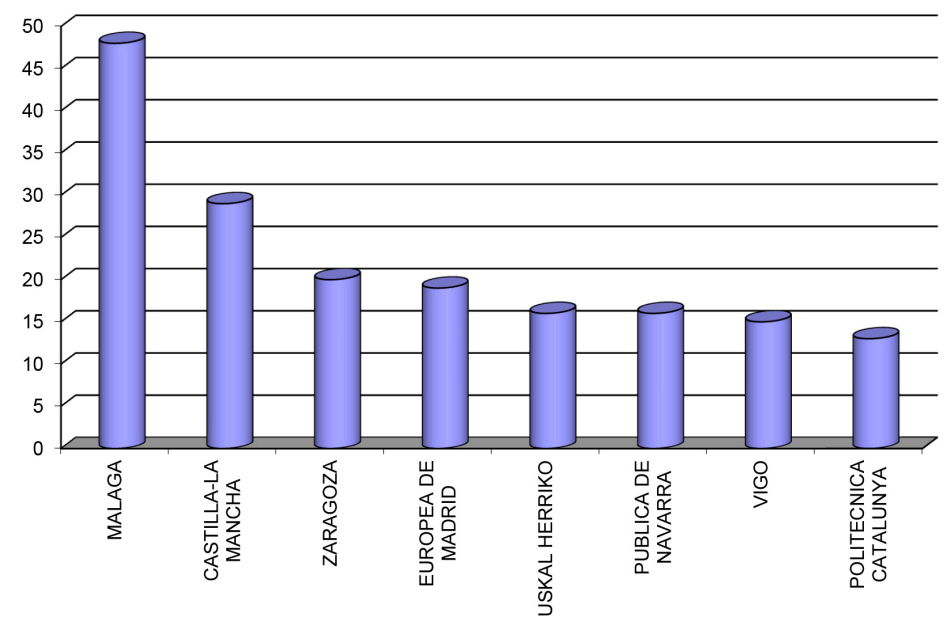

Ilustración 13. Universidades con más bibliografía IG. 
Sólo un $43 \%$ de las universidades aportan bibliografía por Internet. Pero además del total de las menciones, el $60 \%$ es aportado tan sólo por el $30 \%$ de las universidades.

Podemos deducir que se aporta poca bibliografía, y que cuesta buscar nuevos libros, que supongan referencias en el área de la expresión gráfica en la ingeniería industrial, que planteen nuevas fuentes de investigación en el área, especialmente relacionadas con las TIC.

\subsection{Estudio comparativo del área en Europa y USA}

En este capítulo se estudia como se desarrolla el área de Ingeniería Gráfica en el mundo occidental para poderlo comparar con España. De hecho lo que se pretende es analizar en Europa y en los EEUU el desarrollo de un área más amplia que en estos países puede denominarse como «dibujo en la ingeniería y la comunicación gráfica».

Para ello está previsto analizar el área en la red de universidades tecnológicas europeas CLUSTER (a la que está afiliada la UPC) por un lado; y por otro el planteamiento general del área en los EEUU. Este capítulo aporta una interesante visión comparativa España-Europa-USA del área de la que podemos deducir por donde se puede desarrollar en España.

\subsubsection{La Ingeniería Gráfica en Europa}

Hemos de tener en cuenta que el potencial del área de la IG (Ingeniería Gráfica) está fuertemente condicionado por la capacidad de cada país en el desarrollo de la sociedad de la información, puesto que los nuevos ámbitos científicos y técnicos de interés para el área proceden de la aplicación de las TIC en nuestro desarrollo, y ello no es posible sin una fuerte penetración de Internet. Esto hay que tenerlo en cuenta, puesto que España está clasificada en el penúltimo puesto europeo en preparación de acceso a las nuevas tecnologías según «The Economist» indica en el gráfico de la llustración $14^{63}$.

\footnotetext{
${ }^{63}$ Fuente «The Economist». Gráfico publicado en El País Negocios de 20 de abril de 2003. Página 5.
} 


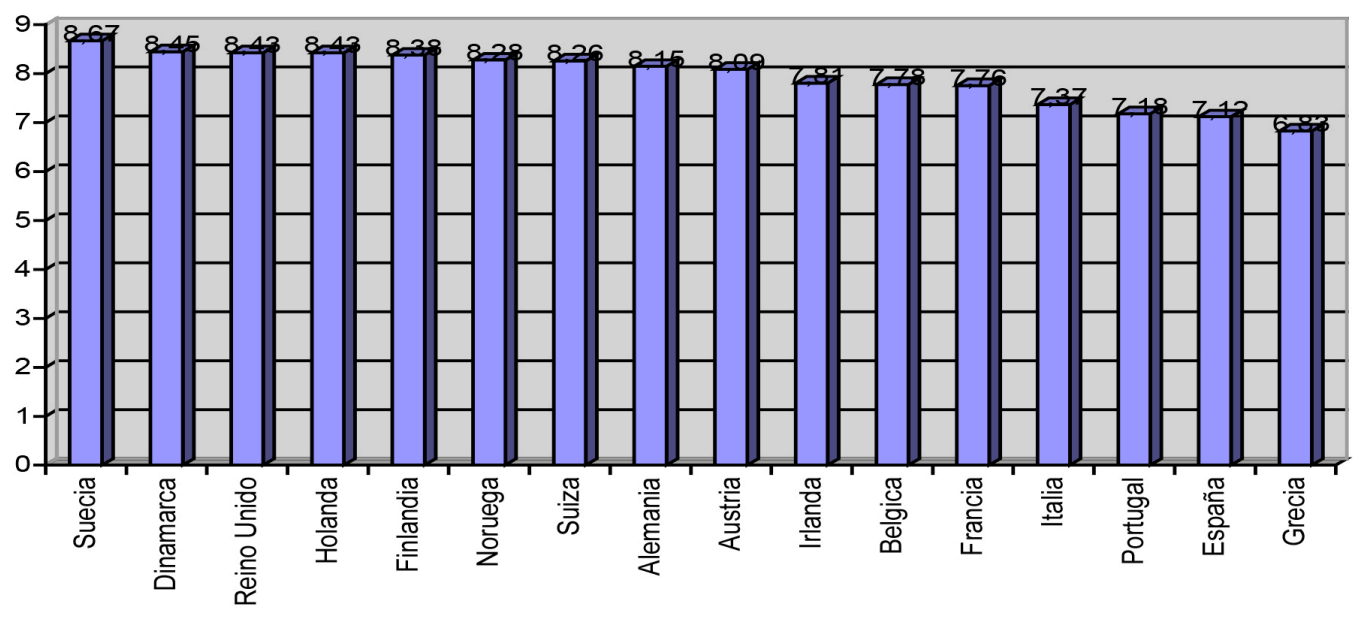

Ilustración 14. Acceso a las TIC en la OCDE.

Para comprender el desarrollo del área en Europa, se ha creído interesante analizar el comportamiento de las universidades del grupo CLUSTER (Consortium Linking Universities of Science and Technology for Education and Research), compuesto por prestigiosas universidades europeas de ámbito tecnológico.

CLUSTER fue fundada en 1990. En el año $2000^{64}$ englobaba a un total de 3.000 profesores, 10.000 investigadores y más de 100.000 estudiantes. CLUSTER puede muy bien considerase como una autentica universidad europea. A partir del año 2000 CLUSTER ha invitado a participar en su funcionamiento a otras universidades del resto del mundo ${ }^{65}$.

Las universidades que componen CLUSTER se pueden ver en la llustración 15.

Como puede comprobarse CLUSTER representa a la casi totalidad de las universidades politécnicas de Europa Occidental, además un breve recorrido por cada una de las universidades puede mostrarnos que siempre suelen representar la vanguardia tecnológica del país al que representan. CLUSTER está organizada en 7

\footnotetext{
${ }^{64}$ Según datos de CLUSTER. http://www.cluster.org

${ }^{65}$ En el año 2000 se integró en CLUSTER la universidad india I. I. T. Delhi, Actualmente están asociadas: Georgia Tech, Tomsk Polytechnic University (Russian Federation), Technion (Israel), Tsinghua University (China), University of São Paulo (Brazil),Ecole Polytechnique de Montreal (Canada).
} 


\begin{tabular}{|c|c|}
\hline Universidades CLUSTER 2002 & Universidades CLUSTER 2011 \\
\hline $\begin{array}{l}\text { EPFL - Ecole Polytechnique Fédérale de } \\
\text { Lausanne }\end{array}$ & $\begin{array}{l}\text { EPFL - Ecole Polytechnique Fédérale de } \\
\text { Lausanne }\end{array}$ \\
\hline Grenoble Institute of Technology & Grenoble Institute of Technology \\
\hline KIT - Karlsruhe Institute für Technologie & KIT - Karlsruhe Institute für Technologie \\
\hline $\begin{array}{l}\text { KTH - Kungliga Tekniska Högskolan, } \\
\text { Estocolmo }\end{array}$ & $\begin{array}{l}\text { KTH - Kungliga Tekniska Högskolan, } \\
\text { Estocolmo }\end{array}$ \\
\hline Politecnico di Torino & Politecnico di Torino \\
\hline TCD - Trinity College Dublin & TCD - Trinity College Dublin \\
\hline Technische Universität Darmstadt & Technische Universität Darmstadt \\
\hline Technische Universiteit Eindhoven & Technische Universiteit Eindhoven \\
\hline $\begin{array}{l}\text { UCL EPL Ecole Polytechnique de Louvain, } \\
\text { Bruselas }\end{array}$ & $\begin{array}{l}\text { UCL EPL Ecole Polytechnique de Louvain, } \\
\text { Bruselas }\end{array}$ \\
\hline Universitat Politècnica de Catalunya & Universitat Politècnica de Catalunya \\
\hline \multirow{3}{*}{$\begin{array}{l}\text { Imperial College of Science, Technology } \\
\text { and Medicine, London }\end{array}$} & $\begin{array}{l}\text { KUL - Katolieke Universiteit Leuven, } \\
\text { Lovaina }\end{array}$ \\
\hline & Aalto University Helsinki \\
\hline & IST - Instituto Superior Técnico, Lisboa \\
\hline
\end{tabular}

Ilustración 15. Tabla Universidades CLUSTER 2002-2011

departamentos. El área IG corresponde al departamento «Information theory and technology: computers and communication».

\subsubsection{El área de ingeniería gráfica en USA}

La enseñanza de la ingeniería gráfica en EEUU está planteada de forma radicalmente diferente que en España y Europa. El Dibujo en Ingeniería está íntimamente relacionado con dos conceptos: la comunicación gráfica, y el proceso de diseño de productos industriales. Por otro lado el papel (y las necesidades) de la empresa privada están siempre presentes en todos sus planteamientos. 
La aplicación de las TIC en las universidades norteamericanas está mucho más avanzada que en España. Ello ha conllevado cambiar de forma fundamental la organización y gestión de sus centros universitarios. A medida que la tecnología va impregnando y cambiando el entorno docente es más importante definir con toda claridad la función de los campus, y la relación de los profesores con sus estudiantes.

\subsubsection{La Ingeniería Concurrente}

En EEUU las técnicas de diseño y las TIC están cambiando el papel tradicional de los ingenieros. El proceso de diseño ya no es una actividad lineal y segmentada sino un conjunto de actividades que involucra a toda la empresa. Este nuevo tipo de diseño (a partir de un equipo pluridisciplinar que usa los ordenadores como herramientas de trabajo) es lo que en EEUU se ha llamado Ingeniería Concurrente. En la ingeniería concurrente se involucra a todos los actores en el proceso de diseño (incluido el cliente), tanto en el momento de crear las ideas, como en el propio proceso de diseño y en la implantación final.

Los ingenieros industriales han de ser capaces de trabajar en equipo; de diseñar, analizar y comunicar mediante potentes software especializados en diseño. El diseño concurrente es una actividad en la que intervienen todos los ingenieros del producto. En EEUU, la tendencia actual de la industria es que los ingenieros sean «modeladores geométricos». El modelado geométrico es "el proceso de crear gráficas por computadora para comunicar, analizar y visualizar el proceso de diseño» ${ }^{66}$. Los diseñadores utilizan los sistemas CAD para crear croquis (definir la idea de los objetos industriales), generar los modelos tridimensionales necesarios, y enviar al departamento de control numérico, de allí se extraen los dibujos 2D de los modelos 3D para añadir las cotas críticas y enviar al departamento de calidad.

El camino recorrido del diseño a la ingeniería concurrente ha significado que el grupo de personas que necesitan aprender a comprender mejor los principios de la comunicación gráfica haya aumentado espectacularmente. Antes, sólo los diseñadores necesitaban comprender el lenguaje gráfico, ahora, en EEUU, los ingenieros, científicos, técnicos, comerciales y gerentes de la empresa necesitan de estos conocimientos.

\footnotetext{
66 «DIBUJO EN INGENIERÍA Y COMUNICACIÓN GRÁFICA» Bertoline, Wielbe, Miller, Moler. 2a edición. Pagina15. Editorial McGraw-Hill Interamericana Editores. ISBN 970-10-1947-4.
} 
La información gráfica por ordenador ha permitido crear grandes bases de datos CAD para la elaboración de un producto. Diferentes actores intervienen en la creación de un producto industrial y necesitan de esta información gráfica. Diferentes individuos con diferentes necesidades gráficas y diferentes capacidades visuales usan las bases de CAD para sus propios fines.

\subsubsection{El proceso del diseño}

EI CAD fue introducido en muchas empresas como una simple herramienta de dibujo automatizada. Se seguía haciendo lo mismo pero con unas herramientas más potentes, precisas y rápidas. A partir de la introducción del modelado 3-D, las empresas americanas descubrieron que podían pasar del concepto «dibujo asistido por ordenador» al "diseño asistido por ordenador», y que esto no era sólo cambio de lenguaje, sino que permitía trabajar de otra manera, introduciendo el proceso de diseño en el momento del "dibujo» y a la inversa. Este proceso permitió el nacimiento de la ingeniería concurrente. Del CAD se pudo pasar a la Manufactura Asistida por Ordenador, a la Manufactura Integrada por Ordenador (CIM) y al Diseño para Facilidad de Manufactura (DFM). La finalidad última de todos estos procesos y de la propia ingeniería concurrente es la mejora de la calidad-precio del producto, en base a acortar el ciclo de diseño, minimizar el material y los costos de mano de obra, y aumentar la calidad final del producto. Al compartir la base de datos 3-D del producto propuesto, más personas pueden trabajar al mismo tiempo en varios aspectos del diseño del producto. La comunicación gráfica entre todos los autores es fundamental para que esto se pueda llevar a cabo.

El modelado 3-D ha permitido una nueva forma de diseñar, introduciendo más «ideas» a la hora de fijar las especificaciones del producto, puesto que a medida que finaliza el proceso de diseño y este se acerca a la fase de producción, los cambios en el diseño se vuelven más costosos. La fase de especificaciones del proceso del diseño establece los requerimientos del producto. Cuando se analizan los diversos conceptos del diseño que se están desarrollando se evalúan respecto a estas especificaciones y si es necesario se llevan a cabo cambios. A medida que el diseño de un producto avanza el coste de los cambios aumenta y la cantidad de opciones de diseño que es posible explorar se reduce.

En EEUU la evolución de la comunicación gráfica (gracias a las herramientas informáticas) ha conllevado una explosión de los usuarios en el área EGI. Todo el 
personal de una institución utiliza herramientas gráficas en tanto que todos ellos forma parte del proceso de diseño del producto.

\subsubsection{Organización postindustrial en la universidad norteamericana}

Las TIC están asociadas con las formas de organización postindustriales, basadas en trabajadores cualificados y flexibles, con un alto grado de autonomía y organizados en unidades operativas relativamente pequeñas y ágiles. En Norteamérica, al creer verdaderamente importante la aplicación de las TIC en sus universidades, han empezado a cambiar la organización interna de sus centros universitarios con mentalidad postindustrial: "Los centros universitarios (...) se han caracterizado por una mezcla de formas de organización agrarias e industriales, con unas estructuras y unos procedimientos jerárquicos, burocráticos y relativamente inflexibles (...) La introducción de nuevas tecnologías para la enseñanza exigirá una evolución importante hacia formas de organización postindustriales en los centros universitarios ${ }^{67}$. En un origen, la introducción de las TIC en las universidades se llevó a cabo a partir de profesores a título individual, pero este sistema no funciona, pues es caro y poco eficaz. El doctor Tony Bates propone un planteamiento de gestión para cada proyecto, basado en una financiación vinculada a unos objetivos previamente fijados, a un equipo de trabajo, a un determinado presupuesto y a planes de producción. Para que ello pueda llevarse a cabo, las universidades norteamericanas están contratando personal tecnológico para apoyo de sus profesores, con una extraordinaria inversión en redes, hardware y software no sólo para las necesidades académicas sino también para las administrativas. Se recomienda que al menos el $5 \%$ del presupuesto base de la enseñanza se dedique al apoyo técnico.

El buen uso de la tecnología, utilizándola en el proceso de enseñanza y aprendizaje, es uno de los puntos que se tienen en cuenta a la hora de contratar (y ascender) al profesorado. Para enseñar tecnología se requiere un alto grado de destreza, y esto exige una formación tecnológica, pero también un gran capacidad educativa.

La aplicación de las TIC en la enseñanza universitaria norteamericana tiene un coste conocido. Los centros de enseñanza superior tienen procedimientos de

\footnotetext{
67 «COMO GESTIONAR EL CAMBIO TECNOLÓGICO. Estrategias para los responsables de centros universitarios.» A.W. Bates. Pág 20. Ediuoc. Gedisa Editorial. Barcelona 2001. ISBN 84-8429-400-5.
} 
contabilidad basados en la actividad desarrollada. La aplicación de las TIC tiene un precio, pero lo importante es saber cual es para poder aplicar las estrategias de financiación más adecuadas en cada caso. En opinión del doctor Tony Bates son básicamente tres: las subvenciones externas, las tasas para tecnologías de los alumnos y la reasignación de recursos. Esta última es la de más difícil aplicación puesto que supone no más dinero para el total de la universidad sino, que con el mismo presupuesto hay que implementar la aplicación de las TIC, pero a la vez es la que demuestra un verdadera implicación en el cambio tecnológico, puesto que reasignar fondos básicos para el funcionamiento de la universidad es cambiar la propia institución.

La estructura organizativa de las universidades norteamericanas basadas en la tecnología es una mezcla de estrategias centralizadas y descentralizadas. Centralizadas como una gran organización que busca una masa crítica que optimice sus inversiones y descentralizadas porque en cada universidad y/o departamento existen servicios de apoyo técnico especializado.

\subsection{Estudio conceptual y semántico}

\subsubsection{Breve historia de la comunicación gráfica}

Se puede afirmar que el dibujo es tan antiguo como la humanidad. La evolución tecnológica de nuestra especie ha tenido un paralelismo directo con la comunicación gráfica del género humano. Los dibujos de las cavernas de 12.000 años antes de Cristo ilustran la experiencia humana prehistórica. Para los paleontólogos estos dibujos son documentos religiosos (¿y quizá dibujos técnicos?) antes que dibujos artísticos.

\subsubsection{Los primeros dibujos técnicos}

En la Edad de Bronce aparecen los primeros «dibujos técnicos». Cuando la tecnología (por rudimentaria que sea) es tan compleja que no se puede aprender sólo con la visión directa y no se puede arriesgar a depositar todo el conocimiento sólo en el cerebro de un personaje de la tribu, aparecen los primeros dibujos técnicos. Dibujos en los que su finalidad no está en mostrar estampas de la vida humana, sino en explicar una rudimentaria tecnología para el aprendizaje de toda la tribu. El lenguaje gráfico es anterior al lenguaje escrito. 
La aparición de los primeros instrumentos de dibujo está documentada en Babilonia, origen de la civilización humana. En Lagash podemos encontrar la primera evidencia del «dibujo técnico». Son dos esculturas de Gudea, ingeniero y gobernador de la ciudad, en la que a sus pies aparece el plan de construcción del templo de Ningirsu, un instrumento de marcaje y una escala.

El siguiente gran paso en dibujo apareció en Grecia. Aunque ciertos conceptos geométricos fueron descubiertos con anterioridad, los griegos fueron los que desarrollaron plenamente la geometría plana. También desarrollaron inteligentes herramientas para perfeccionar el dibujo, como el compás y las escuadras. El máximo esplendor lo podemos encontrar en los arquitectos del Partenón, que desarroIlaron técnicas de contracción de ejes y líneas paralelas convergentes. Pitágoras y Tales fundamentaron el canon clásico y los principios de la geometría. Euclides estableció los cinco principios elementales con que todos los objetos geométricos clásicos pueden construirse.

Los romanos fueron inteligentes usuarios de las herramientas de dibujo de los griegos y gracias a su perfeccionamiento pudieron llevar a cabo las grandes obras civiles que desarrollaron por todo su Imperio. Los romanos llevaron a cabo una primera industrialización de sus obras civiles y eso sólo fue posible merced a la sistematización en la comunicación gráfica de sus planos. Vitrubio definió una tríada fundamental en toda la arquitectura romana: "utilitas, firmitas, venustas». Las construcciones tenían que cumplir estos tres requisitos, ser útiles, firmes y bellos. De la misma manera los dibujos romanos tenían que ser claros, comprensibles y agradables.

\subsubsection{El Renacimiento}

Durante la Edad Media no hubo progresos sustanciales en el dibujo, de la misma manera que tampoco fue una gran época para la humanidad. En el Renacimiento aparece un doble enfoque en el dibujo: el no matemático y el matemático. Los grandes precursores del dibujo no matemático fueron Giotto (avances en simetría, escorzos y líneas convergentes) y Massaccio (mejoras en sombreados, coloreados y dibujo en "perspectiva aérea»). Los avances en el enfoque matemático fueron llevados a cabo por el arquitecto italiano P. Brunelleschi, quien demostró los principios teóricos de la perspectiva. A él le siguió Alberti que escribió el tratado »Della Pintura» en el que definió matemáticamente la perspectiva en pintura. Durante todo el Renacimiento, varios matemáticos, arquitectos e ingenieros mejoraron las 
técnicas de la perspectiva. De todos ellos es imprescindible citar a Piero de la Francesca, Leonardo da Vinci, y Durero.

A lo largo de la historia los seres humanos han tratado de representar objetos tridimensionales en superficies bidimensionales. Los primeros artesanos trataron de representar aquello que sus ojos veían. A partir del siglo xv la técnica de la perspectiva ha sido el principal método para comunicarse de manera gráfica.

A principios del siglo XIX Wilian Farish introdujo el dibujo isométrico y a lo largo del siglo XIX se introdujo la gráfica para representar la variación de cantidades dibujadas a lo largo de dos ejes de coordenadas, como método gráfico para la mejor comprensión de los resultados de los numerosos experimentos científicos que se estaban empezando a desarrollar.

\subsubsection{Gaspard Monge}

Este brillante matemático francés, nacido en 1746, fue el precursor de la primera ciencia del dibujo técnico a la que él mismo definió como Geometría Descriptiva en su libro publicado en 1795. También desarrolló el sistema de los planos acotados cuando trabajó como técnico cartográfico de Napoleón, pero estas técnicas fueron consideradas secreto militar durante más de treinta años por el ejército francés.

Los fundamentos de la actual proyección ortogonal gráfica no han cambiado mucho desde entonces, aunque si lo hayan hecho los métodos y las herramientas, así como los estándares y las convenciones. Nuestro dibujo CAD se fundamenta en las bases matemáticas de Monge y en la geometría computacional.

\subsubsection{Diseño Asistido por Ordenador}

El ordenador ha supuesto un gran impacto en los métodos para el diseño y la representación gráfica de objetos industriales. Comúnmente se considera a Ivan Shuterland como el origen del Diseño Asistido por Ordenador (DAO, CAD en inglés). Cuando en 1963 este estudiante del MIT presentó su tesis doctoral sobre las gráficas interactivas por ordenador, estaba sembrando la semilla de nuestro actual CAD del que tenemos los primeros rudimentarios inicios en 1970 . El modelado tridimensional se puede datar en 1985, y en 1990 el modelado con res- 
tricciones. El Diseño Asistido por Ordenador con herramientas 3D ha permitido una síntesis de conocimientos de nuestra área EGI: «el desarrollo de cuerpos en tres dimensiones da al alumno una imaginación espacial, a la vez que potencia los conocimientos de Geometría Plana, Sistemas de Representación, Normalización, etc... ya que debe crearse un boceto del cuerpo, analizar sus formas, generar el sólido, proyectarlo, cortarlo, acotarlo, etc... y se dentar en una nueva didáctica de montaje de elementos sobre cualquier tipo de mecanismos» ${ }^{68}$. En la actualidad la realidad virtual está empezando a utilizarse como herramienta de diseño.

\subsection{2. ¿Qué es la comunicación gráfica? Algunas definiciones}

Para algunos autores la comunicación gráfica es la demostración de la superioridad humana: "Mediante la inteligencia un hombre puede suplir las deficiencias que en su fortaleza biológica puede tener respecto de las demás especies animales. Pero es gracias a la comunicación (gráfica) y la consecuente formación de sociedades por lo que el género humano desarrolla al máximo sus capacidades ${ }^{69}$. La mayoría de los autores relacionados con la comunicación gráfica tienen una visión de su disciplina próxima a este enunciado. Para ellos, los dibujos tienen una importancia más allá de ellos mismos, y son parte de un proyecto de ingeniería, no sólo una representación de este proyecto, para ellos pensamiento gráfico y comunicación gráfica son sinónimos: «El pensamiento gráfico o comunicación gráfica, no es lo único necesario para resolver problemas o pensar creativamente, pero puede ser una herramienta básica, pudiendo abrir canales de interacción con uno mismo y con las personas con quien trabaja. El pensamiento gráfico aprovecha la capacidad de la percepción visual explicando las imágenes visuales, que al ponerlas sobre papel les otorga una existencia propia. Los dibujos generados tienen importancia porque muestran como se piensa sobre un problema, no sólo que se piensa del mismo, contribuyendo al diseño: 1- Facilitando la exploración y diversidad del pensa-

\footnotetext{
68 DESARROLLO DEL PRODUCTO: DEL BOCETO A LA REPRESENTACIÓN EN VIDEO. Ponencia presentada por Bermúdez Rodríguez, Fernández Martínez y otros en el XI Congreso Internacional de Ingeniería Gráfica. Bilbao-Donostia. Junio 1997. Edita Departamento de Expresión Gráfica y Proyectos de Ingeniería de la EHU. Pág. 219 volumen 1. BI-788-97.

69 «EXPRESIÓN GRÁFICA EN LA INGENIERÍA. Introducción al Dibujo Industrial». J.L. Perez Diaz, S. Palacios Cuenca. Página XI. Editorial Prentice Hall. Madrid 1998. 1a edición. ISBN 84-8322-139-X.
} 
miento de cada diseñador. 2- Abriendo el proceso de diseño desarrollando la comunicación $»^{70}$.

Para el profesor Bertoline, la comunicación gráfica «es un medio eficaz para comunicar ideas y soluciones a problemas técnicos ${ }^{71}$. Evidentemente esta es la respuesta de un reputado profesor de dibujo técnico (jefe del departamento de Dibujo Técnico de Purdue University en 1999), pero existen otras posibles definiciones.

También nos interesa diferenciar los términos Comunicación Gráfica, de Dibujo Técnico, de Dibujo Industrial y de Geometría Descriptiva, muchas veces citados erróneamente como sinónimos. De hecho, algunos autores empiezan a hablar de comunicación gráfica con la aparición de los ordenadores y las primeras aplicaciones informáticas, buscando el primitivo origen en la electrónica industrial aplicada a la comunicación. Como ejemplo, la presentación del año 1983 del catedrático Alexandre Sanvisens respecto un libro dedicado a la comunicación visual: "Convé remarcar la contribució que la informàtica i els ordinadors electrònics estan fent i poden fer als mitjans de comunicació, ajudant en forma decisiva a la seva precisió i al seu millorament, a la seva evolució, ja sia completant els medis comunicatius pròpiament dits, ja sia coordinat la seva tasca amb la dels medis indicats, venint a constituir en vista al futur, una nova forma de realització informativa-comunicativa $~^{72}$ más aun previendo la explosión de Internet «i encara s'esdevindran noves i sorprenents modalitats comunicatives, que caldrà descobrir, desxifrar i discriminar en tot el seu impuls i la seva repercussió».

\subsubsection{El Dibujo Técnico}

Según los profesores de Dibujo Técnico, su disciplina es siempre aquello que "hace» al ingeniero. Así lo definen los profesores de la ETSIIM (UPM) Jesús Felez y Ma Luisa Martínez "El Dibujo Técnico es el lenguaje a través del cual el técnico, por

\footnotetext{
70 «EL PENSAMIENTO GRÁFICO. UN PROCESO DE COMUNICACIÓN». Fernando Julián Pérez y otros. XIV INGEGRAF. Santander. Junio 2002. http://departamentos.unican.es/digteg/ingegraf/cd/ xivcongreso.html

71 «DIBUJO EN INGENIERÍA Y COMUNICACIÓN GRÁFICA». Bertoline, Wielbe, Miller, Moler. 2a edición. Página 6. McGraw-Hill Interamericana Editores. México 1999. ISBN 970-10-1947-4.

72 Presentación de Alexandre Sanvisens «LA COMUNICACIÓ VISUAL». Federico Fernández y Josep Ma Monguet. Página 8. Edicions de la Universitat Politècnica de Catalunya. 2a edición. 1985. ISBN 84-7653-000-5.
} 
un lado registra sus ideas y la información exterior y, por otro las comunica a otras personas para su materialización práctica ${ }^{73}$. La idea que aquí subyace es que sin dibujo técnico no hay comunicación.

Otros autores también definen el Dibujo Técnico como Dibujo Industrial, recordando la importancia de su reconocimiento para el correcto desarrollo de la actividad del ingeniero. El catedrático Javier Rodríguez de Abajo afirma que «El Dibujo Industrial es un lenguaje universal y, como tal, está sujeto a unas normas, que deben conocer aquellos que lo practican. Este lenguaje se manifiesta de forma escrita en los planos industriales que se transmiten entre empresas y entre personas $y$, por ello, todos deben interpretar correctamente lo que en ellos se representa. $)^{74}$. Quien no conozca las "normas» no podrá establecer comunicación. No sólo el castellano tiene esta acepción del término, el "Diccionari de la Llengua Catalana» define dibujo industrial como "sistema de representació emprat en la industria per a representar ginys mecànics, instal.lacions, processos, etc...». El «Diccionari» nos aclara que además de servir para representar elementos mecánicos puede representar otros elementos industriales como instalaciones y procesos.

En el mismo sentido anterior el profesor Iñiguez Herrero define el dibujo técnico como "Representación convencional de un objeto que nos permite conocer con exactitud, en su forma y dimensiones, como es dicho objeto. Los convencionalismos citados se basan en los sistemas de representación, estudiados por la geometría descriptiva y en una serie de normas establecidas por los organismos nacionales $e$ internacionales de normalización. La ejecución y el trazado de los dibujos técnicos tiene lugar en base a los conceptos de la geometría métrica, la cual se aplica en la práctica mediante el denominado dibujo geométrico o geometría gráfica » ${ }^{75}$.

\subsubsection{La Geometría Descriptiva}

La geometría descriptiva es una parte de la Geometría, una antigua ciencia que ha acompañado al hombre desde el origen de la historia escrita. El desarrollo in-

\footnotetext{
73 «DIBUJO INDUSTRIAL». Jesús Félez, Mā Luisa Martínez. Página 19. Editorial Síntesis SA. Madrid 1999. ISBN 84-7738-331-6.

74 «NORMALIZACIÓN DEL DIBUJO INDUSTRIAL». F. Javier Rodríguez de Abajo, R. Galarraga Astibia. Prólogo. Editorial Donostiarra. San Sebastián 1993. ISBN 84-7063-181-0.

75 http://aegi.euitig.uniovi.es/teoria/dibujo_industria
} 
telectual humano ha estado parejo en el desarrollo de diferentes ramas geométricas, desde la geometría demostrativa de los antiguos griegos hasta su liberación camino de las neoeuclidianas, contribuyendo al desarrollo de las matemáticas, la ciencia y la tecnología. Algunos autores actuales están trabajando en un intento de recuperar una visión conjunta de la geometría "se propoem a presentar uma proposta alternativa para o encino da Geometría onde se establece e se privilegia a visao de conjunto e se busca reduzir a distancia entre os conteudos de Matemática e a sua efetiva implementaçao práctica. Para atingir as metas propostas, utilizouse de um ambiente hipermídia onde o conteudo geómetrico é veiculado por meio da arte e da hsitoria e o usuariointerage em um anmbiente lúdico que tem por metafora una viagem do tempo» ${ }^{76}$.

Según la Real Academia Española, la Geometría Descriptiva es «parte de las matemáticas, que tiene por objeto resolver los problemas de la geometría del espacio por medio de operaciones efectuadas en un plano y representar en él las figuras de los sólidos » ${ }^{77}$. Es importante destacar la base matemática de la Geometría Descriptiva, a la vez que se destaca que es la geometría del espacio, una parte de la geometría.

Para muchos autores la Geometría Descriptiva representa las normas gramaticales del lenguaje universal de Dibujo. Por ejemplo para el Dr. Giesecke (de la universidad de Texas): "La Geometría Descriptiva es la geometría tridimensional que proporciona las bases para las aplicaciones prácticas del lenguaje, y mediante la cual, muchos de sus problemas pueden resolverse de forma gráfica ${ }^{78}$. Desde este punto de vista, la Geometría Descriptiva no sería aquello que aterra a muchos de los actuales estudiantes de dibujo, sino sólo la herramienta «mecánica» que permitiría desarrollar el dibujo técnico, y por lo tanto llegar a posibilitar la comunicación. Hoy en día no precisamos de la geometría descriptiva porque los ordenadores están basados en la geometría computacional. Los ordenadores calculan la geometría de los objetos, las personas tienen que diseñar los objetos: "del mismo modo que la calculadora no excluye la necesidad de comprender las matemáticas, las compu-

\footnotetext{
76 «CAMINANDO NO TEMPO COM A GEOMETRIA». Vania Ribas Ulbricht. XIV INGEGRAF. Santander. Junio 2002. http://departamentos.unican.es/digteg/ingegraf/cd/xivcongreso.html

77 «DICCIONARIO DE LA LENGUA ESPAÑOLA» Real Academia de la Lengua Española. 20a edición. 1984. Página 687. ISBN-84-239-4778-5.

78 «DIBUJO TÉCNICO». Frederick E. Giesecke, Alva Mitchell, Henry C. Spencer, Ivan L. Hill. Pagina19. Grupo Noriega Editores. México 1992. 5ạ edición. ISBN 968-148-0963-7.
} 
tadoras no eliminan la necesidad de aprender los principios básicos del modelado y el dibujo geométricos para el proceso de diseño ${ }^{79}$. No tiene sentido que desarrollemos los mismos ejercicios que Gaspard Monge, de la misma manera que no tiene sentido que recordemos como se calcula una raíz cuadrada, porque tenemos calculadoras, pero sí que tenemos que saber cuando aplicar una raíz cuadrada y el significado matemático de ella.

La utilización de las herramientas informáticas sólo puede ser beneficiosa para la Geometría Descriptiva si se comprende el concepto propio de la base técnicacientífica que la sustenta. De esta misma opinión es Xavier Codina, profesor del departamento EGE de la UPC, al afirmar: "hemos podido comprobar que la utilización de los programas de CAD en 3-D cumple perfectamente los objetivos que proponía Gaspard Monge (...). Al mismo tiempo que simplifica las operaciones, potencia aún más la concepción espacial»»0.

\subsubsection{La Normalización Industrial}

En 1917, M. Frontard definió el concepto norma como «un dato de referencia resultante de un acuerdo colectivo y razonado, con vista a servir de base de entendimiento para la resolución de problemas técnicos».

A finales de siglo XIX Alemania intentó reducir el coste de las fabricaciones en serie aplicando una cierta normalización. En 1917 se creó el «Comité de Normas de la Industria Alemana» que en 1926 se convirtió en la famosa "Deustcher Normenausschus» (DNA). Otros países industriales hicieron lo propio: en 1919 se creaba la "British Standards Institution» y 1918 se constituyó la "Associattion Française de Normalization» (AFNOR). En 1926, y fruto del aumento del comercio internacional después de la 1a Guerra Mundial, se puso de manifiesto la necesidad de creación de un organismo multinacional que regulara su cooperación, así nació la «International Federation of the Natinal Standardizing Associations».

\footnotetext{
79 «DIBUJO EN INGENIERÍA Y COMUNICACIÓN GRÁFICA». Bertoline, Wielbe, Miller, Moler. 2aa edición. Página 14. McGraw-Hill Interamericana Editores. México 1999. ISBN 970-10-1947-4.

80 «PASADO, PRESENTE Y FUTURO DE LA INFORMATIZACIÓN DE LA DOCENCIA DE TÉCNICAS DE REPRESENTACIÓN GRÁFICA». Xavier Codina. XI INGEGRAF. Volumen III. Pág. 1345. ISBN 84-6990475-2. Ed. Secretaría del XI CIIG. Logroño-Pamplona 1999.
} 
Según la definición fundamental (de 1940) del Comité Alemán de Normalización "La Normalización es un término general que significa la reglamentación de un gran número de fenómenos, a fin de ordenarlos de una manera tan unificada y lógica como sea posible» ${ }^{81}$. Normalizar no es nada más que simplificar, unificar y especificar elementos industriales. La Normalización del Dibujo Industrial no es más que la aplicación de unas normas para la comprensión universal de nuestros dibujos industriales, para permitir la existencia de comunicación. De la misma manera lo explica el profesor Rudolf Schmidt "para que el dibujo pueda utilizarse como medio auxiliar práctico en la resolución de problemas técnicos y sea posible "leerlo" inequívocamente, tiene que trazarse siguiendo unas reglas determinadas ${ }^{82}$.

\subsubsection{Laboratorio virtual}

Un Laboratorio Virtual es "la combinación de diversas tecnologías e interfaces que permiten a uno o más usuarios interactuar en tiempo real con un entorno o mundo dinámico tridimensional generado por ordenador ${ }^{83}$. Esta primera definición presupone que la diferencia entre un laboratorio «virtual» y otro «real» sólo radica en la condición no presencial del laboratorio virtual. Pero un laboratorio virtual tiene otras ventajas. En los últimos años las herramientas que facilitan el desarrollo de aplicaciones de Realidad Virtual han experimentado un gran avance. Mediante estas herramientas se crean entornos multimedia que permiten interactuar de forma amigable e intuitiva, pedir información, mostrar resultados, ver aplicaciones, etc. Este tipo de tecnologías, se pueden utilizar en una primera fase como complemento en la formación universitaria, sustituyendo a los clásicos laboratorios costosos de acceder, mantener y manipular. Pero lo más interesante de los laboratorios virtuales es que no precisan de la presencia física, y eso permite la explosión del aprendizaje por toda la geografía virtual, de modo que la costosa inversión necesaria para poder mantener al día estos nuevos laboratorios se recupera con un aumento potencial de los usuarios, optimizando las herramientas.

\footnotetext{
81 «ELEMENTOS DE NORMALIZACION. DIBUJO TÉCNICO 3». D. Corbella Barrios. Madrid 1970. Editorial Donostiarra. Depósito legal M-17669-1970.

82 "GEOMETRICA DESCRIPTIVA CON FIGURAS ESTEREOSCOPICAS». R. Schmidt. Ed. Reverte. Barcelona 1986. Página VII. ISBN-84-291-5135-4.

${ }^{83}$ LABORATORIO VIRTUAL www.paisvirtual.com/educacion/pedagogia/labvir
} 
Términos como Laboratorios Virtuales, Espacios Virtuales de Aprendizaje y otros parecidos empiezan a ser normales en nuestros procesos de aprendizaje. Los laboratorios virtuales permiten integrar estas herramientas en un verdadero nuevo paradigma de aprendizaje.

\subsubsection{Realidad Virtual}

Para Mike Hammer el término realidad virtual es un concepto redundante. La realidad virtual puede hacer que lo artificial parezca tan real, o incluso más, que la propia realidad. De hecho, la única finalidad de la realidad virtual es que parezca real. Si los simuladores de vuelo no fueran muy reales los pilotos no aprenderían como comportarse cuando subieran a un avión de verdad cargado de pasajeros.

En 1968 Ivan Shuterland presentó el primer sistema de realidad virtual instalado en un casco. Después la NASA, y el Departamento de Defensa norteamericano llevaron a cabo algunos carísimos prototipos utilizados en la exploración espacial y en aplicaciones militares, como el pilotaje de tanques y submarinos. Era la prehistoria de la realidad virtual, sólo posible en organizaciones con mucho dinero para la investigación, y en usos idóneos, puesto que la realidad «real» obligaba de todos modos a mirar a través de un casco o unos binoculares. Hoy en día, que disponemos de ordenadores de gran capacidad de memoria, velocidad y bajo coste, la realidad virtual se instalará primero como un medio más de entretenimiento, y después como una herramienta complementaria en el proceso de aprendizaje, pero nunca sustituirá a los demás sistemas.

La idea básica de la realidad virtual es provocar la sensación de «estar ahí», cambiando instantáneamente la imagen cuando uno cambia de punto de vista. La percepción de la realidad espacial la genera el tamaño relativo de los objetos, el brillo, el movimiento angular y la perspectiva entre otras indicaciones visuales. Esta última es particularmente poderosa en su forma binocular, en la que el ojo derecho e izquierdo ven imágenes diferentes, que fusionando da lugar a la percepción en tres dimensiones (que es la base de la estereovisión). El «paralaje del ojo» (la sensación de profundidad que experimentamos cuando cada ojo ve un imagen ligeramente distinta del otro) es más efectivo en objetos cercanos. Esa es la explicación por la que la mayoría de las películas en 3D siempre aparecen objetos volando hacia el público para poder apreciar esta realidad virtual. Cuando miramos con unas gafas de realidad virtual y movemos la cabeza, las imágenes se actualizan tan deprisa que nos da la impresión de estar haciendo estos cambios con el movimiento de la cabeza, pero es el ordenador el que sigue nuestro movimiento. Se tiene la sensación de que uno mismo es la causa, no el efecto. 
Las imágenes más reales logradas mediante los gráficos por ordenador son aquellas basadas en el uso de las técnicas Ray Tracing (Trazado de Rayos) y Radiosity (Radiosidad). La primera no tiene en cuenta los efectos difusos de la iluminación, mientras que la segunda no aborda los efectos especulares, por eso desde el inicio de la década de los 90 surgen unos modelos de iluminación denominados Técnicas Híbridas que pretenden incluirlos.

\subsubsection{Comunicación Mediatizada}

La Comunicación Multimedia «tan sólo» es una comunicación mediatizada. La comunicación mediatizada existe desde mucho antes de la aparición de las TIC. Podemos encontrar la definición de 1983 de Federico Fernández y Josep Mạ Monguet en la que afirman «entenem per comunicació mediatitzada aquella que es serveix d'un mitjà tècnic pel registre o la transmissió del missatge. El missatge mediatitzat ha de ser analitzat com a imatge del missatge directe ${ }^{84}$. Traspasar documentaos directamente desde la comunicación directa a la mediatizada es un error. No podemos crear entornos virtuales de comunicación despreciando todos los conocimientos adquiridos de la comunicación presencial, copiando directamente cosas que funcionaban en la comunicación cara a cara pero nunca podrán funcionar en entornos multimedia.

Los mensajes creados con registros de la realidad convenientemente expresados pueden crear en el receptor una sensación de imagen fiel y «real» y no manipulada de la realidad. Cualquiera que sea el tipo de intervención sobre el mensaje original, el emisor lo elabora de manera que transmita al receptor aquello que él quiere decir. El receptor identifica el símbolo con la realidad, cuando este símbolo no es nada más que la traducción que el emisor hace de la realidad.

\subsubsection{Comunicación Multimedia}

Llamamos Comunicación Multimedia a un sistema de información en la que se combinan diferentes sentidos, vista y oído principalmente, para poder aumentar su capacidad comunicativa "A term that refers to the combined use of such media

\footnotetext{
84 "LA COMUNICACIÓ VISUAL». Federico Fernández y Josep Ma Monguet. Página 35. Edicions de la Universitat Politècnica de Catalunya. 2ª edición. 1985. ISBN 84-7653-000-5.
} 
as audio, text, graphics, and/or video clips to present information ${ }^{85}$. Si no hay una mejora en la comunicación, los sistemas multimedia dejan de tener sentido. La Comunicación Multimedia sólo ha podido existir desde el momento que la técnica ha permitido digitalizar la información. Así lo explica el profesor Negroponte: "Los bits se mezclan fácilmente. Se combinan y pueden usarse y reutilizarse juntos o por separado. La combinación de sonido, imagen e información se llama multimedia; aunque suenen complicado, sólo se trata de mezclar bits» ${ }^{86}$.

Las técnicas y comunicaciones multimedia son una oportunidad para desarrollar nuevos ámbitos científicos y técnicos de interés para el área de la Ingeniería Gráfica. De hecho, la emergencia de las comunicaciones multimedia puede permitir el paralelo resurgir de un área de conocimiento que en los últimos años en España se estaba estancando. Desde mediados de los años 90 existen autores que ya presagiaban esta emergencia, como por ejemplo el profesor José Luis Caro: "unir la docencia del dibujo industrial con la multimedia en el entorno universitario (...) adecuar las actuales herramientas a los nuevos planes de estudio y en este caso potenciar la Expresión Gráfica en la Ingeniería ${ }^{87}$. El objetivo último de la comunicación multimedia es intentar facilitar el trabajo para alumnos y profesores. A finales de los años 90, esto empieza a ser una realidad, como podemos ver en los libros de actas de los Congresos de Ingeniería Gráfica, donde se presentan muchas ponencias mostrando experiencias propias de cada departamento. Así, por ejemplo, el departamento de Ingeniería Gráfica y Fabricación de la UPM presenta una comunicación en 1999 explicando las virtudes de la informatización y comunicación multimedia que han aplicado a sus asignaturas troncales destacando las siguientes ventajas: "Para el alumno: 1-Adquirir conocimientos de una forma guiada, pudiendo en todo momento constatar lo aprendido. 2-Plantear las consultas al profesor sin ningún tipo de limitación (...) 3-Trabajar con herramientas que le permiten dibujar con precisión. 4- Disponer de librerías de ejercicios adaptados a cualquier tema. 5-disponer de un conjunto de herramientas interactivas. Para el profesor: 1-Aprovechar las clases presenciales para incidir en los aspectos más conceptuales y de comprensión compleja. 2- Realizar el seguimiento de los alumnos con mayor eficacia.

\footnotetext{
85 «TELECOSM. How infinite bandwidth will revolutionize our world». George Gilder. Página 320. The Free Press. New York 2000. ISBN0-684-80930-3.

86 «EL MUNDO DIGITAL» N. Negroponte. Ediciones B. Barcelona 1995. Pág. 33. ISBN-84-406-5925-3. 87 «EJEMPLO DE APLICACIÓN DE MULTIMEDIA AL DIBUJO INDUSTRIAL». José L. Caro Rodríguez y otros. VI INGEGRAF. Tomo II. Página 307. Toledo. 1994. ISBN 84-88248-28-8.
} 
3- Disponer de un material didáctico de gran ayuda para la mejora de la visión espacial del alumno ${ }^{88}$.

\subsubsection{Sistemas Interactivos Multimedia}

Existen varias definiciones de los sistemas multimedia. Para algunos autores es un punto de confluencia de varias técnicas que permite diferentes formas de representar información, para otros es toda la metodología que permite una conexión lógica de los diferentes medios disponibles para obtener y almacenar toda esta variedad de informaciones, y por último, para otros es el logro tecnológico de la electrónica reflejado en el alto poder de los computadores.

Para Miguel Brigos, profesor del programa de doctorado «Enginyeria Multimedia» de la UPC, un «Sistema Multimedia» es "simplemente» cualquier sistema basado en la implementación óptima del concepto de comunicación Hombre-Máquina. En esta definición hay dos conceptos básicos. 1-- La finalidad de un sistema Multimedia es la comunicación, y específicamente la comunicación entre los seres humanos y las máquinas. 20- La comunicación ha de ser óptima, o sea que la función de la tecnología es la de mejorar en todo lo posible esta comunicación. En este sentido podemos encontrar otras definiciones que hacen hincapié en este concepto de comunicación: "Multimedia es la integración de los sentidos del ser humano al mundo del computador, con el fin de que la interacción entre computador y usuarios, sea totalmente natural. Multimedia desde la simple capacidad de un computador de controlar periféricos no tradicionales como lo sería un videodisco, 0 definiciones como la integración de los medios audiovisuales con el fin de mejorar los procesos de dar información, hasta definiciones en las cuales se considera a Multimedia como la nueva revolución del mundo de la computación. Multimedia realmente es el medio más novedoso y efectivo de comunicación y no se debe ver tan sólo como una tecnología. Tampoco como aplicaciones tradicionales a las que se han agregado elementos audiovisuales sin una guía clara» ${ }^{89}$.

La Universidad de Antioquia se basa en los sistemas multimedia para incrementar sus capacidades docentes y crear nuevas capacidades de aprendizaje. Así es como

\footnotetext{
88 «ENSEÑANZA DE INGENIERÍA GRÁFICA ASISTIDA POR INTERNET» A. Carretero Díaz y otros. XI INGEGRAF. Volumen I. Pág.267. ISBN 84-699-0473-6. Logroño-Pamplona 1999.

$89 \mathrm{http}: / /$ www.geocities.com/peprubio2000/definiciones
} 
definen un sistema multimedia: "Usando una combinación innovadora de SOFTWARE de computadores y de HARDWARE de video y computadores, las instituciones pueden crear ambientes de aprendizaje que permitan a los estudiantes moverse de un concepto a otro de acuerdo con su propio ritmo y siguiendo sus propios intereses. Este nuevo uso del control computarizado de medios es a menudo a lo que se refieren como INTERACTIVE MULTIMEDIA (multimedia interactiva), porque permite todo un nuevo nivel de interacción del usuario con su entorno y materiales en formas como: el texto, el audio, los gráficos y el video»» ${ }^{90}$.

Para Christian Guittet un sistema interactivo multimedia es «la realización de una simbiosis dinámica entre diversos medios de expresión y diversas representaciones de mundos reales o imaginarios ${ }^{91}$. Para este autor los sistemas multimedia sólo se impondrán realmente cuando el público pueda acceder sin esfuerzo a productos de una calidad técnica equivalente a aquella a la que está acostumbrado. El desarrollo de los sistemas multimedia unidos al de las autopistas de la información permite que se aprecie actualmente la aldea global anunciada por McLuhan y estas nuevas posibilidades de acceder al conocimiento y la información constituyen sin duda una revolución comparable a la invención de la imprenta hace 500 años.

\subsection{Las TIC, evolución informática en el Área Gráfica}

La evolución de las TIC es la que ha permitido el paso del simple concepto de «expresión gráfica» al de la "comunicación multimedia» que parece ser hacia donde se puede desarrollar nuestra área de conocimiento. Por eso es preciso en este capítulo hacer una recapitulación de los principales hitos tecnológicos de los últimos 40 años relacionados con la comunicación visual.

No todos los profesores de los departamentos EGI de las universidades españolas están completamente convencidos de la irreversibilidad de las TIC en nuestra área de conocimiento y continúan creyendo en la imbatibilidad del lápiz: "¿cómo se puede justificar el binomio lápiz-papel como instrumento por excelencia en la fase conceptual del diseño? A pesar de los esfuerzos, por parte de algunos, que tienden a dar una menor importancia al dibujo en el contexto del diseño, nadie parece capaz de negar que el dibujo potencia la percepción y la creatividad. Los

\footnotetext{
${ }^{90}$ http://ayura.udea.edu.co/tecnologia/defmulti.html

91 http://www.fuentesestadisticas.com/numero2/paginas/feu_multi.html
} 
croquis, bocetos, apuntes, etc., son imágenes que se crean casi con un vínculo directo entre la imaginación y la mano, y todo lo que signifique utilizar instrumentos que mediaticen este proceso implica un distanciamiento que va en detrimento de la expresividad $\|^{92}$. Las TIC no tiene por qué limitar el diseño, siempre dependerá del uso que se le dé a la tecnología.

\subsubsection{La tecnología}

La palabra tecnología deriva del griego tekhné, que significa "oficio o arte», y logía que significa "estudio de», de modo que tecnología significa "estudio de habilidad de un oficio", entendiendo por oficio la actividad por dar forma a los recursos necesarios para un fin práctico. La tecnología comprende la producción de recursos materiales y no materiales, como es la información y la comunicación. La especie humana se ha esforzado en aplicar su conocimiento registrado a la confección de herramientas. A medida que la tecnología ha evolucionado también ha evolucionado los medios para registrar estas bases de conocimientos, desde las tradiciones orales de la antigüedad a las anotaciones escritas de los artesanos del siglo XIX, a la explosión universitaria de los años 80 y finalmente a las bases de datos con asistencia informática de finales de siglo xx.

El lenguaje es otra forma de tecnología de creación humana. Una de las primeras aplicaciones de la tecnología es la comunicación, que permitió al homo sapiens sobrevivir en un medio hostil siendo la especie de menor poder de las que lo rodeaban.

De hecho, las TIC han permitido un salto tecnológico inigualable en la historia de la humanidad, mayor incluso que otros grandes hitos en la evolución humana. Para algunos autores como Miquel Barceló, los factores multiplicadores de las TIC suponen uno de los mayores saltos de la humanidad: "Las grandes revoluciones tecnológicas que han configurado nuestra historia como especie civilizada corresponden también a tecnologías con un factor multiplicador reducido. Se estima un factor del orden 100 en el caso de la agricultura (...). El factor multiplicador sería de 1.000 en el caso de la revolución industrial. El hecho diferenciador de las mo-

\footnotetext{
92 «EL PENSAMIENTO GRÁFICO. UN PROCESO DE COMUNICACIÓN». Fernando Julián Pérez. XIV INGEGRAF. Santander. Junio 2002. http://departamentos.unican.es/digteg/ingegraf/cd/ xivcongreso.html
} 
dernas Tecnologías de la Información, y con ello la posible justificación de lo que algunos ya han bautizado como la revolución de las Tecnologías de la Información, radica en unos factores multiplicadores muy superiores, en realidad del orden del millón. La informática (...) permite hacer en millonésimas de segundo los cálculos y operaciones que, sin informática, exigen tiempos de como mínimo un segundo. Las telecomunicaciones electrónicas aportan igualmente un factor multiplicador del orden del millón ya que transmiten en millonésimas de segundo (...) lo que sin esta tecnología de transmisión debe medirse como mínimo en una escala del orden de segundos. Por ello las tecnologías de la información (informática más telecomunicaciones) pueden llegar a disponer de un factor multiplicador del orden de un billón $»^{93}$.

\subsubsection{Las primeras máquinas automáticas}

En 1810 en Alsacia se construyeron las primeras máquinas automáticas de calcular. Eran máquinas basadas en la Máquina de Leibniz, es decir mecanismos capaces de realizar eficientemente sumas y multiplicaciones. Pero estas máquinas no eran automáticas del todo, pues siempre necesitaban de alguien que las manejara. La primera máquina completamente automática es obra de Charles Babbage. Para que su Máquina Analítica fuera completamente autónoma, Babbage la dotó de los siguientes elementos: un lugar de almacenamiento (donde guardar y leer los números del problema a resolver), una unidad de proceso (para realizar los cálculos de los números almacenados), un sistema de control (que dictara a la unidad de proceso la adecuada secuencia de realización de operaciones), un dispositivo de introducción de los datos del problema, y un sistema de salida que presentase los resultados de un determinado proceso. La concepción de la máquina de Babbage es la misma que la de los ordenadores actuales, cambiando los términos almacenamiento por memoria RAM, unidad de proceso por CPU, sistema de control por software, dispositivo de introducción por teclado, y sistema de salida por pantalla o impresora.

Babbage murió en 1871 amargado e incomprendido. El ingeniero textil Jacquard adaptó la máquina de Babbage con la utilización de varillas metálicas y fichas perforadas para la confección de telas con los dibujos más complicados, que indicaban

\footnotetext{
93 «EL MUNDO DIGITAL» N. Negroponte. Ediciones B. Barcelona 1995. ISBN-84-406-5925-3. Prólogo de Miquel Barceló, pág 10.
} 
al telar cuando debía introducirse una determinada varilla con ciertos hilos de determinados colores y cuando no.

\subsubsection{International Business Machines. IBM}

El siguiente gran avance tecnológico para conseguir la máquina automática perfecta llegó desde los EEUU, a raíz del concurso para mejorar la elaboración del censo en 1890. Su ganador fue Herman Hollerith, que tomado como modelo las tarjetas perforadas de Jacquard y observando que las respuestas al cuestionario del censo podían ser codificadas, ideó un sistema para realizar los orificios en las tarjetas en determinadas posiciones que a su vez podían ser detectados por medios eléctricos, no mecánicos. Con el sistema de Hollerith, el censo de los 62 millones de norteamericanos sólo tardo dos años en realizarse, contra los siete años y medio que tardó el censo de 1880. La revista Scientific American publico el número de agosto de 1890 casi íntegramente al gran avance de Hollerith. Además de inventar la ficha perforada, fundó la Tabulating Machine Company, que en 1924 se fusionaría con otras empresas para crear la International Business Machines (IBM), cuyos ingresos en el periodo 1930-1950 provenían en un 30\% de la venta de fichas perforadas.

En 1937 la IBM financió la Automatic Sequence Controlled Calculator (ASCC), máquina completamente automática de Howard Aiken de la Universidad de Harward. La MARK I (nombre con la que fue popularmente conocida) era un gigantesco aparato electromecánico que pesaba 5 toneladas y ocupaba toda una habitación. Contenía más de 300 relés y más de $800 \mathrm{Km}$. de cables. A pesar de su tamaño y peso, y que sólo podía realizar cálculos aritméticos relativamente sencillos en un lapso de tiempo relativamente corto (por ejemplo para multiplicar dos cifras de 23 dígitos tardaba unos 6 segundos) la MARK I fue considerada un gran ingenio.

\subsubsection{Leonardo Torres Quevedo}

El Ingeniero Leonardo Torres Quevedo es uno de los pocos españoles que destaca en la investigación y el desarrollo histórico del campo de la Automática, y de lo que él particularmente llamaría máquinas algebraicas, cuya finalidad sería resolver las ecuaciones numéricas de cualquier grado con magnitudes continuas, es decir, generar de una manera continua y automática todos los valores por los que va pasando un polinomio racional y entero. Primero estu- 
dió las maquinas analógicas de tipo mecánico, pero su gran aportación llegó en 1914 con la presentación del estudio «Ensayos sobre Automática. Su definición. Extensión teórica de sus aplicaciones» donde muestra dos tipos de autómatas según actúen de forma continua (máquinas analógicas) o lo hagan a través de impulsos (digitales). En esta obra Torres Quevedo desarrolla un proyecto para realizar operaciones aritméticas por procesos digitales y expone un procedimiento original para comparar dos cantidades. El ingeniero explica que el fracaso de Babbage estaba en el uso de elementos mecánicos, que el sustituye por dispositivos electromecánicos.

Torres Quevedo construyó tres máquinas para desarrollar sus ideas en Automática: el Telekino (1903) autómata que ejecutaba órdenes recibidas a través de la telegrafía sin hilos (considerado el primer aparato de teledirección del mundo); el Ajedrecista (1912) máquina de tipo electromecánico que constituye una de las primeras manifestaciones en Inteligencia Artificial, y el Aritmómetro Electromecánico (1920) una de las primeras computadoras digitales electromecánicas.

\subsubsection{La primera generación}

La utilización de las válvulas (o tubos de vacío) y la implantación del sistema de numeración binario (en vez del sistema decimal de numeración) fueron los dos grandes hitos hacia la Primera Generación de ordenadores. En 1929 la American General Election se decidió a usar la válvula Thyratron como relé, haciendo posible la acumulación de datos. En el mismo sentido, en 1931 el inglés Wiliam Philips publicó un trabajo en el que se abogaba por la utilización de válvulas y un sistema de numeración binario. Sin embargo, históricamente se ha considerado a John von Newman como el auténtico impulsor del sistema binario, diseñando una arquitectura que sería usada por la industria durante mucho tiempo, conocida como arquitectura von Newman.

En 1947, Eckert y Machly (de la Universidad de Pennsylvania) construyeron la ENIAC, máquina electrónica desarrollada con fines militares (para resolver problemas relacionados con la trayectoria de proyectiles) que es considerado el Primer Ordenador, al aplicar enteramente los desarrollos antes mencionados.

En 1949 Eckert y Machly abandonan la universidad para fundar su propia compañía, que desarrollaría en su primer contacto en BINAC, ordenador de diseño secuencial que introduciría la novedad de utilizar cinta magnética para almacenar 
información. Su siguiente proyecto, el Universal Automatic Calculator (UNIVAC I) supuso un hito importante en la historia de la informática, al ser el primer ordenador fabricado en serie para vender a clientes civiles (aunque todavía grandes corporaciones) y no sólo a organismos estatales o paraestatales. EI UNIVAC suele considerarse el prototipo de la primera generación de ordenadores. En 1952 una televisión americana afirmó contra pronóstico, mediante el uso de uno de los primeros ordenadores, la victoria de Eisenhower en las elecciones presidenciales. Desde ese momento inició la carrera hacia la popularización de los ordenadores.

\subsubsection{La segunda generación}

En 1947 el descubrimiento del transistor tuvo consecuencias trascendentales en el desarrollo de la informática. Los transistores eran más seguros, disipaban mucho menos calor $y$, sobretodo, ocupaban mucho menos espacio que las válvulas de vacío. Los ordenadores provistos de transistores en vez de válvulas de vacío, supusieron un cambio tan radical en la arquitectura de los ordenadores que fueron denominados ordenadores de segunda generación.

En la década de los 50 se mejoraron los dispositivos de representación de información elaborada por los ordenadores. El Whirlwind del Massachusetts Institute of Technology (MIT) fue el primer ordenador que contaba con un sistema de representación visual autocontrolado. Podía realizar dibujos sencillos, tarea para lo que utilizaba un tubo de rayos catódicos (CRT), aunque el tiempo que empleaba en realizar los cálculos y representarlos impedía cualquier tipo de operación recíproca con el sistema, de manera que la pantalla sólo era un mero dispositivo de salida y no una interface (entendida como superficie de contacto) entre usuario y ordenador.

En esta época se desarrollaron dos tecnologías completamente diferentes. La primera que se desarrolló fue el Direct View Storage Tube (DVST) también conocido como Tubo de Almacenamiento. En ella la información gráfica se envía de una sola vez y se muestra permanentemente en pantalla, siendo la imagen enviada de tipo vectorial, es decir dibujando vectores continuos en línea recta entre dos puntos de la pantalla. Este tipo de representaciones se caracterizaron por la excelente calidad gráfica de sus líneas, pero fue abandonado por la imposibilidad de borrar elementos aislados del dibujo, el no permitir la visualización de animaciones ni imágenes en color, y su ineficacia en el relleno de un área de dibujo. 
Para realizar estas tareas que no permitían los DVST se desarrollaron los Refresh Tube, en los que se regenera la imagen cada fracción de segundo inferior al nivel de persistencia de la visión, bajo el control de la CPU. Los primeros Tubos de Refresco solucionaron el problema del borrado y la realización de secuencias animadas, pero todavía utilizaban representaciones vectoriales que seguían imponiendo dificultades a la hora de crear áreas de dibujo rellena. Otro problema es que tendían a parpadear, a producir sensación visual de discontinuidad en la representación de la imagen, por lo que se impuso el tubo de refresco que utiliza una trama (Raster) como soporte para generar imágenes.

Hacia finales de la Segunda Generación de ordenadores aparecieron los primeros programas gráficos de acción recíproca o interactiva, pero no fue hasta la lectura de la tesis doctoral de Shuterland "A Machines Graphic Communication System» que se puede empezar a hablar de Computer Aided Design (CAD).

\subsubsection{Los primeros CAD}

Cuando Ivan Shuterland desarrolló en 1962 el sistema SKETCHPAD en el MIT, se inició la época del CAD. El aspecto innovador del sistema de Shuterland consistía en que permitía que el usuario interactuara gráficamente con el ordenador, a través de una presentación visual y un lápiz óptico.

La estructura de datos utilizada por Shuterland en el ordenador TX-2 era completamente diferente a todo lo que se había realizado hasta entonces, pues estaba basada en la Topología del objeto que iba a representar, es decir, describía con toda exactitud las relaciones entre las diferentes partes que lo componían, introduciendo lo que hoy se conoce como Programación Orientada a Objetos. Con ella las representaciones visuales de un objeto realizadas en el ordenador estaban basadas en el objeto en sí mismo y no en un dibujo del propio objeto.

La historia del software de CAD se encuentra completamente vinculada al desarrollo del hardware por ordenador. El coste de los ordenadores tipo mainframe en la década de los sesenta y setenta era tan elevado que sólo las grandes empresas y algunos gobiernos podían tener sistemas capaces de poder soportar el software de CAD de la época. Las principales empresas usuarias de estos prehistóricos sistemas CAD eran las corporaciones estadounidenses militares, aeronáuticas y grandes fabricantes de automóviles. El modelado 3-D que desarrolló T.E. Johnson a partir del modelo de Shuterland, conocido como SKETCHPAD-III estaba muy limi- 
tado comercialmente por las escasas prestaciones de los mainframes más grandes de la época.

La Tercera Generación (años 60) de los ordenadores vino dada por la aparición de los Chips (circuitos integrados de estado sólido) que sustituyeron a los circuitos formados por componentes individuales, permitiendo una miniaturización de las máquinas. En los años 70 se desarrolló la Cuarta Generación, caracterizada por la fabricación de Ordenadores Personales (PC).

En los años 80, en EEUU se produjo el boom de los primeros paquetes comerciales de modelado 3-D gracias al aumento de las prestaciones de los ordenadores y sobre todo a la disminución de costes de éstos. A partir que estos programas de modelado fueron migrando de los grandes sistemas de cómputo a los sistemas de minicomputadoras, y de aquí a los ordenadores personales, se extendió su uso cada vez más. Hoy en día cualquier PC puede cargar grandes programas de modelado CAD.

Las limitaciones computacionales de los primeros programas $C A D$, originó que estos fueran diseñados para muy determinadas tareas específicas. La explosión llevada a cabo a partir de los 80 y sobre todo a partir de los PC en los años 90, permitió la aparición de un software CAD de aplicación más universal y capaces de construir modelos muy sofisticados.

El potencial de los ordenadores permitió la aparición de paquetes comerciales de gráficos informatizados, que dejaron de ser dominio exclusivo de matemáticos y científicos, y permitieron la explosión de usuarios de programas de gráficos por ordenador. La Association for Computing Machinery (ACM) creó la Special Interest Group on Graphics (SIGGRAPH), que a partir de 1976 empezó a organizar congresos y a difundir los nuevos conocimientos que se estaban desarrollando.

\subsubsection{De la línea al píxel}

A finales de la década de los años 60, los investigadores del PARC ${ }^{94}$ inventaron un sistema de gráficos por ordenador basado en las formas, en el cual se gestionaba y

\footnotetext{
${ }^{94}$ Centro de Investigaciones de Palo Alto, de Xerox.
} 
se daba textura a las áreas amorfas a través del almacenamiento y la presentación de imágenes como una colección masiva de puntos. En esos momentos, algunos investigadores, como el profesor Negroponte, llegaron a la conclusión de que el futuro de los gráficos por ordenador no residía en las máquinas de trazo de líneas originarias del modelo Sketchpad, si no en sistemas punto a punto como la televisión, que mostraba las imágenes almacenadas en un ordenador sobre la pantalla, al contrario que un tubo de rayos catódicos.

El elemento fundamental de los gráficos por ordenados pasó de la línea al píxel. El término píxel fue inventado por los que trabajaban en gráficos por ordenador comprimiendo la palabra picture y la palabra element para designar una matriz de puntos a rellenar como si se tratara de un crucigrama. Un crucigrama que se llena de números. Tres si queremos asignar colores. Los colores primarios necesarios en la televisión que se obtienen por adición son el rojo, el verde y el azul. Se puede definir un píxel como una molécula compuesta de carios bits. Cuantos más bits por píxel, más calidad de gráficos, pero más memoria que ocupamos. Cuantos más píxel asignemos por gráfico, más calidad, pero también ocupamos más memoria. Hoy en día esto no es problema, la memoria de los ordenadores crece de forma logarítmica a medida que su precio desciende, pero en los orígenes de los gráficos por ordenador (años 60-70) era muy cara ${ }^{95}$, de manera que la poca potencia que poseía el ordenador se empleaba en otras cosas por fuerza. De ahí que aparecieran los dentados en los gráficos, o en los textos dibujados en las letras O, G, S, etc... En los años 90, el problema de la memoria desapareció, pero los diseñadores inventaron una tipografía con dentados para cuando querían que se producto se viera «informatizado».

\subsubsection{La Universidad de Utah}

El director del departamento de Informática de la Universidad de Utah, David Evans, tras visionar un documental en que Shuterland mostraba las posibilidades de los gráficos por ordenador, decidió concentrar todos los recursos con que contaba su departamento en una sola área: la creación de imágenes por ordenador (el estudio de las leyes de perspectiva, de la naturaleza de la luz, y de la ciencia del color). Fue una apuesta estratégica arriesgada pero certera, que

\footnotetext{
95 En 1961 en USA un bit valía aproximadamente 1 dólar. En 1995, 24 millones de bits valían 60 dólares. En 2003, en España 40 GB costaban 70 euros.
} 
convirtió a la modesta universidad de Utah en un referente en la creación de gráficos por ordenador. Sus equipos de investigadores fueron reconocidos entre los más avanzados de la época. En 1973 B.T. Phong leyó su tesis doctoral en la que desarrolla el algoritmo que lleva su nombre y que representa una de las posibles soluciones para el tratamiento de la iluminación realista de las imágenes de objetos generados por ordenador. En 1975 E. Catmull investigó la generación de imágenes de superficies curvas generales (sin ecuación matemática). En 1976 James Blinn abordó las técnicas de modelado de superficies, mediante la adición de bloques de color compacto a un dibujo tridimensional que imitaba una estructura de alambre (Wireframe).

\subsubsection{New York Institute of Technology}

Cuando el New York Institute of Technology puso en marcha el proyecto The Works, respaldado por muchos millones de dólares, arrebató la primacía en la investigación de los gráficos por ordenador a la universidad de Utah. Con este proyecto la investigación se centraba en los aspectos puramente gráficos de la generación de imágenes por ordenador, o sea la imagen como fin en sí mismo. El proyecto contemplaba la realización de una película de 90 minutos de duración generada íntegramente por ordenador.

Desde mediados de los años 90 la investigación se lleva a cabo en dos líneas fundamentales: 1- El desarrollo de entornos amigables: se trata de diseñar sistemas para que personas sin experiencia puedan operar sin ningún problema en ellos. 2- El estudio de la Realidad Virtual, es decir, la creación de mundos virtuales en los que el usuario pueda tener todo tipo sensaciones reales.

\subsubsection{Ingeniería multimedia}

La posición de emergencia de nuestra área de conocimiento sólo es posible si adecuamos nuestra docencia e investigación a la conjunción de tres elementos indisolubles: el desarrollo de la Comunicación Multimedia, la emergencia de la Sociedad de la Información y la evolución constante de la Tecnología de la Información.

Las aplicaciones multimedia han revolucionado el concepto de comunicación. Hace diez años las comunicaciones podían ser resueltas en un sólo soporte (por ejemplo un libro en papel, un discurso por la radio, la música en un disco, etc...). 
Las aplicaciones multimedia han cambiado esto. Las actuales comunicaciones multimedia mezclan música, lectura, video, etc... puesto que lo importante no es el soporte sino la propia información. Lo que llevan a cabo las aplicaciones multimedia es una mezcla de bits para mejorar nuestra comunicación.

Las aplicaciones multimedia se han desarrollado por toda nuestra sociedad en muy diferentes ámbitos. Si se pretende estudiar una aplicación multimedia dedicada a la docencia lo que tenemos que analizar son sus objetivos y la programación, saber que estructuras desarrollan, el nivel de interacción que se pretende y el grado de multimedia conseguido. La tabla de la llustración 16 muestra las diferentes tipologías de aplicaciones y su análisis con las estructuras, interacción y grado de multimedia que se pueden llegar a implementar ${ }^{96}$.

Parece lógico pensar que las aplicaciones multimedia son potentes herramientas que mejoran el aprendizaje de nuestros alumnos. En el caso que estemos hablando de aprendizaje no presencial esta afirmación aún puede ser más rotunda como lo explica Hernane Borges: "el uso de aplicaciones multimedia como modelos de

\begin{tabular}{|c|c|c|c|c|}
\hline Tipología & Análisis & Estructuras & Interacción & Multimedia \\
\hline Entretenimiento & Reglas & \multirow{6}{*}{$\begin{array}{l}\text { Secuencial } \\
\text { Jerárquica } \\
\text { Árbol } \\
\text { Nodal } \\
\text { Hipertexto }\end{array}$} & \multirow{4}{*}{$\begin{array}{l}\text { Manipulación } \\
\text { directa }\end{array}$} & \multirow{6}{*}{$\begin{array}{l}\text { Textos } \\
\text { Imagen digital } \\
\text { Esquemas } \\
\text { Ilustraciones } \\
\text { Modelos 3d } \\
\text { Modelos 2D } \\
\text { Animación 2D } \\
\text { Animación 3D } \\
\text { Fotografía } \\
\text { Video } \\
\text { Voz } \\
\text { Música }\end{array}$} \\
\hline Información & $\begin{array}{l}\text { BBDD } \\
\text { Hipertextos }\end{array}$ & & & \\
\hline Educación & $\begin{array}{l}\text { Objetivos } \\
\text { programación }\end{array}$ & & & \\
\hline Promocional & Briefing & & & \\
\hline $\begin{array}{l}\text { Expresión } \\
\text { artística }\end{array}$ & $\begin{array}{l}\text { Diversas } \\
\text { aproximaciones }\end{array}$ & & $\begin{array}{l}\text { Comandos o } \\
\text { instrucciones }\end{array}$ & \\
\hline $\begin{array}{l}\text { Sistemas } \\
\text { expertos }\end{array}$ & $\begin{array}{l}\text { Adquisición del } \\
\text { conocimiento }\end{array}$ & & & \\
\hline
\end{tabular}

Ilustración 16. Aplicaciones multimedia.

\footnotetext{
${ }^{96}$ Francesc Alpiste. Conferencia sobre la ingeniería del conocimiento, el 8 de mayo de 2003 en el marco del Programa de Doctorado «Enginyeria Multimedia» de la UPC.
} 
instrucción para la educación y formación a distancia aumenta la adquisición y retención del conocimiento por los usuarios $»^{97}$.

\subsubsection{Internet}

La clave del desarrollo científico y tecnológico actual se apoya en las comunicaciones que permiten difundir la información. Con la llegada de los ordenadores, la información reside en ellos, por lo que se hace necesario que los ordenadores se puedan comunicar, así nacen las redes de ordenadores. De esta manera define Internet George Gilder: "The global Wide Area Network that utilizes the TCP/IP protocol to connect business, government, home, organizational, and other computers. (...) Often referred to as "the net ${ }^{98}$. Internet sirve para mover información en todos los niveles de nuestra vida: trabajo, diversión, estudio, etc...

Podemos situar el origen de Internet a principios de la década de los 70, en plena guerra fría, década en que nace ARPANET (Advanced Research Projects Agency Network), desarrollada por el Departamento de Defensa de los EEUU. Los Estados Unidos pretendieron desarrollar una red informática que uniera los principales puntos estratégicos del país y que se comportara de forma estable ante una posible destrucción parcial de la red.

Después del nacimiento de ARPANET, la tecnología fue evolucionando hasta llegar a los TCP/IP. Al mismo tiempo se fueron conectando otras redes como fueron Patnet, Usenet, Compuserve y Fidonet. Esto último es lo que caracteriza principalmente a Internet. Se trata de una red de redes, que permite la comunicación entre todos los países, las sociedades, empresas y personas distantes en el espacio pero próximas en una realidad cada vez más virtual. Este el concepto de aldea global. Se han roto todas las barreras. Fronteras, religión, política o cualquier otra barrera imaginable ya no es obstáculo para la globalización del planeta y para que vivamos en una cultura común. Internet ha propiciado un boom científico al incrementar exponencialmente la comunicación entre el saber de todo el

\footnotetext{
97 «ANÁLISIS EXPERIMENTAL DE LOS CRITERIOS DE EVALUACIÓN DE USABILIDAD DE APLICACIONES MULTIMEDIA EN ENTORNOS DE EDUCACIÓN Y FORMACIÓN A DISTANCIA». Hernane Borges de Barros. Pág 294. Tesis doctoral 2002. www.tdx.cbuc.es

98 «TELECOSM. How infinite bandwidth will revolutionize our world». George Gilder. página 314. The Free Press. New York 2000. ISBN0-684-80930-3.
} 
mundo. Lo que define a Internet no es su tecnología, o sus interfaces gráficas, lo que define a Internet es la comunicación y la transmisión de información.

Los grandes beneficiados de las ventajas de Internet fueron en principio las grandes corporaciones industriales, únicas capaces de poder pagar el desarrollo tecnológico que implicaba, pero a partir de los años 90 los costes empezaron a caer vertiginosamente, lo que implicó un despegue de los usuarios potenciales. Muchos autores prevén que la relación inversa entre costes y usuarios siga aumentando de forma exponencial hasta finales de la primera década de nuestro siglo como lo manifiesta el doctor Monguet Fierro en el gráfico de la llustración $17^{99}$.

A medida que se globalice el mundo e Internet crezca, se producirá un lugar de trabajo sin fisuras. Antes que el GATT logre liberalizar el comercio mundial basado en materias físicas, la información (como bits que son) se almacenará y se manipulará por todo el mundo independientemente de las barreras geopolíticas. Para algunos autores como el profesor Negroponte, las franjas horarias desempeñaran un papel más importante en el futuro que las zonas comerciales.

Estamos asistiendo a un proceso de fusión a gran escala de las tecnologías que conformaran las telecomunicaciones del futuro, y donde Internet es la pieza fundamental en tanto que argamasa de unión. Con la generalización de la tecnología digital, y la convergencia de las telecomunicaciones y la informática nació Internet. Hoy en día el siguiente salto tecnológico consistirá en converger las ventajas de Internet con las de la
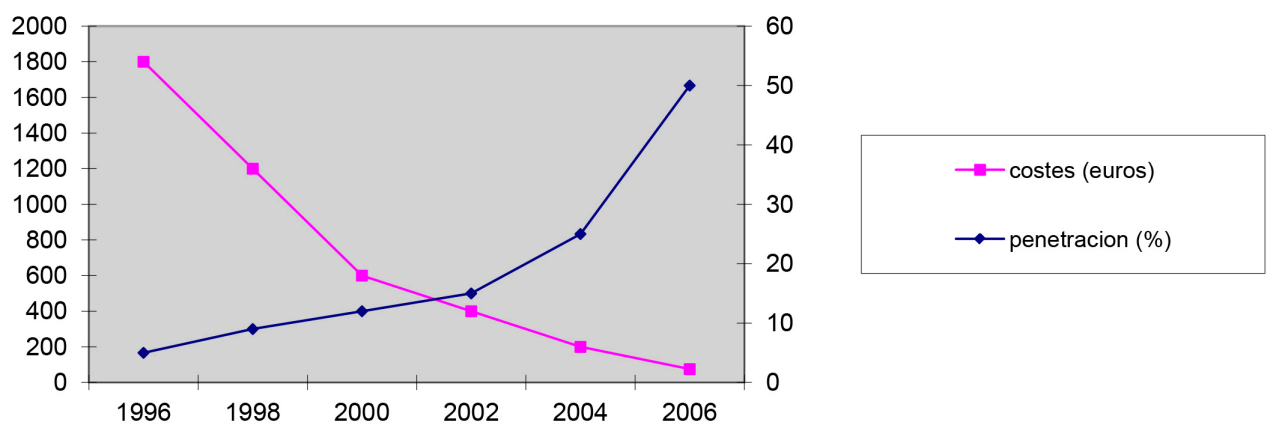

Ilustración 17. Relación inversa costes/usuarios en Internet.

\footnotetext{
99 «LA EXPANSION DEL ESPACIO EN INTERNET» Editorial del 19-3-2002 del Laboratori d’Apliacacions Multimedia. J M. Monget Fierro. http://lam.e-gim.net
} 
telefonía móvil, mediante la tecnología UMTS, para lo que las compañías de telecomunicaciones mundiales (pero sobretodo europeas) se gastaron 109.085 millones de euros en licencias. Así lo expresa Jesús Banegas Nuñez, presidente de Aniel: «El teléfono, las redes, la conmutación automática de las llamadas, la transmisión de datos, la telefonía móvil e Internet son los seis hitos fundamentales que han aportado más de un siglo de telecomunicaciones. Muy pocos aparentemente, pero de alcance extraordinario. EI nuevo, quizás venga representado por el UMTS, quintaesencia contemporánea de las telecomunicaciones, como consecuencia de la fusión funcional de todos sus atributos: la libre comunicación universal de voz, datos e imágenes en cualquier tiempo y espacio» ${ }^{100}$.

\subsubsection{Internet y la comunicación gráfica}

Hasta el momento Internet no ha aportado al área de la ingeniería gráfica sustancialmente nada distinto de lo que ha aportado a otras áreas del conocimiento técnico y científico. Permite la localización de la información deseada de forma inmediata y casi sin costos ni molestias y permite contactar con cualquier persona del mundo de forma instantánea.

Pero Internet empieza a servir para más. Internet puede servir como estándar para el trabajo cooperativo y concurrente. Se pueden reestructurar las organizaciones para introducir una nueva forma de trabajar donde la distancia física no es obstáculo. Para que dos ingenieros comenten un plano, no hace falta estar en el mismo espacio físico. Internet es la base para una nueva forma de trabajar la ingeniería gráfica. Internet es un nuevo sistema de Información y Comunicación: "La utilización de nuevos sistemas de información es de gran utilidad en todas las fases de proyecto: Desde la ingeniería básica, donde es posible integrar la información procedente de diferentes áreas dentro del modelo de la planta informar a la propiedad de la solución propuesta de forma simultánea, hasta el montaje donde el responsable de la obra puede visualizar la materialización de la solución escogida» ${ }^{101}$.

Internet está abriendo un gran campo (futuro, pero ya en marcha) de posibilidades de investigación en el área EGI, desde el diseño de espacios en Internet (retículas,

\footnotetext{
100 ¿EL SEPTIMO HITO DE LAS TELECOMUNICACIONES? Jesus Banegas Nuñez. El País Negocios. 6 abril 2003. Pág. 6.

101 LOS SISTEMAS DE INFORMACIÓN EN INGENIERÍA. Ponencia presentada por Bello García, Ordieres Meré. XI INGEGRAF. Bilbao-Donostia. Junio 1997. EHU. Pág. 569 Volumen 1. BI-788-97.
} 
interfícies multimedia, etc.) hasta la tecnología para el desarrollo de espacios en Internet (bases de datos multimedia, espacios virtuales, etc.) Desde la gestión y explotación de espacios en Internet (estrategias y metodologías de producción multimedia) hasta el análisis de la evolución del entorno socioeconómico (usabilidad, escenarios de evolución de las TIC, etc.)

\subsection{Herramientas tecnológicas basadas en las TIC}

El significado del término virtual es sobre algo que tiene una existencia aparente, no real. El aprendizaje virtual es aquel que no se desarrolla en aulas físicas, despachos y laboratorios en nuestras escuelas, sino que se produce en la red, gracias a nuevas herramientas tecnológicas basadas en la información y la comunicación.

Este capítulo responde a preguntas como: ¿La enseñanza basada en la utilización de las TIC puede suponer un cambio de paradigma?; ¿Cómo debemos cambiar los profesores para desarrollar todo el potencial de las TIC en la enseñanza?; ¿ ¿nuevos conceptos como Inteligencia Artificial, Sistemas Basados en Conocimiento, Ingeniería del Conocimiento, etc... significan un aprendizaje diferente?

\subsubsection{Enseñanza virtual versus enseñanza presencial}

Parece lógico pensar que las perspectivas de análisis y valoración de la enseñanza virtual pueden ser diferentes que en la enseñanza presencial. La diferencia más significativa entre la educación en la presencialidad y en la virtualidad reside en el «cambio de medio». No podemos hacer lo mismo en dos medios diferentes. Aunque nuestra finalidad sea la misma (que nuestros alumnos comprendan la visión gráfica de los objetos industriales), no podemos recorrer el mismo camino. El proceso de aprendizaje es un planteamiento global que se concreta de diferente forma en función del medio que se utiliza. Las clases virtuales se benefician de las posibilidades creativas de la red.

Según el profesor de la UOC Albert Sangrà ${ }^{102}$, los elementos diferenciales en los procesos educativos en entornos virtuales son de dos tipos: metodológicos y or-

\footnotetext{
102 «Enseñar y aprender en la virtualidad». «Educar» (revista del Departament de Pedagogía Aplicada de la UAB) no 28, 2001, ISSN0211-819-X.
} 
ganizativos. Para este autor, la metodología educativa para entornos virtuales de aprendizaje debe "estar centrada en el estudiante». Se trata de adaptar la metodología a un perfil de estudiante, con dificultades de tiempo para asistir a la universidad. Se trata de "llevar la universidad a casa de cada estudiante». El modelo UOC se basa en cuatro pilares: flexibilidad, cooperación, personalización e interactividad.

Pero existen otros modelos. Mercé Gisbert, vicerrectora de Docencia y Nuevas Tecnologías de la Universitat Rovira i Virgili de Tarragona, propone ${ }^{103}$ empezar a pasar de la Sociedad de la Información a la del Conocimiento, a la cual dijo que es mucho más difícil de llegar, puesto que se basa en introducir "amablemente» la información, y esta es la función del profesorado. Para la autora la tecnología no cambia la docencia en sí, sino que tiene que ser un valor añadido a la tarea docente. Por otro lado, si en la docencia siempre tiene que existir un cierto entendimiento, en la docencia no presencial, los alumnos tienen que saber siempre que se les va a exigir. Esto supone una cierta negociación con los alumnos justo al empezar un curso de docencia no presencial. Para Mercé Gisbert, existen dos ámbitos de aplicación claramente definidos, uno local (que funciona a través de una aula, de un $C D$, incluso de una intranet) y otro global (Internet). El alumno del futuro pivotara sobre diferentes instituciones académicas (Erasmus, etc...) gracias a este ámbito más global. La vicerrectora de la Universitat Rovira i Virgili, defiende que el principal valor de nuestras universidades es su presencialidad, pero que esto no nos impide ir aproximándonos a sistemas bimodales (semipresencialidad).

Aprender con tecnología es diferente, implica que el alumno por supuesto domine esta tecnología, pero le obliga además a ser activo en el aprendizaje. La tecnología primero nos complica la vida (puesto que el aprendizaje es diferente para el alumno pero también para el profesor), pero después nos la simplifica mucho más.

La organización de la enseñanza en entornos virtuales debe poner al servicio del alumno las posibilidades de las Tecnologías de la Información y la Comunicación. Las TIC no han de ser una finalidad en si misma sino tan sólo un medio con un determinado valor añadido. En esta organización, los diferentes

\footnotetext{
103 "Docència i noves Tecnologies: Recomanacions Pedagògiques». Jornada «LAS TIC EN LA DOCENCIA EN LA UPC: EXPERIENCIAS REALIZADAS», de 14 de junio de 2002 en la UPC.
} 
materiales de aprendizaje (debates, foros, mensajes, enlaces...) deben permitir la interacción y la construcción colectiva del conocimiento. La estructura particular en una organización virtual de educación ha de gestionar, además de los procesos académicos y docentes, la producción y edición de materiales educativos.

Pero la enseñanza virtual ¿es un nuevo paradigma, o sencillamente es la evolución de la enseñanza tradicional? Según Wedemeyer ${ }^{104}$, no existe un autentica teoría de la educación a distancia, aunque este autor se refiere a la tradicional enseñanza a distancia por correo convencional (modelo UNED). Otros autores, por el contrario sí que llegan a definir diferentes teorías propias para la educación a distancia: " $L a$ teoría de la autonomía e independencia del estudiante» (Delling), "La teoría basada en el proceso de industrialización de la educación" (Peters) y la "Teoría basada en la interacción y la comunicación» (Baath, Holberg, Sewart), pero fuere cual fuere la teoría estudiada, todas identifican tres elementos fundamentales para la enseñanza virtual:

- El estudiante (el tipo de estudiante específico de estos estudios)

- El docente (la relación que establece con el estudiante)

- Los recursos (permitentes de la interacción)

La relación que se establecen estos tres elementos en juego es lo que posibilita un nuevo paradigma en la docencia no presencial. Así, según Sangrà "Las redes tecnológicas permiten la interacción entre estudiantes, expertos y fuentes de información para acumular conocimiento de manera progresiva y, así, desarrollar habilidades. Los atributos del trabajo en la red hacen hincapié en las oportunidades y recursos disponibles para los estudiantes y los profesores. Éstos no están limitados a causa de su situación geográfica: es fácil llegar a los expertos, ya que tenemos acceso a las mejores bibliotecas y bases de datos en el mundo». Más aún: "La mayor parte de los aspectos que se aprenden en las redes no se puede alcanzar en una clase tradiciona/» ${ }^{105}$. El trabajo en red permite al estudiante no sólo aprender del profesor, sino también de sus compañeros y de los mejores profesionales del mundo.

\footnotetext{
104 «Learning at the Back-door». 1981. Madison: University of Wisconsin.

105 "ENSEÑAR Y APRENDER EN LA VIRTUALIDAD». «Educar»(revista del Departament de Pedagogía Aplicada de la UAB) no 28, 2001, ISSN0211-819-X.
} 


\subsubsection{Semipresencialidad}

Otros autores no creen que exista un barrera entre enseñanza presencial y virtual, para ellos es posible combinar ambas, como por ejemplo Eulàlia Griful ${ }^{106}$ (Coordinadora de los estudios semipresenciales de la ETSEIT en el curso 200102) presenta la comparativa del plan de estudios de Ingeniería de Organización Industrial (2001-02) en versión presencial (2 años) con la versión semipresencial (3 años). En versión semipresencial aparecen algunas asignaturas nuevas, por ejemplo se "obliga» al alumno a matricularse a una ALE (Asignatura de libre elección) de introducción a la enseñanza semipresencial, para que conozca las funcionalidades del Campus Digital, que será su vínculo con la Escuela, con los profesores y con sus compañeros. En estos estudios, las asignaturas tienen diferente grado de presencialidad, pero que en ningún caso puede superar el $50 \%$. El requisito de acceso de los alumnos es que trabajen en el mundo de la empresa. El $100 \%$ del alumnado cumple este requisito. Las solicitudes de estos estudios semipresenciales se han incrementado hasta llegar al curso 2001-02, en que para las 80 plazas ofertadas ese año, existía una demanda de más de 300 candidatos.

Para Eulàlia Griful las cuatro grandes ventajas de los estudios en versión semipresencial respecto a los completamente no presenciales y a los totalmente presenciales son:

- Tienen más baja tasa de abandono que los enteramente virtuales, puesto que introducen un vínculo de unión periódica.

- La sesión presencial es más valorada por los alumnos que si asistieron cada día a clase. El esfuerzo de la presencialidad anima a los alumnos a ser exigentes con la calidad de las clases.

- Los indicadores que se generan son útiles para la mejora de la docencia en general.

- Los semipresenciales han permitido mejorar los planes de estudios en versión presencial.

\footnotetext{
106 «Els estudis semipresencials de 2on cicle d'Enginyeria d'Organització Industrial a l'ETSEIT». Jornada "LAS TIC EN LA DOCENCIA EN LA UPC: EXPERIENCIAS REALIZADAS», 14 junio 2002 en la UPC.
} 


\subsubsection{Modelos de educación a distancia}

La educación a distancia existe muchos años antes de la aparición de Internet, pero con otros modelos docentes, puesto que ha sido una necesidad de la sociedad para poder satisfacer el aprendizaje de los ciudadanos que por razones de tiempo y/o espacio no podían asistir a la universidad pero tenían deseo de mejorar sus conocimientos. El doctor J. Taylor, presidente de la International Council for Open and Distance Education (ICDE) ha analizado cuatro modelos de educación a distancia que se han ido superando en el tiempo y en el espacio. Estos modelos están basados en la tecnología útil del momento histórico de su aplicación, lo que les ha permitido ciertas aplicaciones en unos casos y otras en los demás. El doctor Taylor destaca que ahora, cuando se está aplicando el cuarto modelo, está apareciendo un quinto, básicamente derivado del anterior, pero explotando todas las capacidades de Internet. Estos modelos son:

Primera Generación - Modelo basado en la Correspondencia. La tecnología que usa es el papel. Este modelo ofrece flexibilidad en el tiempo y en el espacio. El alumno puede estudiar y hacer los ejercicios cuando quiere y donde quiere, y luego enviarlos por correo. No existe interactividad.

Segunda Generación - Modelo Multimedia. La tecnología que usa es el papel, el audio, el video, el video interactivo y el primer aprendizaje por ordenador. Este modelo ofrece flexibilidad en el tiempo y en el espacio. El alumno puede ver los videos y escuchar las casetes cuando quiere y donde quiere, grabar los resultados y luego enviarlos por correo. No existe interactividad (salvo en el caso del video interactivo).

Tercera Generación - Teleaprendizaje. La tecnología al uso es la videoconferencia, las emisiones de televisión y radio. Este modelo ha perdido toda flexibilidad en tiempo y espacio, puesto que hay que estar en un lugar determinado donde haya televisión para poder asistir a la emisión del programa que nos interesa y además a una hora determinada. Por el contrario esta tercera generación ha ganado en interactividad, puesto que la videoconferencia permite las consultas en «directo» con el profesor.

Cuarta Generación - Aprendizaje Flexible. La tecnología que usa es el multimedia interactivo online (IMM), Internet y las comunicaciones por ordenador. Este modelo ofrece flexibilidad en el tiempo y en el espacio y además interactividad. Suma las ventajas de la Primera, Segunda y Tercera Generación, sin ninguna de sus limitaciones. 
Quinta Generación - Aprendizaje Flexible Inteligente. La tecnología que usa es el multimedia interactivo online (IMM), Internet y las comunicaciones por ordenador (con sistemas de automatización) y el campus virtual. Este modelo ofrece todas las ventajas del cuarto, pero además puede reducir significativamente el coste de la enseñanza aproximándolo a cero. "the fifth generation distance education has the potential to decrease significantly the costs associated with providing access to institutional processes and online tuition ${ }^{107}$.

No todos los autores están plenamente de acuerdo en estas cinco generaciones. El profesor Javier Suárez Quirós ${ }^{108}$ reconoce sólo cuatro etapas en los modelos de educación a distancia: 1-Utilización de material impreso, 2- Docencia basada en material analógico, 3-Incorporación de herramientas informáticas, 4- Utilización de tecnología digital a través de Internet principalmente. De todas formas el esquema es muy parecido, y en todos los casos se destaca que ha existido una evolución en la enseñanza a distancia, siempre basada en la tecnología hábil en cada momento histórico, independientemente que existan cuatro o cinco modelos.

La aplicación de todo el potencial de las TIC en la enseñanza a distancia conlleva la aparición de un nuevo modelo de aprendizaje cada vez más eficiente y barato, con plena intercomunicación y que lleva aparejado un nuevo modelo de campus virtual, aunque se puede ir implementado en diferentes fases sucesivas. El potencial que Internet ofrece como herramienta docente se extiende a diversas perspectivas: Como complemento a la docencia presencial, mediante el desarrollo de webs que contengan materiales de trabajo útiles a los alumnos; Como soporte a la gestión, mediante herramientas que faciliten las tareas tanto docentes como administrativas; Como aula virtual efectiva, llegando a crear en la red un infraestructura capaz de integrar todos los elementos docentes habitualmente empleados en la formación universitaria.

\subsubsection{Nuevos escenarios universitarios virtuales}

El escenario localista, que se ha desarrollado desde los años 90 , consiste en un estallido del número de universidades, cada vez más próximas físicamente al es-

\footnotetext{
107 «FITTH GENERATION DISTANCE EDUCATION» J. Taylor. 25/02/2003. www.icde.org

108 «NUEVAS TECNOLOGÍAS EN LA ENSEÑANZA VIRTUAL A TRAVÉS DE LA RED: GRÁFICOS POR COMPUTADOR EN EL CAMPUS VIRTUAL DE AULANET» Javier Suárez Quirós. XIV INGEGRAF. Santander. Junio 2002. http://departamentos.unican.es/digteg/ingegraf/cd/xivcongreso.html
} 
tudiante. Es un modelo a priori completamente ilógico con la explosión de las TIC. No hace falta llevar las universidades hasta la puerta de casa de cada estudiante, puesto que las TIC permiten un aprendizaje a distancia. Pero en este escenario, lo que prima no es la tecnología existente sino la política, en la que cada región (e incluso ciudad) quiere "su» universidad.

El escenario global prevé cada vez menos universidades, puesto que el estudiante podrá escoger la universidad que mejor satisfaga sus necesidades independientemente de la distancia física del centro, merced a las TIC. De esta manera sólo las «mejores» universidades podrán sobrevivir puesto que tendrán la suficiente masa crítica de estudiantes para poder sufragar los costos de la implementación de las nuevas tecnologías.

Pero existe un tercer escenario no intermedio sino mezcla de ambos. La proliferación de universidades en ciudades de poco peso demográfico, económico y/o tecnológico ha incentivado que estas instituciones desarrollasen todo el potencial de las TIC para poder atraer hacia ellas a estudiantes, no físicamente, sino a través de la red. De esta manera lo que se está llevando a cabo es una red de universidades (en general de la misma región) que comparten una serie de servicios. Se ha empezado por lo que es más fácil desde el punto de vista burocrático, las asignaturas de libre elección. El ejemplo más paradigmático es el proyecto Intercampus, auspiciado durante el curso 2002-03 por el Departament d'Universitats, Recerca i Societat de la Informació de la Generalitat de Catalunya.

El proyecto Intecampus tiene como modesto objetivo el intercambio de asignaturas de libre elección que se imparten en Internet. Las universidades participantes son: UAB, UB, UdG, UdLL, UOC, UPC, UPF, y URV. Lo único que hacen las universidades es facilitar la comunicación y simplificar la burocracia, pero es un primer paso. A éste seguirán otros lógicos, como el incremento de las asignaturas no sólo a las de libre elección, el compartimento de cada vez más información, y la expansión territorial (si la enseñanza está basada en las TIC, qué sentido tiene que el Intercampus sea de universidades catalanas y no puedan sumarse al proyecto otras instituciones españolas, latinoamericanas o de cualquier otro lugar del mundo). De este modo habremos llegado a un escenario global basado en universidades locales.

El proyecto Intercampus forma parte de hecho de un planteamiento mayor, la Universitat Digital de Catalunya, que pretende: 
- Crear una plataforma para producir y gestionar material educativo. Compartir materiales didácticos multimedia y metodologías profesor-estudiante.

- Construir una plataforma en Internet de base a las editoriales de las universidades catalanas.

- Diseñar un servidor de tesis doctorales. Crear un consorcio virtual de universidades catalanas, el CBUC.

- Potenciar la conectividad universitaria catalana de Internet a nivel internacional.

\subsubsection{El profesor en las TIC}

Las TIC han provocado la transformación del concepto de aprendizaje al concepto de intercambio de información. Los profesores hoy no tenemos todo el conocimiento, sino que las TIC nos permiten ser facilitadores del proceso de intercambio de conocimiento. Según Josep Ma Monguet «el poder reside cada vez menos en la información, y más en la capacidad para compartirla. En este sentido, cuando se habla de gestión del conocimiento se hace referencia a las estructuras funcionales y operativas que permiten acumular y gestionar la información de forma que esta sea reutilizable para la organización ${ }^{109}$. El antiguo planteamiento de explicar a base de repetir el mismo conocimiento ha fracasado tal como avanza el catedrático M. Bermejo Herrero "Tradicionalmente la facultad de ver en el espacio se ha basado en la imaginación, y el estudiante que carecía de ella fracasaba. Así el desarrollo de las clases se hacía a base de ejercicios, muchos de ellos repetitivos, en los que el alumno a base de dibujar, aprendía a dibujar. Este sistema perfectamente válido, es evidente que requiere bastante tiempo, lo que cada vez va siendo más difícil de mantener en los planes de enseñanza, dado el acortamiento de las carreras, y el continuo incremento de las tecnologías ${ }^{110}$.

\subsubsection{El trabajador del saber}

Los profesores siempre hemos sido considerados trabajadores del saber respecto a los trabajadores manuales (o industriales), puesto que el resultado de nuestro

${ }^{109}$ ESPACIO INTERNET. APRENDER E INVESTIGAR EN LA UNIVERSIDAD. Editorial de diciembre 2002 del «Laborati d'Aplicacions Multimedia» de la UPC. www.lam.upc.es

110 «GEOMETRIA DESCRIPTIVA APLICADA» Miguel Bermejo Herrero. Editorial Tebar-Flores. Madrid 1996. Prólogo. ISBN-84-7360-159-9. 
esfuerzo no era una manufactura, un edificio o sencillamente un servicio, sino que transmitíamos saber, conocimiento. Durante el siglo XXI todos los trabajadores se convertirán en trabajadores del saber, puesto que es lo que precisan las organizaciones en nuestra sociedad para triunfar. Los profesores, como trabajadores del saber del siglo XXI tenemos que mejorar nuestra productividad a partir de seis puntos básicos que propone Peter Druker:

1. La pregunta del trabajador del saber es ¿Cuál es la tarea?

2. Tiene que gestionarse a sí mismo. Tiene que tener autonomía.

3. Parte del trabajo es la innovación continuada

4. Aprendizaje continuado a lo largo de la vida

5. La calidad de nuestra productividad es más importante que la cantidad.

6. El trabajador del saber es un «activo» de la empresa no un «coste»

En la enseñanza con las TIC el rol del profesor cambia de un mero expendedor de conocimiento a ser una persona dedicada a facilitar el aprendizaje. Esto requiere diferente formación (tanto inicial como permanente). El profesor se convierte en un filtro dedicado a diferenciar lo útil de lo inútil. Los profesores hemos de ayudar a nuestros alumnos a que aprendan facilitándoles criterios críticos. Las cinco características básicas del «buen profesor» en la aplicación de las TIC son ${ }^{111}$ :

1. Colaboración

2. Participación (fomentándola por todos los canales)

3. Reconocimiento de la no posesión del conocimiento total

4. Habilidad organizativa

5. Experimentación y capacidad de modificar sobre la marcha la metodología de aprendizaje aplicada

Se trata de «enseñar a aprender» a nuestros alumnos, puesto que la evolución de los conocimientos profesionales va mucho más deprisa de lo que somos capaces de enseñar.

El paradigma de la enseñanza presencial definía que el conocimiento se encontraba dentro del mismo profesorado y las fuentes estáticas de información, mientras que en

\footnotetext{
111 «PROJECTE ASTROLABI. 2on informe de l'observatori sobre la implantació i l'ús de les tecnologies de la informació i comunicació a l'ensenyament universitari.» Sangrà, Bellot, Hinojosa. UOC. IN3 Edu Lab. Fundació Jaume Bofill. Barcelona. 2000.
} 
la enseñanza no presencial, los estudiantes pueden acceder al conocimiento donde quieran, cuando quieran y como quieran. Así pues para muchos autores la enseñanza virtual supone un nuevo paradigma, como para Ferraté: «las metodologías basadas en conceptos de virtualidad se irán extendiendo y generalizando a causa de las inmensas posibilidades pedagógicas y sociales que comportan. Debemos tener presente que las metodologías asociadas al concepto de virtualidad pueden ayudarnos a romper, no solamente las barreras del tiempo y del espacio sino también las barreras sensoriales» ${ }^{112}$.

\subsubsection{Sistemas basados en conocimiento}

Los orígenes modernos de la transmisión de conocimiento proceden del constructivismo. Según Liliana Tolstschinski, los cinco principios básicos de la transmisión de conocimiento según el constructivismo son:

- Aprender haciendo. Para poder enseñar/aprender, hay que saber hacerlo.

- Adaptación. Conocer las cosas en el contexto en la que se desenvuelven.

- Estructuración. Los datos no son importantes en sí mismos, sino su orden.

- Confrontación. Un mismo hecho puede ser entendido de diferentes maneras en función del punto de vista.

- Reflexividad. Como conocer el conocimiento, punto de vista personal.

De la misma manera David Merrill ${ }^{113}$ pretende favorecer la formación con principios "constructivistas» como son: proponer la resolución de problemas de base real a los estudiantes, activar nuevos conocimientos a partir de los previos de los estudiantes, demostrar los conocimientos que se vayan adquiriendo, aplicar estos nuevos conocimientos recientemente adquiridos en la resolución de problemas, integrar los nuevos conocimientos al entorno del estudiante.

Cuando trabajamos en sistemas virtuales de aprendizaje, muchas veces se confía ciegamente en el software pero tenemos que tener en cuenta que podemos fundamentar nuestra enseñanza y el aprendizaje de nuestros alumnos en otros sistemas apoyados en la Inteligencia Artificial, sistemas basados en conocimiento.

\footnotetext{
112 «UNIVERSIDAD Y NUEVAS TECNOLOGÍAS. EL CAMINO HACIA LA HIPERUNIVERSIDAD» Ferrate, Porta, LLadonosa. «La universidad en el cambio de siglo». Madrid. Alianza Editorial.

113 «FIRST PRINCIPLES OF INSTRUCTION» Submitted for publication to Educational Technology Research \& development. Utah State University. 2002. www.id2.usu.edu
} 
Tradicionalmente el software ha trabajado con problemas de resolución algorítmica: dado un problema en concreto existe una única solución y, además, tal solución puede hallarse siguiendo un conjunto de pasos conocidos, precisamente aquellos implementados por el mismo software. En los Sistemas Basados en Conocimiento, por el contrario, la solución no es algorítmica, sino heurística. La solución no es única; para un mismo caso puede existir un abanico de soluciones más o menos adecuadas, de la misma manera como para curar a un enfermo se pueden seguir diferentes caminos. Para comprender la Ingeniería del Conocimiento, conviene entender el concepto de Inteligencia Artificial y tener las bases para el desarrollo de software.

\subsubsection{La Inteligencia Artificial}

La Inteligencia Artificial (IA) es una Ciencia (que trata de entender la naturaleza de la inteligencia) y a la vez una Ingeniería (que trata de construir artefactos que presenten una conducta inteligente). Según Nilsson, la problemática científica que plantea la IA se puede resumir en tres cuestiones:

1. Pretende proporcionar una base teórica al concepto de inteligencia, por lo que utiliza el ordenador como un laboratorio donde desarrollar nuevas formas de pensar acerca del pensar.

2. Entra en confluencia con la psicología cognoscitiva al buscar procesos básicos que confirmen el funcionamiento de la inteligencia. El estudio de estos procesos básicos es una de las líneas de investigación de la IA.

3. Ciertos programas complejos (sobre todo los capaces de modificar sus propias operaciones y crecer mediante la incorporación de otras nuevas) pueden ser modelos empleados en la investigación científica.

Según Asunción Gómez «La IA como ciencia trata del estudio del comportamiento inteligente, siendo su fin el conseguir una teoría de la inteligencia que explique la conducta en seres de natural inteligentes, y que guíe la creación de entes artificiales capaces de alcanzar dicho proceder inteligente ${ }^{114}$. Para esta autora la IA es una rama de la ciencia íntimamente relacionada con otras ramas de la ciencia y la Ingeniería.

\footnotetext{
114 «INGENIERÍA DEL CONOCIMIENTO». Asunción Gómez, Natalia Juristo, Cesar Montes y Juan Pazos. Página 3. Editorial Centro de Estudios Ramón Areces. Madrid 1997. ISBN 84-8004-269-9.
} 
Como Ingeniería, la IA «se ocupa de los conceptos, la teoría y la práctica de como construir máquinas inteligentes; es decir máquinas que resuelvan problemas coextensivos con los que, al resolverlos los seres humanos, estos son tenidos por inteligentes ${ }^{115}$. Los Sistemas Basados en Conocimientos en general, y los Sistemas Expertos en particular, son el ejemplo paradigmático de la IA como Ingeniería. La Ingeniería del Conocimiento pretende adquirir, conceptualizar formalizar y usar grandes cantidades de conocimientos de la más alta calidad. Las relaciones entre IA y la Ingeniería del Conocimiento son descritas por Asunción Gómez en el siguiente esquema donde los sistemas expertos son una parte de los sistemas basados en conocimientos, todos ellos dentro de la Ingeniería del Conocimiento, que forma parta a la vez de la Inteligencia Artificial.

\subsubsection{Sistemas Basados en Conocimientos frente a Convencionales}

Tradicionalmente los Sistemas Convencionales son desarrollados por la Ingeniería del Software, mientras que la Ingeniería del Conocimiento utiliza los Sistemas Basados en Conocimientos. Pero esta división está más desarrollada según tres magnitudes.

La primera hace referencia respecto a los tipos de problemas que resuelven. En la Ingeniería del Software son básicamente sistemáticos y procedimentales, mientras que Ingeniería del Conocimiento son eminentemente heurísticos. La metodología empleada es otra de las magnitudes que diferencia Ingeniería del Software de Ingeniería del Conocimiento. En el primer caso la metodología es algorítmica, mientras que en el segundo es declarativa, para que permita separar los conocimientos expertos de los mecanismos de razonamiento que los manejan. La tercera diferencia entre estas dos ingenierías obedece a como organizan sus conocimientos. La Ingeniería del Software los organiza en dos niveles: datos y programas. La Ingeniería del Conocimiento en tres: datos, reglas operativas o heurísticas, e inferencia y control. Los dos primeros niveles forman la base de conocimientos.

Las tres diferencias fundamentales de los Sistemas Basados en Conocimientos respecto a otras aplicaciones de IA son:

115 «INGENIERÍA DEL CONOCIMIENTO». Asunción Gómez, Natalia Juristo, Cesar Montes y Juan Pazos. Página 4. Editorial Centro de Estudios Ramón Areces. Madrid 1997. ISBN 84-8004-269-9. 
1. Ejecutan tareas difíciles con las prestaciones de un experto

2. Enfatizan estrategias de solución de problemas de dominios específicos

3. Emplean autoconocimientos para razonar sus propios procesos de inferencia

Los Sistemas Basados en Conocimientos se describen en tres niveles. El primero es funcional, de como aparece el sistema ante el usuario, de como se muestra la arquitectura del sistema. El segundo es el lógico, que es el que se corresponde con la implementación que tiene que soportar la arquitectura mostrada. El tercero es el físico, que se corresponde con la realización concreta del sistema. 
CAPítulo 4

Aprendizaje 



\subsection{Modelos de Aprendizaje}

De forma general, en todos los congresos universitarios sobre aprendizaje se plantea la necesidad que la universidad desarrolle habilidades acordes a las demandas económicas y productivas de la sociedad, y para ello introduzca los cambios necesarios en los procesos de aprendizaje para conseguirlos (ver llustración 18).

El motivo principal del éxito del aprendizaje radica en la motivación de los estudiantes, puestos que ellos son los protagonistas del proceso. Esto se puede con-

\section{Aprendizaje}

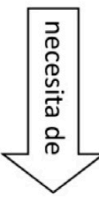

\section{Motivación estudiantes}

Menos

ejercicios

abstractos

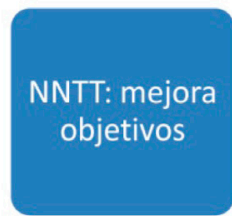

Perfeccionar

conocimientos

pedagógicos

profesores

Ilustración 18. Aprendizaje y motivación. 
seguir de diferentes maneras. Algunos profesores (Corbella Barrios) pretenden conseguirlo huyendo de los ejercicios de enunciados abstractos. Otros autores proponen incorporar las NNTT (Nuevas Tecnologías) (Sangrà, 2000), aunque para ellos más que potenciar el punto de vista de innovación tecnológica, hay que utilizar esa tecnología para conseguir los objetivos de una forma mucho más eficaz. Y para otro grupo (Camiña, Ballester) es imprescindible llevar a cabo un seguimiento individualizado y una información de retorno, como elemento de estímulo para el aprendizaje de los alumnos. Se destacan los tres elementos fundamentales que componen el aprendizaje en la teoría constructivista: los conceptos, los procesos, y las condiciones para que se produzca la instrucción. Otros autores (Troncoso) afirman que el aprendizaje de los alumnos se ve penalizado por la falta de conocimientos pedagógicos de los profesores.

Varios profesores (Álvarez Peñín, Pellejero, Rodríguez) presentan en sus escritos nuevas herramientas didácticas o nuevas estrategias, cuyo principal objetivo es la mejora del aprendizaje.

Gran parte de los artículos que exponen sus planteamientos sobre el sistema EEES y los créditos ECTS destacan que nos aproximamos a una enseñanza orientada al aprendizaje. En este contexto es inevitable (Jiménez) orientar el proceso de enseñanza-aprendizaje hacia la adquisición de competencias, y con ello se abre un marco de trabajo sobre el que se pueden revisar los contenidos para ajustarlos a la demanda (ver llustración 19).

Existe unanimidad en intentar evitar tanto el aprendizaje estratégico (el alumno se centra en conocer el sistema de notas y los temas clave para conseguir el aprobado) como el aprendizaje superficial (el alumno memoriza conceptos, sin reflexionar sobre ellos). Frente a estos modelos los autores proponen otros tipos de aprendizaje. Aparece el aprendizaje colaborativo (Suárez Quirós, Sánchez), consistente en la realización de proyectos y prácticas por grupos de alumnos, destacando la necesidad de fomentar los aspectos socializantes del proceso de enseñanza. Los participantes están estrechamente vinculados, de forma que sólo pueden conseguir sus objetivos sí los demás pueden conseguir los suyos. Las técnicas del aprendizaje basado en proyectos son útiles para muchos ponentes (Sánchez), y se destacan como una de las estrategias de metodología más utilizadas en los últimos años. Otro modelo presentado es el aprendizaje activo (Capó, Hernández) con un doble objetivo, romper con el modelo de clase magistral, y darle un enfoque práctico a la asignatura. Se presentan diferentes ponencias en que se explica a grandes rasgos que el aprendizaje activo es un aprendizaje que exige más dedicación por parte 


\section{Aprendizaje constructivismo}

\section{Procesos}

Conceptos

\section{Condiciones}

Ilustración 19. Aprendizaje constructivismo.

del profesor y del alumno, pero que se ve recompensado por unos resultados más positivos, siempre que los grupos de clase sean inferiores a 30 alumnos.

Es necesario mejorar la coherencia entre objetivos de aprendizaje y los procesos de evaluación. Hay que definir los objetivos de aprendizaje a partir de las competencias a adquirir (ver llustración 20).

Jiménez, Fernández y Tortajada exponen como experiencia los denominados «objetos de aprendizaje» (OA), para favorecer la estructuración y secuenciación de contenidos. Para elaborar estos OA hay que tener en cuenta que: tienen que ir asociados a objetivos muy concretos, no deben ser demasiado extensos, tienen que desarrollarse en tecnología estándar, deben incluir una guía de aprendizaje (descripción de las actividades a realizar y como hacerlas), y el procedimiento de evaluación tiene que formar parte del propio OA.

En varios artículos se destaca el aprendizaje a lo largo de la vida (García, Troyano, 2008) como un potencial para la universidad.

El blended learning es un método de aprendizaje que combina la enseñanza presencial con la enseñanza no presencial utilizando las TIC (Ferreiro Prieto, Pérez 


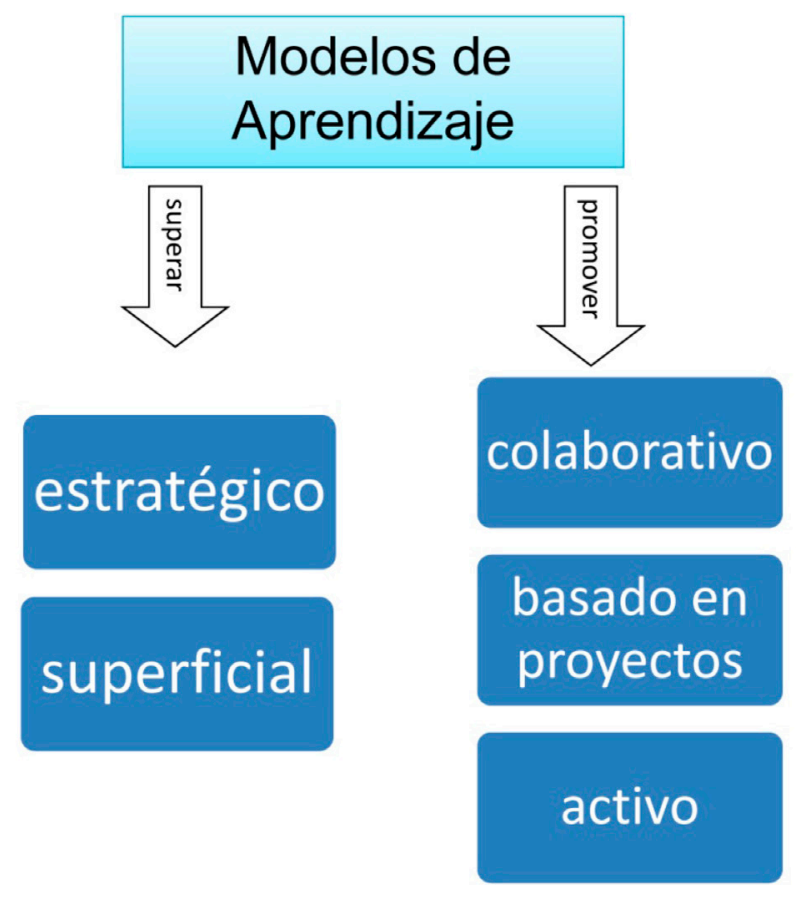

Ilustración 20. Modelos de aprendizaje.

del Hoyo) suponiendo una atención personalizada al alumno, y requiriendo de un seguimiento y orientación.

La informática (Bustinza, Fernández) es un medio adecuado para mejorar el aprendizaje en las carreras técnicas, ayuda al profesor a impartir su enseñanza, y al alumno a aprender. Sin embargo, la premisa fundamental a tener en cuenta es que el método es superior al medio, es decir que la calidad del proceso de aprendizaje radica en la metodología utilizada más que en las características técnicas de las nuevas tecnologías. Existe consenso (Zulueta) en afirmar que es necesario que el cambio del paradigma docente de la enseñanza al aprendizaje no suponga una merma en la calidad de la docencia.

\subsection{Aprendizaje Virtual}

Los orígenes del aprendizaje virtual (Pellejero, Rodríguez) se basan en buena medida en el diseño de prácticas virtuales que permitían al alumno desarrollar un tipo de aprendizaje de carácter interactivo. Se destaca (Suárez Quirós, Rubio) que el aprendizaje virtual es resultado de un proceso evolutivo histórico en el que 
se distinguen varias etapas: utilización del material impreso, docencia basada en material analógico, incorporación de herramientas informáticas, y utilización de tecnología digital a través de Internet.

Hacia el 2000 (Martín, Suárez) las herramientas que facilitan el desarrollo de realidad virtual han experimentado un gran avance, pues el equipo tecnológico necesario para ejecutar estas aplicaciones es simple y estándar, gracias en parte al nuevo escenario basado en la web, y ello permite una explosión de experiencias de aprendizaje virtual. Existe confianza entre los ponentes de que, en el futuro, los laboratorios virtuales se convertirán en elementos integrados en los procesos de aprendizaje, incluso hay autores (Cruz) que afirman que el aprendizaje virtual facilitará la convergencia europea de los programas docentes universitarios (ver llustración 21).

Otros autores (Alpiste, Brigos) proponen incidir en el aprendizaje desde el lado del profesorado mediante la creación de portales de aprendizaje virtuales temáticos de trabajo colaborativo para los profesores de la asignatura.

Con la integración al EEES, algunas metodologías docentes sustentadas en tecnología incorporan entornos virtuales de aprendizaje, complementando las actividades presenciales, facilitando la publicación, la comunicación y el trabajo en grupo, de manera que el modelo didáctico pasa a ser semipresencial.

\section{Entornos de Aprendizaje Virtual}

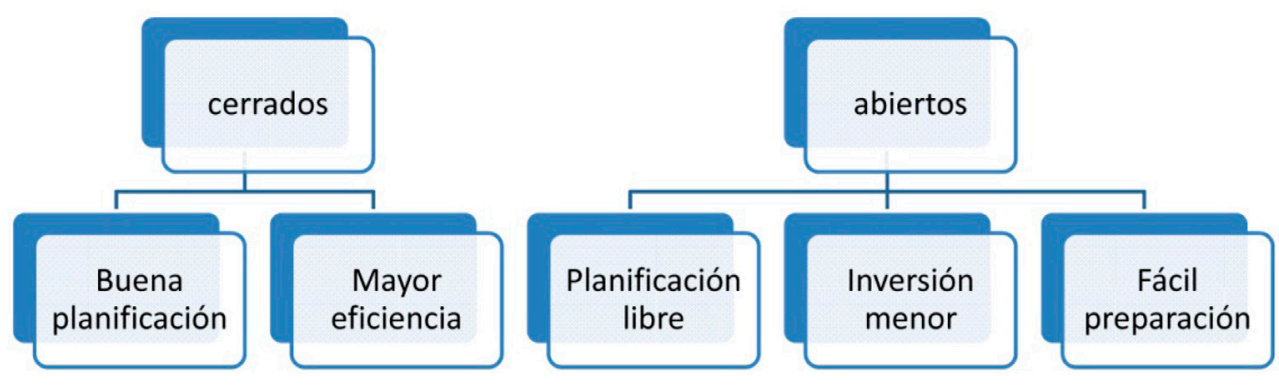

Ilustración 21. Entornos de aprendizaje virtual. 
El nuevo entorno el aprendizaje virtual (Cruz) proporciona al alumno la posibilidad de intervenir en su propio proceso de aprendizaje como un elemento de mejora docente. Pero para la mayoría de los autores (Zulueta) con la idea de aula virtual como una herramienta de apoyo a la docencia presencial, no como un recurso con el que elaborar conocimiento, sino como un vehículo de intercambio de información relevante y de mejora del aprendizaje.

Los objetivos de crear un entorno virtual de aprendizaje (Alpiste) son: introducir la asignatura en un entorno de trabajo basado en nuevas tecnologías, potenciar la planificación del trabajo de forma no presencial, facilitar herramientas para la gestión de documentos y, fomentar el uso de las nuevas técnicas de integración ofimática y multimedia.

Existe unanimidad (Moreno, Suarez Quirós) en definir aula virtual como un nuevo método docente que supone grandes ventajas: flexibilidad de horario y lugar de la docencia, adaptación al ritmo de aprendizaje del alumno, aprendizaje no lineal, e interactividad entre agentes docentes; pero también con sus limitaciones, sobretodo en temas de seguridad (ver llustración 22).

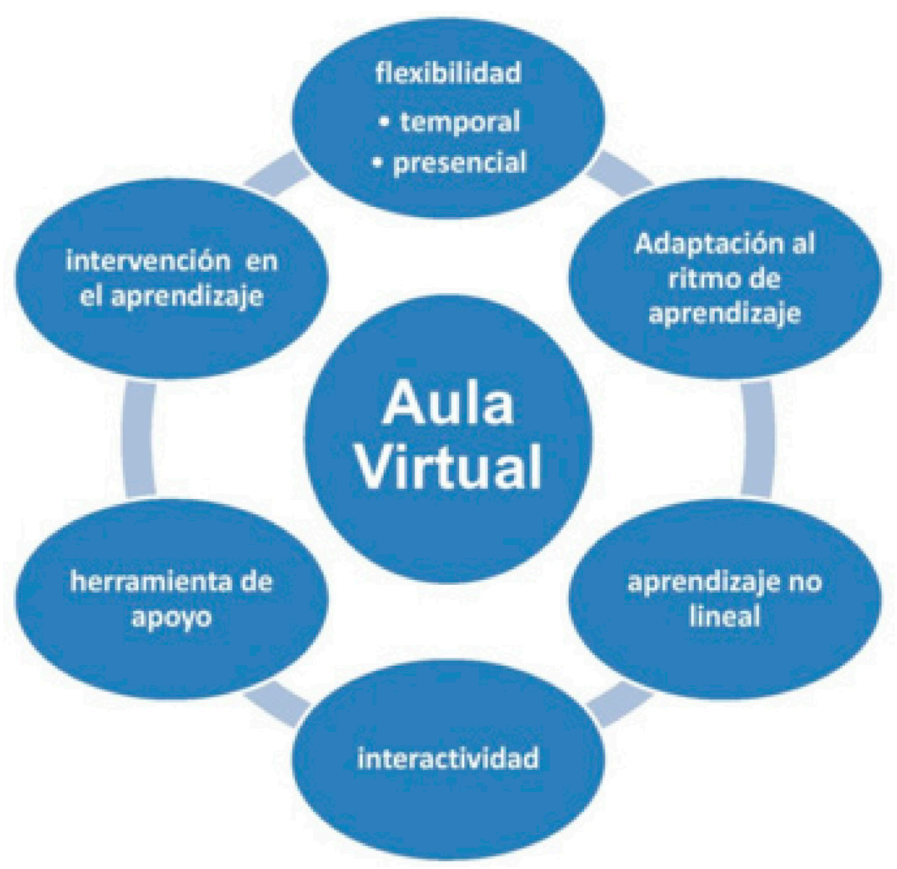

Ilustración 22. Aula virtual. 
Los autores (Hernández, Monguet) presentan dos tipos de entornos de aprendizaje virtuales: abiertos y cerrados. En general, se identifica a los entornos virtuales cerrados como sistemas que están bien planificados y que tienen una mayor eficiencia: el contenido de las materias ha sido creado y revisado por expertos, gran facilidad de uso, coherencia de los elementos que lo componen, el seguimiento de los alumnos es una tarea compartida, con un coordinador que asegura la uniformidad. Por el contrario, los sistemas abiertos, a pesar de no tener la eficiencia de los cerrados, destacan por las ventajas siguientes: la planificación es más libre, la inversión en la generación del material es mucho menor, el material empleado es de más fácil preparación, hay una dependencia mucho mayor de la formación del profesorado y de su experiencia en la elaboración de material. 

CApítulo 5

Docencia 



\subsection{El profesor no enseña; el alumno aprende}

Algunos autores (Tortajada, Brusola, Rubió) definen el modelo tradicional de docencia como aquel cuyas características son: primacía de los contenidos; lección magistral como metodología predominante; pasividad por parte de los alumnos; el profesor es un experto en contenidos transmisor de información; sólo planifica el profesor; las única fuente de información son los apuntes de clase; sistema de evaluación rígido basado exclusivamente en exámenes recopilatorios de conocimientos. Frente a este modelo, las NNTT están cambiando significativamente la sociedad, mientras que la docencia tradicional sigue métodos de trabajo artesanales (Álvarez Peñín, Charro Hernández, García Díaz, Suarez Quirós). Por eso proponen replantear objetivos, contenidos y métodos.

Existe cierta opinión (Álvarez Peñín, Charro Hernández) de que la docencia ocupa un plano secundario en la actividad del profesor, dominada fuertemente por la investigación. En las conclusiones de los CUIEET se destaca que es necesaria una adaptación de la docencia a la realidad social y concurre preocupación en el ámbito docente sobre las necesidades que presumiblemente la empresa demanda. Existe gran interés del profesorado en aprender y aplicar nuevos métodos que mejoren la calidad de la docencia, por ello en los congresos se presentan herramientas de apoyo a la docencia. No se ha valorado suficientemente su repercusión en el aprendizaje.

Para que este nuevo modelo de enseñanza-aprendizaje aporte un valor añadido a la docencia, más que potenciar el punto de vista de innovación tecnológica, hay que utilizar esa tecnología para conseguir los objetivos de una forma mucho más eficaz (Sangrà, Guàrdia, Bellot). 


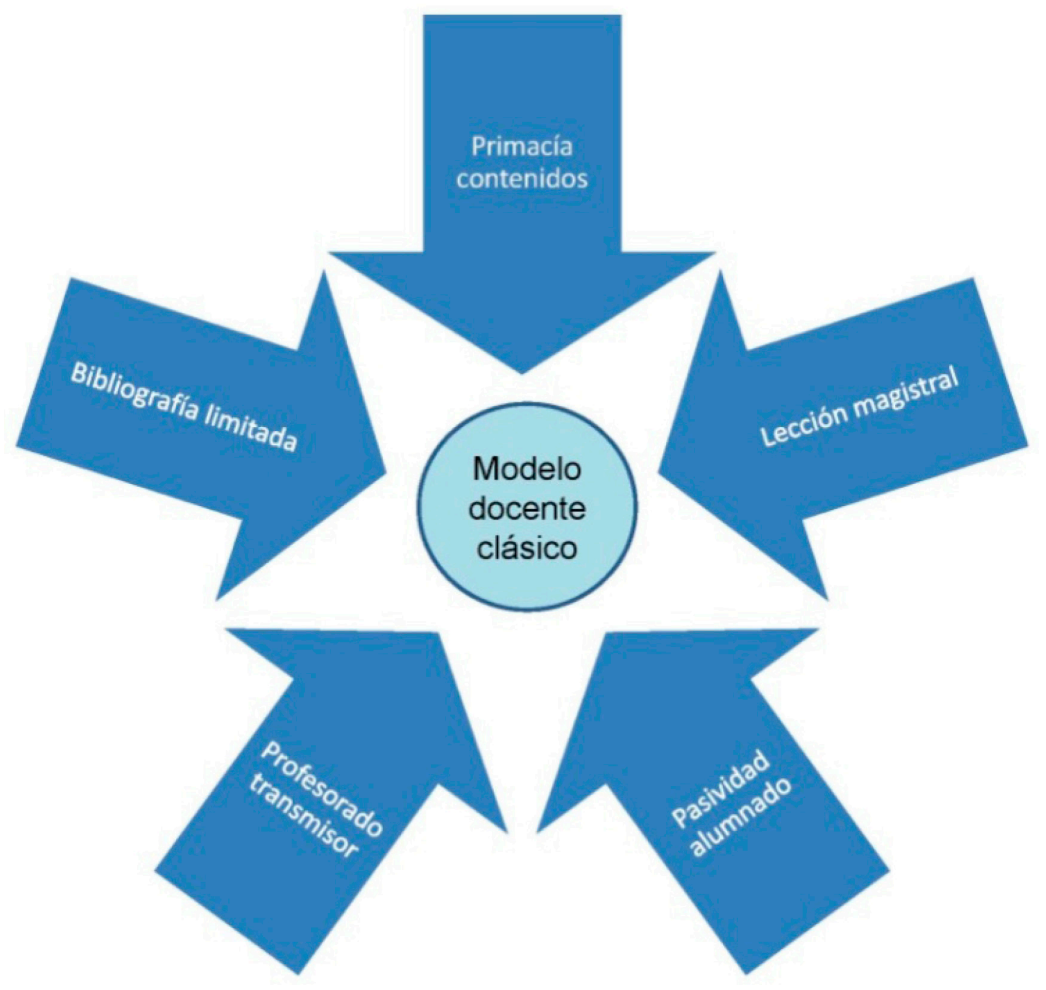

Ilustración 23. Modelo docente clásico.

Para mejorar la docencia se proponen diferentes alternativas. Algunos autores (Herrero de Lucas, González González, Acebes Arconada, Fernando Velázquez, Martín Bravo) destacan las ventajas que conlleva la coordinación entre los profesores que imparten docencia en una misma Titulación Universitaria, tanto respecto a los contenidos, como respecto a las diferentes metodologías docentes utilizadas. Se propone (Font Andreu) coordinar la docencia en distintas áreas de conocimiento a fin de paliar la excesiva parcelación del conocimiento universitario. Para otros (Pallisera Díaz, Carretero Torres) es imprescindible aportar a los profesores la información y formación suficiente para iniciar procesos innovadores en la docencia. Para un tercer grupo (Bermúdez Rodríguez, Lapaz Castillo, Marqués Calvo, Povill Cartoixà, Morón Tarifa, Voltas Aguilar) las TIC pueden suponer una potente ayuda a la docencia para mantener el nivel de calidad del área y adaptarse a las nuevas dedicaciones fijadas en los planes de estudio. En este sentido (García Almirall) la informatización de las asignaturas del área de Ingeniería Gráfica supone la realización de una serie de cambios, tanto en la estricta docencia como en su organización. 


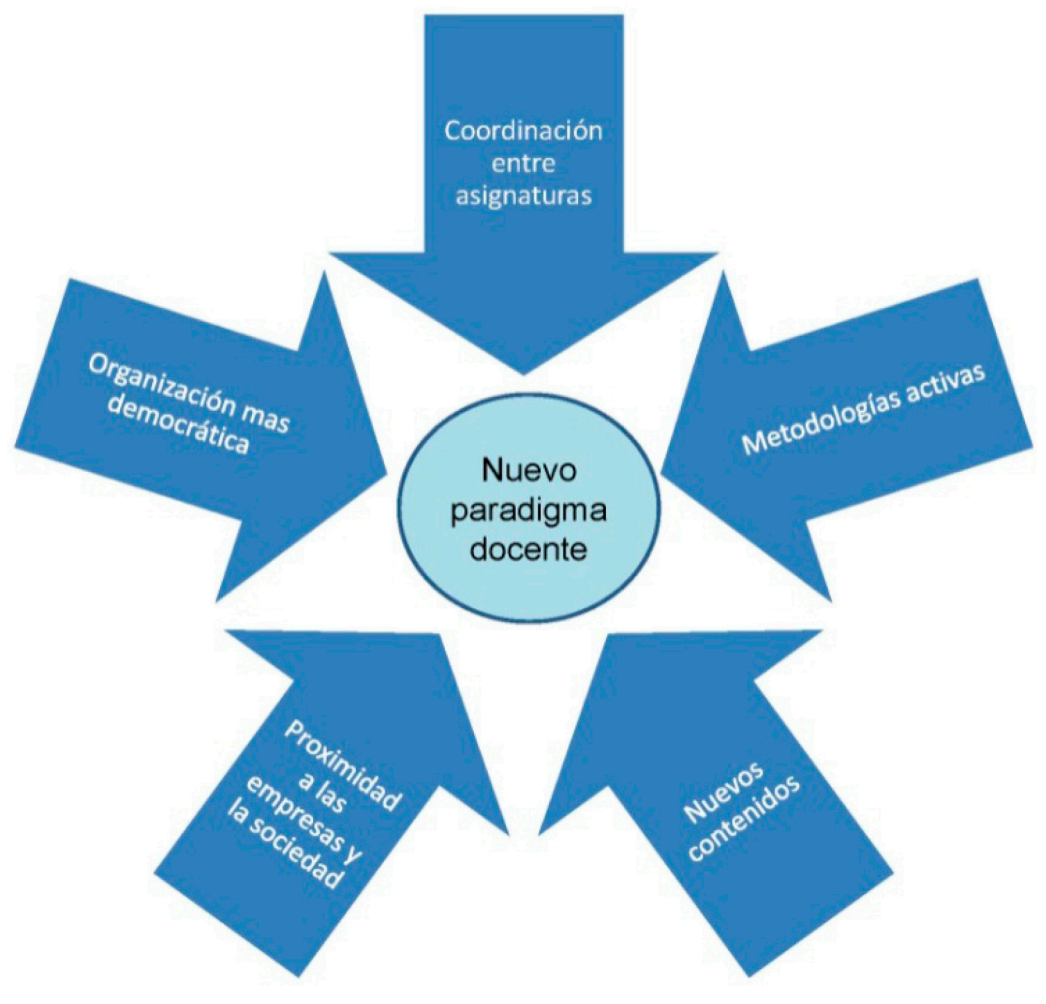

Ilustración 24. Nuevo paradigma docente.

Parece claro que las TIC influirán de manera significativa en la docencia de la Ingeniería Gráfica, aunque en un grado diferente según pareceres. Para un cierto número de profesores (Bermúdez Rodríguez, Lapaz Castillo, Marqués Calvo, Povill Cartoixà, Morón Tarifa, Voltas Aguilar) las nuevas tecnologías de soporte a la docencia conducirán inexorablemente a un nuevo cambio de paradigma. Las herramientas informáticas (Moreno Cazorla) no sólo plantean un cambio en la forma de aplicar la docencia sino también en los contenidos, por todo ello es el CAD la herramienta «fundamental» de Ingeniería Gráfica.

Otros (Marín Granados, Gutiérrez Ariza, García Ceballos, Mora Segado) proponen un modelo de docencia en la que se combina la lección magistral, la tutorización y un sistema de enseñanza asistida por ordenador para las asignaturas de ingeniería gráfica. La solución para aumentar la eficacia de la docencia, entendida como mayor cantidad de conocimiento impartido en menos tiempo, está, para un grupo de profesores (Mateo Carballo, Llorente Geniz, Sánchez Jiménez, Reina Valle, Fernán- 
dez de la Puente), en la animación asistida por ordenador, aunque destacando que este medio didáctico no puede utilizarse como único, ni de forma independiente al resto.

Entre los problemas históricos arrastrados de forma periódica en la docencia de la ingeniería gráfica (Díaz Blanco, Fernández Villegas, López Vázquez, Souto López), se destaca la perversa combinación de reducción de las horas de docencia, con el bajo nivel de conocimientos previos y básicos con que los estudiantes ingresan en la un universidad.

Hay autores (Martín Gutiérrez, Martín Dorta, Saorín Pérez, Acosta González) que identifican tres factores de cambio docente: el nuevo modelo educativo diseñado por el Espacio Europeo de Educación Superior, la exigencia social de incorporación de las nuevas Tecnologías de la Información y Comunicación a la universidad, y la necesidad de mejorar la calidad universitaria.

\subsection{Docencia semipresencial}

Para algunos autores (Rajadell, Astals) los estudios de carácter semipresencial se justifican en base a tres grandes ventajas: 1- completar la oferta de estudios presenciales, 2- ampliar el ámbito geográfico de los campus, y 3-permitir la compatibilidad de los estudios con las responsabilidades laborales. Para otros (Jiménez, Fernández, Pérez, Leo, Navarro, Arraiza, Barrera, Lozano) su principal ventaja reside en que permite una introducción progresiva a la impartición a distancia. Para estos últimos la semipresencialidad es sólo un paso intermedio. En esta línea se manifiestan algunos profesores (Griful, Gibert) que exponen que el cambio del modelo docente de presencial a semipresencial, no tiene más motivación que la mejora de la calidad docente. También se destaca como elemento ventajoso (Lapaz, Voltas) que la semipresencialidad permite flexibilizar e individualizar el aprendizaje de los alumnos.

Para la casi totalidad de los autores, el éxito de la docencia semipresencial radica en conseguir que los estudiantes saquen el máximo provecho de las herramientas dispuestas para su aprendizaje, basándolo en un uso intensivo de les TIC. La utilización de Entornos Virtuales de Aprendizaje (EVA) en modalidad semipresencial (Alpiste, Brigos, Fernández) se perfila como una estrategia de grandes posibilidades en la incorporación de las TIC, sobre todo en los estudios técnicos. Las herramientas que incorporan estos EVA permiten favorecer una metodología 
de aprendizaje basada en proyectos, en trabajo en grupo y en el asesoramiento personalizado (ver Ilustración 25).

Los estudios semipresenciales presentados siguen siempre el mismo Plan de Estudios que los presenciales, pero generalmente con una diferente distribución de las asignaturas entre obligatoria, optativas y libre elección, y alargando la carga crediticia en más semestres o cursos (ver Ilustración 26).

Se considera (Alpiste) de vital importancia en entornos semipresenciales de aprendizaje (más incluso que en los meramente presenciales) la existencia de métodos empíricos para evaluar la satisfacción del estudiante.

\subsection{Informatización de la docencia}

En experiencias presentadas en los congresos (García Almirall) se destaca que la informatización completa de una asignatura tipo de Ingeniería gráfica supone la

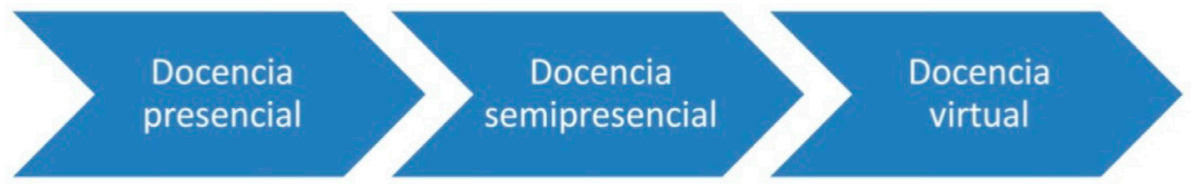

Ilustración 25. Evolución docencia.

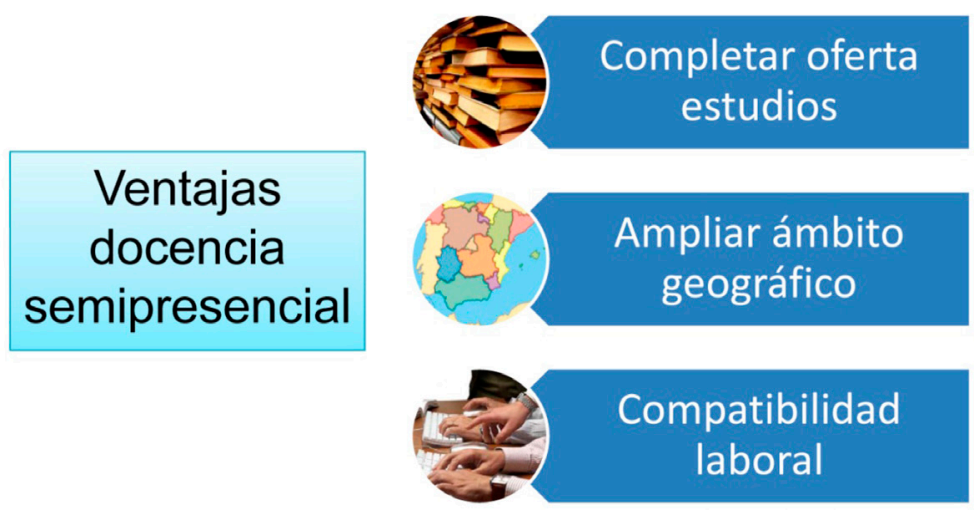

Ilustración 26. Ventajas docencia semipresencial. 
realización de profundos cambios en dos ámbitos diferentes: en la estricta docencia, pero también en la organización de la asignatura (ver Ilustración 27).

En un primer momento los ejercicios son los mismos, pero han cambiado de formato: del papel al documento electrónico. Este primer paso supone mejoras docentes puesto que permite una optimización de los siempre menguantes recursos de espacio-tiempo. Pero la verdadera revolución viene después, cuando los ejercicios se modifican y se adaptan a las nuevas posibilidades gráficas. La informatización de la docencia (Gómez Galán) permite implantar un nuevo paradigma idóneo para la educación, potenciando la capacidad de aprendizaje del usuario y estableciendo un diseño apoyado en las teorías del constructivismo. Para que ello sea productivo hay que evitar anteponer el atractivo estético de las nuevas herramientas a las condiciones de interactividad.

Pero siempre (Medeiros Filho, Cintra) destacando que los ordenadores son sólo un vehículo que permiten expresar con calidad las tareas docentes (antiguas o nuevas). La esencia de la relación pedagógica no cambia con la utilización de la tecnología, a pesar de que ahora es necesaria en nuestro contexto para el correcto proceso de enseñanza.

Otros profesores (Tardio Monreal, Fernández Sora, Agustín Hernández, SánchezLafuente Lahulla) destacan, además, que la informatización docente permite una mejora en la gestión y el control académico en la asignatura, mediante aplicaciones informáticas se puede conseguir automatizar las tareas de gestión y control, no para liberar al docente del seguimiento de la evolución académica de los alumnos, sino para mejorar esta labor haciéndola mucho más rápida y eficaz.

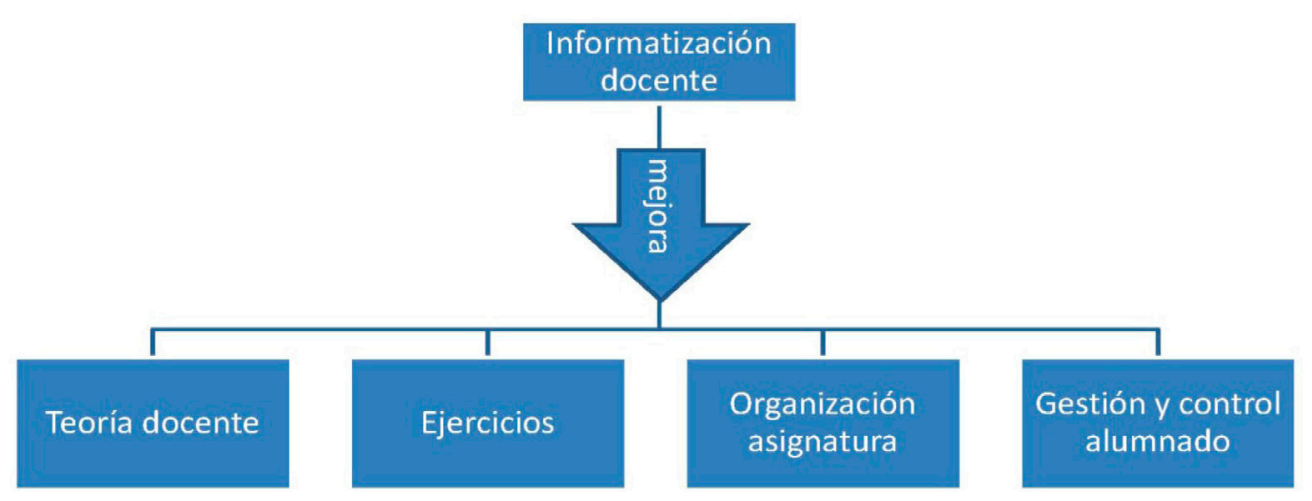

Ilustración 27. Informatización docente. 


\subsection{Evaluación continuada}

Para ciertos autores (Rajadell, Astals) el éxito académico de los estudiantes está directamente relacionado con el ritmo de estudio y trabajo continuado, razón por la cual proponen un sistema de evaluación continuada, como método para forzar a los estudiantes a este esfuerzo continuado. Para llegar a esta evaluación se dispone de un gran aliado (Bermúdez, Lapaz, Marqués, Povill, Morón, Voltas): las TIC aplicadas a la docencia permiten disponer de una importante cantidad de material de los alumnos, clasificado según entradas, autocorregido, etc, de manera que existe la posibilidad de obtener una puntuación de casi cada práctica y ejercicio, y la facilidad de manejar toda esta ingente cantidad de información de manera ágil y ordenada. También se destaca la necesidad de un procesado rápido de esta evaluación, para que el alumno tenga un retorno de su trabajo, e incremente la motivación por el estudio (ver llustración 28).

La evaluación continuada aparece repetidas veces ligada al éxito de las enseñanzas semipresenciales, como un aliado indispensable para evitar abandonos prematuros de estudiantes (Griful, Gibert)

La evolución continuada es motivo de diferentes ponencias desde los años 90, pero sólo empieza a aparecer como uno de los ejes de estudio propios de los congresos a partir de 2004.

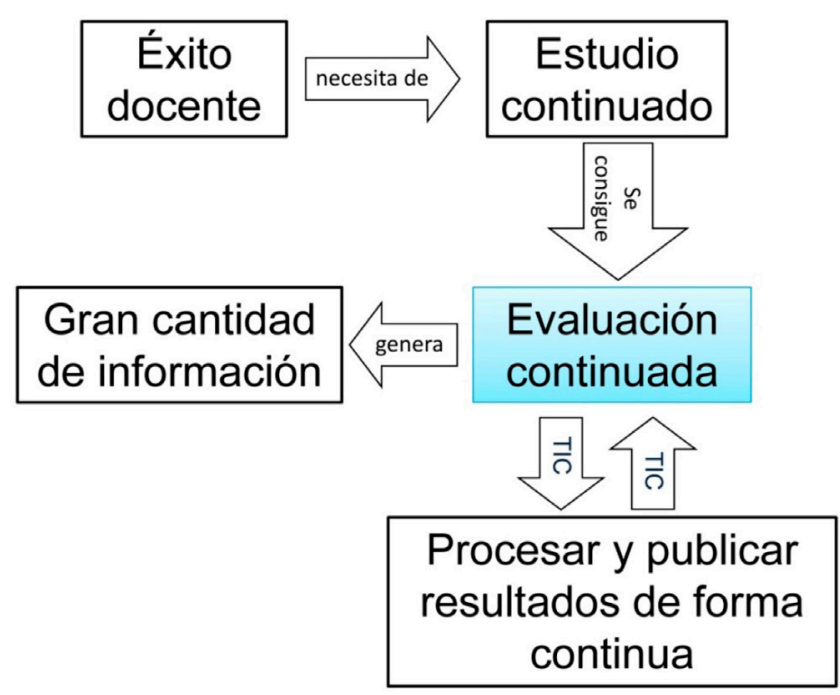

Ilustración 28. Evaluación Continuada. 


\subsection{Planes de estudio}

Desde inicio de los años 90, se incurre en un continuo recorte de horas lectivas en el área de la Ingeniería Gráfica en los nuevos planes de estudios (Bermúdez Rodríguez, Lapaz Castillo, Marqués Calvo, Povill Cartoixà, Morón Tarifa, Voltas i Aguilar) que acarrea preparar otro tipo de material docente tendente a economizar tiempo de aprendizaje por un lado, y a permitir su utilización fuera del aula y a cualquier hora por otro. Se afirma que para mantener la calidad docente y cumplir con las dedicaciones fijadas en los planes de estudio, es imprescindible implementar las TIC en las tareas docentes (ver llustración 29).

Con los planes de estudio ya reformados, y sobre todo a partir de 1993, se comprueba que se han introducido nuevas pautas en cuanto a los modos y métodos didácticos apoyándose en las TIC, y se destaca que la labor del profesor universitario no sólo es la de transmisor de conocimientos, sino también la de soporte en el proceso de aprendizaje. Los planes reformados suponen la transición desde un modelo basado principalmente en la enseñanza en el cual la función del estudiante era básicamente pasiva y la del profesor era la de transmisor de conocimiento a un modelo basado esencialmente en el aprendizaje, donde el estudiante es mucho más activo y el profesor es el guía en el proceso de aprendizaje.

Los nuevos planes de estudios de los años 90 suponen una drástica reducción de los créditos (entre $50 \%-30 \%$ de los créditos del plan antiguo según Voltas, Lapaz) en el área de la Ingeniería Gráfica, provocando para algún autor (Moreno Cazorla), la amortización de conceptos historicistas del dibujo (materiales en desuso, técnicas complejas sin apenas aplicación práctica, sistemas de representación muy laboriosos) e incrementando por el contrario otros conceptos
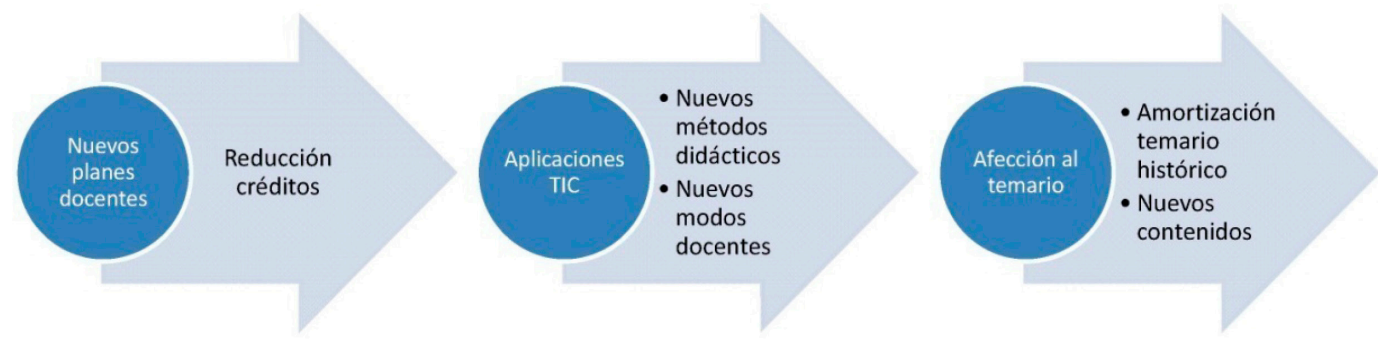

Ilustración 29. Planes de estudio. 
que en antiguos planes no tenían cabida (textura, color luminosidad) y ahora necesitan ser estudiados. Para los autores de esta opinión, la evolución de los planes de estudio suponen cambios de herramientas, y las nuevas herramientas informáticas no sólo plantean un cambio en la forma de aplicar la docencia sino también en los contenidos.

Para determinar los nuevos conocimientos que tienen que implementarse en los nuevos planes de estudios, hay autores (Grión) que proponen tener en cuenta las modificaciones que la informática ha producido en todas las disciplinas del conocimiento y en su enseñanza. Se destaca lo particularmente difícil en el caso de la geometría descriptiva dado que ha permanecido inalterada desde hace décadas. Se plantea proporcionar al alumno sólo aquellos conceptos geométricos que permanecerán invariables en el futuro aprovechando las técnicas actuales, pero sin extenderse en exceso en la docencia de unos conceptos que pueden quedar obsoletos en muy poco tiempo. La autora se arriesga a afirmar que algunos contenidos que se imparten pueden ser eliminados, pues los aportes de los programas informáticos resultan decisivos y apuntan a una reorganización de los contenidos tradicionales. La evolución de los planes de estudio significa la eliminación de las cuestiones que han quedado obsoletas para la práctica profesional, para dejar espacio a las nuevas temáticas.

Hacia 2003-2004 se produce una nueva reducción de créditos y una aproximación a la unificación de titulaciones en el ámbito español y europeo. Los planteamientos docentes para crear estos nuevos planes de estudio concretan, a juicio de ciertos profesores (Sentana Gadea, Sentana Cremades, Serrano Cardona, Tomás Jover, Pigem Boza, Gomez Gabaldón, Perez Carrion, Diaz Ivorra, Ferreiro Prieto, Poveda Pérez, Martinez Sentana), como objetivos generales establecer criterios sobre conocimientos mínimos comunes de geometría básica, proponer líneas de trabajo de comunes partiendo de las nuevas tecnologías y presentar una metodología para elaborar contenidos.

Hacia 2007, con la aprobación de los nuevos planes, hay autores (Font Andreu, F. Hernández Abad, Ochoa Vives, V. Hernández Abad) que destacan que los objetivos del área han conservado sus grandes líneas históricas de facilitar el desarrollo de la visión espacial, el razonamiento, y la creatividad, gracias al uso de programas informáticos de diseño asistido por ordenador que han permitido mantener los objetivos a pesar de la reducción del encargo docente en forma de horas de clase (tanto teóricas como prácticas). La reducción de créditos troncales ha estado 
compensada por un aumento de las asignaturas optativas que han permitido un trabajo mucho más eficiente.

En 2008 se destaca la aparición de Agencia Nacional de Evaluación de la Calidad y Acreditación como organismo de control de la calidad en el diseño de los planes de estudio. 
CApítulo 6

\section{Contenidos teóricos}





\subsection{Geometría Descriptiva}

La máxima del catedrático Javier Rodríguez de Abajo: "La geometría Descriptiva no hay que considerarla complicada, sino que hay que hacerla comprensiva y sencilla para nuestros alumnos» es repetida más de una vez entre los ponentes.

Hay unanimidad en la mayoría de los autores en cuanto a que la geometría descriptiva es el área de la Ingeniería Gráfica que más fuertemente ha recibido el impacto de la utilización del CAD, hasta el punto, para algunos autores, de poner en crisis la eficacia de los sistemas de representación clásicos. También hay unanimidad en que eso no implica que la geometría descriptiva este condenada a desaparecer de nuestras aulas, aunque para un reducido grupo de profesores (Grión,...) algunos temas que se imparten pueden ser eliminados, gracias a los aportes de los programas informáticos que apuntan a una reorganización de los contenidos tradicionales, eliminando las cuestiones que han quedado obsoletas para la práctica profesional.

Este fuerte impacto puede ser visto desde un punto de vista positivo o negativo, generando posturas encontradas, aunque siempre coincidentes en reconocer al ordenador como una herramienta capaz de facilitar el aprendizaje. Hay autores (Bustinza Esparta, Fernández Villegas) que afirman que la utilización de sistemas telemáticos en la docencia de la geometría descriptiva permite reducir el número de horas dedicadas a la exposición teórica de la materia, de forma que el profesor puede tener una mayor dedicación a las clases prácticas, como de un sistema personalizado de aprendizaje se tratara, mejorando los resultados académicos.

Otros autores (Martín, Saorín, Contero, Navarro) alegan que las herramientas CAD no pueden sustituir los conocimientos de geometría descriptiva. Para ellos, las di- 


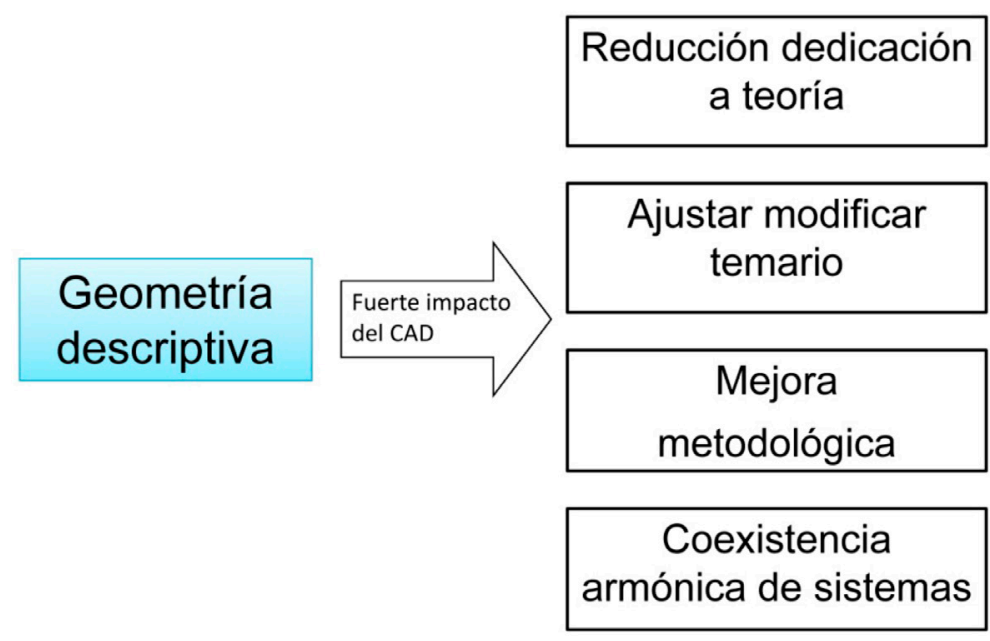

Ilustración 30. Geometría descriptiva.

ferencias entre las diferentes metodologías de aprendizaje son mínimas en cuanto a adquisición de las capacidades de visión espacial, aunque se reconoce que por parte del alumnado hay preferencia por las metodologías basadas en nuevas tecnologías.

Existe un tercer grupo de profesores (Villar Ribera, Hernández Abad) que son partidarios de una coexistencia armónica de sistemas, puesto que si bien determinados problemas pueden ser resueltos mediante la utilización de las prestaciones de los programas de CAD, para otros es necesario utilizar los conceptos clásicos de la geometría descriptiva.

Para el profesor Vicario los principios básicos que deben regir la enseñanza de la geometría descriptiva actual son: 1- explicar los fundamentos de los sistemas de representación tradicionales, pero utilizando programas de CAD. 2- evitar el uso de herramientas sofisticadas y específicas de CAD. 3- secuenciar los contenidos del mismo modo que en los sistemas de representación tradicionales.

\subsection{Normalización industrial}

En general, la normalización industrial se considera uno de los objetivos inherente a cualquier asignatura de Ingeniería Gráfica (Rojas Sola, Jordá Albiñana, San Antonio Gómez, Manzano Agugliaro). Para el conjunto de los docentes de nuestra área 
de conocimiento es necesario dominar las normas y criterios de la normalización industrial aplicada al Dibujo Técnico.

De esta idea generalmente aceptada existe un grupo de autores (Martínez Sentana, Sentana Gadea) que cree recomendable un conocimiento profundo de toda la normalización, destacando que con la ayuda de las bibliotecas existentes de elementos normalizados para CAD, se facilita la enseñanza de componentes mecánicos. Para estos profesores (Lapaz Castillo, Voltas Aguilar) a pesar de la relativa buena posición actual del área, se presentan nuevos retos para consolidar y ampliar la participación en las diferentes especialidades y grados, y para ello es necesaria una complementación de los temas tradicionales de ingeniería gráfica impartidos con contenidos del área de normalización industrial.

En 2008 surge la propuesta (Sentana Gadea, Sentana Cremades, Gutiérrez Diego, Poveda Pérez) de crear un grado común de ingeniería gráfica para todas las ingenierías cuyos conocimientos básicos para este curso genérico serían: conocimientos mínimos de geometría métrica, conocimientos básicos de sistema diédrico, normalización de dibujo industrial y fundamentos de perspectivas axonométricas.

\subsection{Multimedia}

Existe unanimidad en destacar que el uso de sistemas multimedia constituye una buena herramienta de enseñanza, aunque diferencia entre autores en destacar el grado mejora que estos sistemas suponen. Para algunos profesores (Ramos Barbero, García Maté, Caro Rodríguez) utilizar tecnología multimedia tiene que ser un recurso didáctico que sirva, por un lado a los profesores como herramienta de apoyo a la docencia en clase, y por otro a los alumnos como herramienta de aprendizaje. En su opinión todos los multimedia creados deben tener una estructura abierta. En este mismo sentido (Merino Egea) la finalidad de la enseñanza multimedia es optimizar el tiempo de formación disponible, de forma que una información multimedia previa a la actividad clásica presencial de los profesores, puede estimular, motivar y favorecer el aprendizaje de los alumnos. Para estos autores la misión de los sistemas multimedia no es sustituir la actividad del profesor ni a los libros como principal medio de estudio, sino complementarla. Para otros (Oriozabala Brit, Garmedia Mujika, Galarraga Astibia, Albisua) la utilización de sistemas multimedia permite reducir el número de horas dedicadas a la exposición teórica de la materia, y al docente volcarse en una mayor dedicación a las clases prácticas y a la atención personalizada al alumno. 
Se destaca (Gazo Cervero, González-Sánchez, García Rodríguez, Sánchez Figueroa) que en la elaboración de material docente multimedia existen dos partes claramente diferenciadas: una para el control y gestión de datos, y otra para las funciones de presentación, de forma que el diseñador puede modificar la apariencia gráfica del entorno sin interferir en las funciones de control y gestión de datos.

En diferentes encuestas llevadas a cabo (Álvarez Peñín, Charro Hernández, García Díaz, Suarez Quirós) se recalca que más del 90 \% de los profesores creen interesante el uso de sistemas multimedia en el aula (independientemente de la edad de los docentes), a pesar que a la hora de organizar la asignatura ideal no se contemple el uso de estos sistemas. Quizá sea porque (Carrera, Alpiste, Massana, Fernández, Monguet) este tipo de asignaturas requieren de ingentes cantidades de trabajo repartidos aproximadamente en dos terceras partes para la generación del contenido y una tercera parte para la propia producción multimedia. Según estudios presentados, la dedicación del profesorado para preparar estos sistemas suele ser de 2 a 3,5 horas por alumno matriculado, por ello este esfuerzo sólo se puede rentabilizar si la asignatura es seguida por un número mínimo de estudiantes.

Los contenidos multimedia y la participación multiusuario en tiempo real, permiten presentar de forma mucho más afable la docencia de la ingeniería gráfica (Contero González, Vergara Monedero). En este sentido (Alvarez Peñín, López Brugos, García Díaz, Suárez Quirós) es importante utilizar técnicas multimedia para conseguir un aprendizaje más ameno y eficaz, sobre todo combinado con la Enseñanza Asistida por Ordenador.

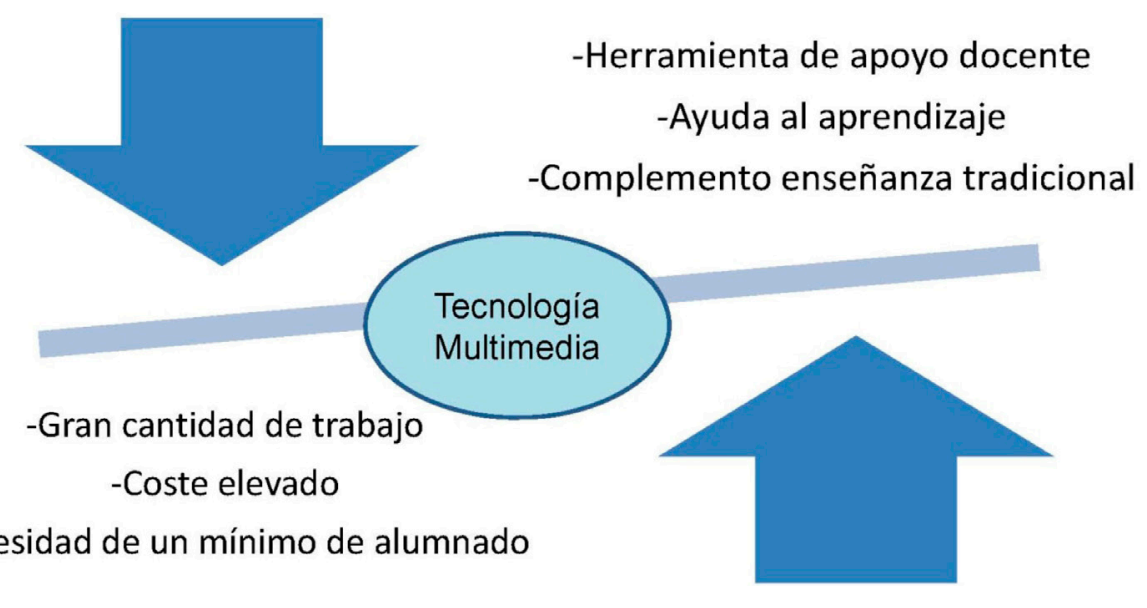

Ilustración 31. Pros y contras tecnología multimedia. 
Existen docentes (Marín Granados, Gutiérrez Ariza, García Ceballos, Mora Segado) que destacan que la incorporación de nuevos medios tecnológicos multimedia soluciona determinados problemas históricos de nuestra área de conocimiento, pero crea otros hasta ese momento desconocidos: por un lado la necesidad de gran cantidad de aulas informatizadas con sus correspondientes medios multimedia y el encarecimiento de las infraestructuras que eso supone, y por otro, cierta resistencia al cambio constante y vertiginoso que obliga al docente a un proceso de reciclaje continuo. Como solución proponen una combinación de diferentes métodos docentes.

El número de aprobados y presentados en las asignaturas del área de Ingeniería Gráfica esta apreciablemente por debajo de otras asignaturas de la universidad, y en general este hecho es atribuido a la dificultad intrínseca de la materia, a la preparación previa de los alumnos, y, sobre todo, a las dificultades didácticas de la enseñanza tradicional (mediante apuntes y pizarra). Por ello (Blanco Caballero, Martín Panero, Prádanos Del Pico, Rodríguez Ovejero, Sanz Arranz, Parra Gonzalo, San Martín Ojeda, Serrano Sanz) se propone el apoyo en sistemas multimedia para mejorar el aprendizaje de las asignaturas de ingeniería gráfica en general y en particular del sistema diédrico.

Hay autores (Villar, Hernández Abad) partidarios de una coexistencia armónica de sistemas, que proponen métodos de visualización multimedia que ofrezcan facilidad para una más rápida y mejor comprensión, tanto de la metodología como de los conceptos expuestos, destacando que la profunda base conceptual del diédrico no ha perdido vigencia. Si bien determinados problemas pueden ser resueltos mediante la utilización de las prestaciones de los programas de $C A D$, para otros tenemos la necesidad de utilizar los conceptos de la Geometría Descriptiva.

\subsection{Lenguaje de Modelado de Realidad Virtual (VRML)}

Para algunos autores (Pellejero Salaberria, Mongelos Oquiñena, Gurruchaga Vázquez, Galarraga Astibia, Garmendia Mujika, Oriozabala Brit) el lenguaje de modelado de realidad virtual ha de servir para apoyar la palabra del profesor en cualquier tipo de proceso. Este tipo de tecnologías se pueden utilizar como mejora y complemento a la formación tradicional en las universidades en general, y en el área de Ingeniería Gráfica en particular (Martín Lorenzo, Suárez Rivero, García Domínguez), combinando las ventajas y minimizados los defectos en el uso de VRLM 
a partir de tres métodos identificados: 1-Editor de texto, 2-Entornos desarrollo VRML, 3-Modelador 3D y traductor de formato.

A finales de los años 90 (Contero González, Vergara Monedero) esta tecnología es asequible técnica y económicamente para hacer más afable la docencia de la Ingeniería Gráfica. Una de las aplicaciones educativas destacadas es el campo de la simulación con su correspondiente ahorro de costes y mejoras de las expectativas docentes, pero para alcanzar un aprendizaje significativo, el marco pedagógico en el que debe apoyarse la VRML son las teorías del constructivismo (Gómez Galán).

Las habilidades espaciales (Martín J, Martín N, Saorín, Contero, Navarro) pueden mejorar mediante un entrenamiento específico basado en modelados de realidad virtual. 
CAPítulo 7

El ordenador en los procesos 



\subsection{Animación por ordenador}

Existe consenso entre varios autores (Gutiérrez de Ravé Agüera, Mármol Benavente; Fernández Pozuelo, Montero Albiol, Hidalgo Fernández) en afirmar que la animación por ordenador facilita la docencia en la Ingeniería Gráfica, toda vez que mejora la calidad docente.

La búsqueda de nuevos métodos docentes lleva a los profesores (Mateo Carballo, Llorente Geniz, Sánchez Jiménez, Reina Valle, Fernández de la Puente) a proponer el uso de la animación asistida por ordenador y las utilidades multimedia, combinándolas para generar tutoriales que ayuden al alumno a la comprensión de los métodos de generación de modelos tridimensionales, y la obtención de los mismos por pasos. Se destaca (Blanco Caballero, Martín Panero, Prádanos Del Pico, Rodríguez Ovejero, Sanz Arranz, Parra Gonzalo, San Martín Ojeda, Serrano Sanz) que la animación interactiva dota la posibilidad de responder a las elecciones del estudiante, dándole el control sobre la animación de forma que es mucho más eficaz.

\subsection{Enseñanza Asistida por Ordenador (EAO)}

Entre los autores que estudian la EAO (Alvarez Peñín, López Brugos, García Díaz, Suárez Quirós) se llega a la conclusión que realizar un programa de EAO es complicado, laborioso y precisa de suficiente tiempo para su éxito. Se destaca la necesidad de la participación de un potente equipo de trabajo.

Entre los profesores se afirma que la importancia de la EAO radica en que potencia la figura del profesor, posibilitando que dedique más tiempo a las labores más críti- 
cas de la enseñanza. Para una asignatura tipo de Ingeniería Gráfica aplicando EAO se propone: realización manual de dibujos por parte del alumno; explicaciones teóricas dirigidas por el profesor; realización de ejercicios optimizando el resultado con EAO; imprescindible interactividad (permitir corregir dibujos realizados por el alumno, evaluar los resultados y presentarlos de forma inmediata); enseñanza es individualizada (garantía que todos los alumnos alcanzan el nivel de conocimientos establecido); utilizar técnicas multimedia para conseguir un producto ameno.

En general (Oriozabala Brit, Garmedia Mujika, Galarraga Astibia, Albisua) la EAO se aprecia como un campo importante de mejora en la calidad de la enseñanza en el área de la Ingeniería Gráfica, e incluso para otros (Marín Granados, Gutiérrez Ariza, García Ceballos, Mora Segado) que como un eficaz recurso en el proceso enseñanza aprendizaje. 
CAPítulo 8

\section{Evaluación por competencias}



En el pasado, el sistema de educación superior se centraba en la impartición de conocimientos desde el punto de vista exclusivamente académico. La nueva propuesta basada en el EEES se aparta del conocimiento por el conocimiento y toma como pieza central del proceso al alumno. Aunque los conocimientos siguen siendo imprescindibles, se tiene que tener en cuenta no sólo el aprendizaje de contenidos, sino también, las capacidades y destrezas que el alumnado trabajará paralelamente: "Al nuevo profesional, la sociedad no sólo le reclamará unos conocimientos, sino que deberá ser competente según el perfil que habrá adquirido, fruto de haber cursado una titulación universitaria específica» ${ }^{116}$. El nuevo paradigma plantea un alcance mucho más amplio de lo que hasta ahora era la formación superior: el alumnado tiene que continuar aprendiendo todo lo que aprendía, pero además tiene que trabajar las competencias que se espera que adquiera al finalizar los estudios. "Si hasta ahora se transmitian conocimientos y se evaluaba el grado de consecución del aprendizaje de estos contenidos, en el nuevo paradigma educativo también se debe explicitar la formación de la asimilación de las competencias esperadas y, en consecuencia, también se debe evaluar el grado de consecución».

Pero, ¿qué se entiende por competencia? En 2006, el MEC (Ministerio de Educación y Ciencia) define: "las competencias se conciben como un conjunto de conocimientos, habilidades (....) aptitudes y valores que capacitarán a un titulado para afrontar la resolución de problemas o la intervención en un contexto académico, profesional o social».

\footnotetext{
${ }^{116}$ Guía para la evaluación de las competencias en el área de Ingeniería y Arquitectura. Elisabet Golobardes Ribé y otros (URL). AQU. Junio 2009. B-27.204-2009. pág. 7.
} 


\subsection{Estudios sobre competencias en Ingeniería}

La incitativa CDIO Syllabus (Conceive Design Implement and Operate) desarrollada por profesores, empresarios, ingenieros y alumnos del MIT pretende impulsar una nueva forma de enseñar ligada a los fundamentos de la ingeniería de acuerdo con: los Conceptos, el Diseño, la Aplicación y el Funcionamiento. El procedimiento se plantea en tres etapas. Primero se estructura una lista de ítems. Segundo se estudia como convertir estos ítems en necesidades estudiando los niveles de competencia requeridos. Finalmente se vuelven a formular los objetivos de aprendizaje usando los términos de la taxonomía de Bloom.

Según la $\mathrm{QAA}^{117}$ (Agencia calidad del sistema universitario del Reino Unido) las competencias genéricas de un graduado en ingeniería industrial deben ser:

1. Conocer y entender conceptos, teorías y principios del ámbito industrial, apreciando el impacto social y comercial de sus decisiones.

2. Habilidades intelectuales para poder sintetizar soluciones y construir una visión global de la situación.

3. Habilidades prácticas en la realización de trabajos en laboratorios.

4. Competencias generales transversales.

En el estudio realizado en 2008 por Ariadna Llorens y la ACET ${ }^{118}$ entre las empresas que buscan ingenieros para contratar, planteaba analizar las competencias más requeridas por orden de importancia, las competencias que las empresas encontraban a faltar en los alumnos recién licenciados, y por contra las que si encontraban en estos alumnos. Proponía conocer si las empresas que buscan un ingeniero encuentran los titulados adecuados y si estos responden a sus intereses (ver llustración 32).

\subsection{Discusión teórica sobre competencias}

Para Jiménez (2005) orientar el proceso de enseñanza-aprendizaje hacia la adquisición de competencias, abre un marco de trabajo sobre el que se pueden revisar los contenidos para ajustarlos a la demanda.

\footnotetext{
117 http://www.qaa.ac.uk/

$118 \mathrm{http}: / /$ www.telecos.cat/
} 


\begin{tabular}{|c|c|c|}
\hline $\begin{array}{l}\text { Competencias más } \\
\text { requeridas }\end{array}$ & $\begin{array}{c}\text { Competencias que no } \\
\text { tienen los ingenieros } \\
\text { egresados }\end{array}$ & $\begin{array}{c}\text { Competencias que si } \\
\text { tienen los ingenieros } \\
\text { egresados }\end{array}$ \\
\hline $\begin{array}{l}\text { Capacidad para trabajar } \\
\text { en equipo }\end{array}$ & Capacidad de negociación & $\begin{array}{l}\text { Capacidad de búsqueda } \\
\text { de información }\end{array}$ \\
\hline $\begin{array}{l}\text { Compromiso para } \\
\text { aprender }\end{array}$ & $\begin{array}{l}\text { Capacidad de } \\
\text { comunicación }\end{array}$ & $\begin{array}{l}\text { Compromiso para } \\
\text { aprender }\end{array}$ \\
\hline Orientación al cliente & liderazgo & Pensamiento analítico \\
\hline Resolución & Orientación al cliente & $\begin{array}{l}\text { Capacidad para trabajar } \\
\text { en equipo }\end{array}$ \\
\hline Innovación & $\begin{array}{l}\text { Compromiso con la } \\
\text { empresa }\end{array}$ & \\
\hline $\begin{array}{l}\text { Compromiso con la } \\
\text { empresa }\end{array}$ & & \\
\hline
\end{tabular}

Ilustración 32. Competencias en la empresa (Llorens, ACET).

Se destacan tres ideas básicas que se creen necesarias en la implementación del aprendizaje por competencias:

1. Es importante el correcto diseño de las estrategias docentes para el óptimo desarrollo de las competencias que el estudiante ha de adquirir.

2. Es ineludible mejorar la coherencia entre objetivos de aprendizaje y los procesos de evaluación.

3. Es inexcusable la utilización de las nuevas metodologías docentes para formar en competencias.

Para Camiña y Ballester (2008) la evaluación de competencias, debe llevarse a cabo bajo una doble dimensión: formativa y de acreditación. La evaluación constituye un mecanismo necesario para confirmar que los estudiantes poseen las competencias precisas para el correcto ejercicio profesional. Formulan un conjunto de propuestas de mejora en la evaluación que posibilite el tránsito hacia una eficaz evaluación de competencias. 
Según exponen Fadón, Cerón y Vallejo ${ }^{119}$ (2009) el profesorado ha de replantear aspectos docentes de la asignatura que imparte, proceso que supone: 1-organizar la docencia para lograr ciertas competencias tras haber superado la asignatura, 2- una nueva evaluación de acuerdo a las competencias asociadas a la asignatura. Para ello proponen estructurar las actividades relacionadas con la asignatura en cuatro partes: "clases magistrales, clases tutorizadas, actividades autónomas y actividades Independientes". De su experiencia en la Universidad de Cantabria estos autores concluyen que "la implantación de mejoras en el proceso de evaluación, de trabajos individuales y actuaciones grupales, ha contribuido a que se mejore notablemente la relación de alumnos que se presentan y que finalmente aprueban la asignatura» aunque destacan el mayor esfuerzo del equipo docente para poder llegar a estos resultados.

\subsection{Competencias transversales en Ingeniería Gráfica}

De lo analizado, podemos conformar el siguiente cuadro de competencias transversales de la Ingeniería Gráfica a criterio de los profesores Ortega (2008), Rojas (2009) y García- García (2009) (ver Ilustración 33).

\footnotetext{
119 «Programación basada en competencias. Implantación en ingeniería gráfica. Fadón Salazar, Fernando; Cerón Hoyos, José Enrique; Vallejo Lobete, Esther. DYNA Ingeniería e Industria. Año 84. № 2. Marzo 2009. ISSN 0012-7361.
} 


\begin{tabular}{|c|c|c|}
\hline Ortega (2008) & Rojas (2009) & García-García (2009) \\
\hline $\begin{array}{l}\text { Aplicar con habilidad y destreza los } \\
\text { programas de DAO }\end{array}$ & $\begin{array}{l}\text { Conocimientos } \\
\text { básicos de la } \\
\text { profesión }\end{array}$ & $\begin{array}{l}\text { Dominar técnicas necesarias } \\
\text { para desarrollar el } \\
\text { razonamiento gráfico }\end{array}$ \\
\hline $\begin{array}{l}\text { Aplicar la capacidad espacial a la } \\
\text { resolución de problemas técnicos }\end{array}$ & $\begin{array}{l}\text { Capacidad } \\
\text { de análisis y } \\
\text { síntesis }\end{array}$ & $\begin{array}{l}\text { Leer o interpretar un plano, } \\
\text { gráfico o esquema de } \\
\text { ingeniería }\end{array}$ \\
\hline $\begin{array}{l}\text { Capacidad de realización } \\
\text { e interpretación de planos } \\
\text { normalizados del Dibujo de } \\
\text { Ingeniería Industrial }\end{array}$ & $\begin{array}{l}\text { Resolución de } \\
\text { problemas }\end{array}$ & $\begin{array}{l}\text { Dominar técnicas DAO que } \\
\text { permitan elaborar planos } \\
\text { gráficos o esquemas en el } \\
\text { ámbito de la ingeniería }\end{array}$ \\
\hline $\begin{array}{l}\text { Aplicar las habilidades de } \\
\text { investigación y creatividad al } \\
\text { diseño industrial }\end{array}$ & $\begin{array}{l}\text { Preocupación } \\
\text { por la calidad }\end{array}$ & $\begin{array}{l}\text { Ser capaz de resolver } \\
\text { problemas técnicos de } \\
\text { ingeniería de forma } \\
\text { eminentemente gráfica }\end{array}$ \\
\hline $\begin{array}{l}\text { Explorar fuentes de información, } \\
\text { exponiendo y justificando los } \\
\text { aspectos relacionados con la } \\
\text { realización de documentos gráficos }\end{array}$ & $\begin{array}{l}\text { Capacidad } \\
\text { de aplicar los } \\
\text { conocimientos } \\
\text { en la práctica }\end{array}$ & $\begin{array}{l}\text { Realizar e interpretar } \\
\text { información en modo gráfico, } \\
\text { posibilitando la comunicación } \\
\text { entre técnicos }\end{array}$ \\
\hline $\begin{array}{l}\text { Capacidad para trabajar en equipo } \\
\text { que facilite el desarrollo de los } \\
\text { conocimientos con un intercambio } \\
\text { cultural crítico y responsable }\end{array}$ & $\begin{array}{l}\text { Capacidad } \\
\text { de crítica y } \\
\text { autocrítica }\end{array}$ & $\begin{array}{l}\text { Incorporar nuevas tecnologías } \\
\text { y herramientas de la } \\
\text { ingeniería industrial en sus } \\
\text { actividades profesionales }\end{array}$ \\
\hline \multirow[t]{4}{*}{$\begin{array}{l}\text { Adoptar actitudes favorables hacia } \\
\text { el aprendizaje en la profesión, } \\
\text { mostrándose proactivo y con } \\
\text { espíritu de superación }\end{array}$} & $\begin{array}{l}\text { Trabajo en } \\
\text { equipo }\end{array}$ & $\begin{array}{l}\text { Demostrar visión espacial y } \\
\text { capacidad para utilizar las } \\
\text { técnicas de representación } \\
\text { gráfica }\end{array}$ \\
\hline & Liderazgo & $\begin{array}{l}\text { Levantamiento de planos para } \\
\text { la realización de proyectos }\end{array}$ \\
\hline & $\begin{array}{l}\text { Desarrollo de } \\
\text { habilidades de } \\
\text { gestión de la } \\
\text { información }\end{array}$ & $\begin{array}{l}\text { Capacidad de interpretación y } \\
\text { representación de planos para } \\
\text { proyectos de ingeniería }\end{array}$ \\
\hline & $\begin{array}{l}\text { Toma de } \\
\text { decisiones }\end{array}$ & \\
\hline
\end{tabular}

Ilustración 33. Competencias IG (Ortega, Rojas, García-García). 

CAPítulo 9

\section{Conclusiones}





\section{1. Ámbito docente}

El área de conocimiento de la Ingeniería Gráfica se encuentra integrada en departamentos diversos, y en pocas ocasiones dispone de un departamento propio, lo que implica que convive con materias e intereses heterogéneos que dificultan su desarrollo.

Cada implantación de nuevos planes de estudio ha supuesto una reducción de los créditos docentes, tanto en horas de exposición docente como en prácticas y laboratorio. Los objetivos docentes del área de Ingeniería Gráfica están evolucionando lentamente desde los objetivos históricos (facilitar el desarrollo de la visión espacial, la facilidad para el desarrollo de dibujos industriales) hacia la adquisición de competencias de acuerdo con el nuevo marco del EEES.

Se constata que se ha reducido el tiempo de exposición teórica relativa a sistemas de representación y métodos de trazado bidimensional a favor de un aumento del tiempo dedicado a las prácticas con herramientas digitales desde la introducción del Diseño Asistido por Ordenador.

A pesar del uso de los sistemas CAD y de las TIC para almacenamiento y transferencia de la información, sigue siendo necesaria la representación diédrica en formato bidimensional para la presentación y construcción de proyectos. La yuxtaposición en la aparición de los sistemas de Diseño Asistido por Ordenador junto con las nuevas posibilidades docentes que propician las TIC, han supuesto un replanteamiento de contenidos teóricos y prácticos del área.

Los nuevos métodos y aplicaciones de la tecnología suponen un riesgo para las antiguas competencias del área de Ingeniería Gráfica, toda vez que su- 
ponen una oportunidad de dinamización del área para incluir nuevos contenidos.

\section{2. Ámbito técnico}

El Diseño Asistido por Ordenador representa un aumento del conjunto de métodos para el modelado geométrico, de forma complementaria a los sistemas de representación usados en soportes bidimensionales. A pesar de la implementación de nuevos procedimientos a partir del modelado usando los sistemas de CAD 3D, se observa el mantenimiento del sistema diédrico como razonamiento teórico e instrumento de abstracción.

Los contenidos necesarios de geometría del espacio para el modelado mediante herramientas CAD 3D no varían respecto a los que se requieren en la representación bidimensional. Los programas de Diseño Asistido por Ordenador han supuesto una reconsideración de parte de los contenidos clásicos de representación gráfica.

\section{3. Ámbito de innovación educativa}

Las TIC han favorecido el cambio en las metodologías de enseñanza-aprendizaje propuestas en el marco del EEES. Se promueve el aprendizaje a lo largo de la vida, basado en problemas y casos prácticos.

El alumnado ha sido uno de los actores influyentes en la transformación del área Ingeniería Gráfica, gracias al interés que despiertan las nuevas tecnologías en ellos. La generalización de los ordenadores personales y el fácil acceso a Internet han permitido sustentar este cambio.

Es necesaria una adaptación de la docencia a la realidad social. Concurre preocupación en el ámbito docente sobre las necesidades que presumiblemente la empresa demanda. Existe gran interés del profesorado en aprender y aplicar nuevos métodos que mejoren la calidad de la docencia, por ello en los congresos se presentan herramientas de apoyo a la docencia.

Parece irrefutable que las TIC influirán de manera significativa en la innovación docente de la Ingeniería Gráfica, Las nuevas tecnologías de soporte a la docencia 
conducirán inexorablemente a un nuevo cambio de paradigma. No sólo plantean un cambio en la forma de aplicar la docencia sino también en los contenidos, por todo ello es el CAD la herramienta «fundamental» de ingeniería gráfica.

\subsection{Hipótesis}

\subsubsection{El empleo de sistemas informáticos en la docencia de Ingeniería Gráfica implica nuevas formas de enseñanza de la materia clásica de geometría}

La informatización completa de las asignaturas de Ingeniería Gráfica suponen la realización de profundos cambios en dos ámbitos diferentes: en la estricta docencia, pero también en la organización de la asignatura.

La informatización de la docencia permite implantar un nuevo paradigma idóneo para la educación, basado en la capacidad de aprendizaje del usuario y estableciendo un diseño apoyado en las teorías del constructivismo. Para que ello sea productivo hay que evitar anteponer el atractivo estético de las nuevas herramientas a las condiciones de interactividad.

La geometría descriptiva es el área de la Ingeniería Gráfica que más fuertemente ha recibido el impacto de la utilización del CAD, hasta el punto de poner en crisis la eficacia de los sistemas de representación clásicos.

La informatización docente permite una mejora en la gestión y el control académico en la asignatura, permitiendo conseguir automatizar las tareas de gestión y control, para mejorar esta labor haciéndola mucho más rápida y eficaz.

\subsubsection{EI DAO supone nuevas oportunidades para el desarrollo del área IG}

El DAO supone un campo importante de mejora en la calidad de la enseñanza en el área de la Ingeniería Gráfica, toda vez que un eficaz recurso en el proceso enseñanza aprendizaje.

El uso de ADI y el DAO de forma conjunta permiten reducir el tiempo en las exposiciones teóricas. Las ventajas que suponen las mejoras de la visualización de modelos, la comprensión de enunciados y soluciones, suponen nuevas oportunidades para la Ingeniería Gráfica. 
Las empresas dedicadas a diseño de producto exigen profesionales con conocimientos en el uso de sistemas CAD. El área de Ingeniería Gráfica está especialmente preparada para ocupar este espacio didáctico.

\subsubsection{Las TIC favorecen el nuevo paradigma de enseñanza-aprendizaje impulsado por la plena implantación del EEES.}

Los proyectos de mejora e innovación docente están evolucionando hacia espacios de aprendizaje virtuales promovidos por el uso de las TIC. El estudiante puede tener un aprendizaje adaptado a su necesidad.

La importancia de la Enseñanza Asistida por Ordenador radica en que potencia la figura del profesor, posibilitando que dedique más tiempo a las labores más críticas de la enseñanza.

Es imprescindible implementar las TIC en las tareas docentes para mantener la calidad docente y cumplir con las dedicaciones fijadas en los planes de estudio, siguiendo las directrices marcadas en el EEES. 


\section{BiBLIOGRAFÍA}

\section{Bibliografía general}

ACREDITION BOARD FOR ENGINEERING AND TECHNOLOGY. www.abet.org

AGUER, Mario «La empresa virtual en el marco de la sociedad de la información». Publicaciones de la Real Academia de Ciencias Económicas y Financieras. Barcelona 2000.

ALPISTE, Francesc. "Modelo de formación híbrido para el diseño, producción e integración de contenidos formativos y entornos virtuales de aprendizaje». Tesis doctoral. Barcelona 2002.

ASOCIACIÓN DE ENSEÑANTES DE INFORMATICA DE CATALUNYA. Educación e informática. www.aeic.es

BANEGAS. «¿El séptimo hito de las telecomunicaciones?» El País Negocios. 6 abril 2003. Pág. 6.

BATES, A.W. «Como gestionar el cambio tecnológico. Estrategias para los responsables de centros universitarios.» Ediuoc. Gedisa Editorial. Barcelona 2001. ISBN 84-8429-400-5

BATLLE, Joan. «El tiempo libre infantil y juvenil». Revista La Factoría no 3 
BELLO, y otros. "Los sistemas de información en ingeniería». XI INGEGRAF. BilbaoDonostia. Junio 1997. Departamento Expresión Gráfica y Proyectos de Ingeniería EHU. BI-788-97

BENEDITO, Josep. "La arquitectura en la universitat i el territori». Artículo en la revista Inde. Julio 2001

BERMEJO. «Geometría descriptiva aplicada». Editorial Tebar-Flores. Madrid 1996. ISBN-84-7360-159-9

BERMÚDEZ y otros. «Desarrollo del producto: del boceto a la representación en video». XI INGEGRAF. Bilbao-Donostia. Junio 1997. Departamento expresión gráfica y proyectos de ingeniería de la EHU. BI-788-97

BERTOLINE. "Dibujo en ingeniería y comunicación gráfica» 2a edición. Editorial McGraw-Hill Interamericana Editores. ISBN 970-10-1947-4

BLADE, Artur. «Universitats i Desenvolupament Regional a Europa». Conclusions. Departament de Universitats, Recerca i Societat de la Informació. Direcció General d'Universitats. Octubre 2003. B-44.808-2003

BOONE, Tonya y otros. "The effect of information technology on learning in professional service organizations». Journal of Operations Management. Volume 19, Issue 4, pag. 485-495. Julio 2001.

BORGES DE BARROS, Hernane. "Análisis experimental de los criterios de evaluación de usabilidad de aplicaciones multimedia en entornos de educación y formación a distancia». Tesis doctoral 2002. www.tdx.cbuc.es

BRICALL, Josep Ma . «La universidad, al final del milenio». Ponencia presentada en la Conferencia «Los objetivos de la Universidad ante el nuevo siglo». Universidad de Salamanca, noviembre 1997. www.crue.org

CARO, José L. y otros. «Ejemplo de aplicación de multimedia al dibujo industrial». VI INGEGRAF. Tomo II. Página 307. Universidad de Castilla la Mancha. Toledo. 1994. ISBN 84-88248-28-8

CARRETERO, A. y otros. «Enseñanza de ingeniería gráfica asistida por Internet» XI INGEGRAF. Volumen I. ISBN 84-699-0473-6. Logroño-Pamplona 1999. 
CASTELLS, Manuel. Entrevista en EL PAIS, 19-07-98. Suplemento Domingo. Páginas 6 y 7.

CODINA, Xavier «Pasado, presente y futuro de la informatización de la docencia de técnicas de representación gráfica». XI INGEGRAF. Volumen III. ISBN 84-699-04752. Logroño-Pamplona 1999.

COLOBRANS, Jordi. «El doctorando organizado. La gestión del conocimiento aplicada a la investigación.». Mira editores. ISBN 84-8465-061-8. Zaragoza. 2001.

CONSEJO DE UNIVERSIDADES. «El stock de titulados universitarios y su relación con el mercado de trabajo». 1976-86. Ministerio de Educación y Ciencia. 1989. ISBAN 84600-7236-3.

CONSEJO DE UNIVERSIDADES. «Profesorado universitario: situación en España y tendencias internacionales». Ministerio de Educación, Cultura y Deporte. M-24.631. Madrid 2000.

CORBELLA, D. «Elementos de normalización. Dibujo técnico 3». Madrid 1970. Editorial Donostiarra. Depósito legal M-17669-1970.

CRUE. «Hacia un espacio europeo de enseñanza superior». Documento № 25. www.crue.org

DE LA POZA, Josep Ma. «Un tomb de 150 anys d'història. Corporació d'enginyers tècnics industrials de Catalunya (1850-1995)». Edita COETIC. Barcelona 1995. ISBN-B-14376-95

DRUCKER, Peter. «El management del siglo XXI». Edhasa. Barcelona 2000. 1a edición. ISBN-84-350-1452-5

DRUCKER, Peter. «La empresa en la sociedad que viene». Empresa Activa / Nuevos Paradigmas. Ediciones Urano. Barcelona 2003. ISBN 84-95787-43-1

ESTEFANÍA, Joaquín. «La precaria sociedad de la información». El País Domingo. 1 julio de 2001. Página 9.

FADÓN Salazar, Fernando; Cerón Hoyos, José Enrique; Vallejo Lobete, Esther. «Programación basada en competencias. Implantación en ingeniería gráfica. DYNA Ingeniería e Industria. Año 84. № 2. Marzo 2009. ISSN 0012-7361. 
FELEZ, Jesús. «Dibujo industrial». Editorial Síntesis SA. Madrid 1999. ISBN 84-7738331-6.

FERNÁNDEZ, Federico y J. Mạ Monguet. «La comunicació visual» Edicions de la Universitat Politècnica de Catalunya. 2ª edición. 1985. ISBN 84-7653-000-5.

FERNÁNDEZ-CARVAJAL, Rodrigo. «Retorno de la universidad a su esencia». Secretariado de Publicaciones. Universidad de Murcia. 1994. ISBN-84-7684-493-X

FERRATE. «Universidad y nuevas tecnologías. El camino hacia la hiperuniversidad». "La universidad en el cambio de siglo». Madrid. Alianza Editorial.

GABILONDO, Ángel. Entrevista en «El País Semanal» n 1429. 15 de febrero 2004. Página 18.

GARCÍA ALMIRALL, Ignasi. «Proyecto de informatización de la docencia de Técnicas de Representación Gráfica (TGR) en la Escuela Técnica Superior de Ingenieros Industriales de Barcelona». XI INGEGRAF. Volumen I. ISBN 84-699-0473-6. Ed. Secretaría del XI CIIG. Logroño-Pamplona 1999.

GIESECKE, M. «Dibujo técnico». Grupo Noriega Editores. México 1992. 5a edición. ISBN 968-148-0963-7

GILDER, George. «Telecosm. How infinite bandwidth will revolutionize our world». The Free Press. New York 2000. ISBN0-684-80930-3

GISBERT, Mercé. «Docència i noves Tecnologies: Recomanacions Pedagògiques» ponencia presentada en la jornada «Las TIC en la docencia en la UPC: experiencias realizadas», de 14 de junio de 2002 en la UPC.

GOLOBARDES Ribé, Elisabet y otros. Guía para la evaluación de las competencias en el área de Ingeniería y Arquitectura. AQU. Junio 2009. B-27.204-2009. pág. 7.

GÓMEZ, Asunción y otros. «Ingeniería del conocimiento». Centro de Estudios Ramón Areces. Madrid 1997. ISBN 84-8004-269-9.

GORDILLO, Susana. Conferencia el 17/3/03 en la ETSEIB, programa de doctorado «Enginyeria Multimedia» 
GRIFUL, Eulalia. "Els estudis semipresencials de 2on cicle d'Enginyeria d'Organització Industrial a I'ETSEIT» ponencia presentada en la jornada "Las TIC en la docencia en la UPC: experiencias realizadas», junio 2002.

GUTIERREZ, Alfonso. «Educación multimedia y nuevas tecnologías». Madrid.

HANNAH, Richard L. «Merging the intellectual and technical infrastructures in higher education: The Internet example». The Internet and Higher Education. Volume 1, Issue 1, pag. 7-20. 1998.

HELMI, Asleena. "An analysis on the impetus of online education: Curtin University of Technology, Western Australia» The Internet and Higher Education. Volume 4, Issues 3-4, pag. 243-253. 2001.

JULIÁN, Fernando y otros. «El pensamiento gráfico, un proceso de comunicación» Ponencia presentada XIV INGEGRAF. Santander. Junio 2002. http://departamentos.unican.es/digteg/ingegraf/cd/xivcongreso

KINDER, Hermann. «Atlas Histórico Mundial». Ediciones Istmo. 10a edición. Madrid 1980. ISBN 84-7090-005-6

KURZWEIL, Ray. "La era de las maquinas espirituales». Planeta. Barcelona 1999. ISBN 84-08-03218-6.

LABORATORIO VIRTUAL. www.paisvirtual.com/educacion

LAFUERTE, Alberto. El País Negocios. 24 de febrero de 2002. Pág. 20.

LEVY, Jack, y otros. "Students' perceptions of interpersonal aspects of the learning environment». Learning Environments Research. Volume 6. pages 5-36. 2003.

MARTíN, Carmela. «El fracaso de la política tecnológica». El País Negocios. 21 octubre de 2001. Pág. 5.

MERRILL, David. «First principles of instruction» Submitted for publication to Educational Technology Research \& development. Utah State University. 2002. www.id2.usu.edu

MONGUET, Josep Ma y otros. "Las comunicaciones multimedia ¿constituyen nuevos ámbitos científicos y técnicos de interés para el área de expresión gráfica en la ingeniería. Ponencia presentada en INGEGRAF 1998. 
MONGUET, Josep Ma. «Aprendizaje a lo largo de la vida y gestión del conocimiento». Editorial de septiembre 2003 del "Laboratori d'Aplicacions Multimèdia» de la UPC. www.lam.upc.com

MONGUET, Josep Mã. «Espacio Internet. Aprender e investigar en la universidad». Editorial de diciembre 2002 del «Laboratori d'Aplicacions Multimèdia» de la UPC. www.lam.upc.com

MONGUET, Josep Mạ. "La expansión del espacio en Internet» Editorial de marzo 2002 del Laboratori d’Aplicacions Multimedia. http://lam.e-gim.net

MORA, Gines. «Profesorado universitario: situación en España y tendencias internacionales». Cuadernos del Consejo de Universidades. Ministerio de Educación, Cultura y Deporte. M-24.631. Madrid 2000.

NEGROPONTE, Nicholas. «El mundo digital». Ediciones B. Barcelona 1995. ISBN84-406-5925-3

OLMOS, Agustín. «Nuevas tecnologías y educación en Andalucía». Quadernsdigitals.net/articles/monográfico/mononuevas

PAHL, Claus. «Managing evolution and change in web-based teaching and learning environments». Computers \& Education. Volume 40, Issue 2, pag. 99-114. Febrero 2003.

PALMER, Stuart. "On- and off-campus computer usage in engineering education». Computers \& Education. Volume 34, Issue 2, Pages 141-154. Febrero 2000.

PEREZ RUBALCABA, Alfredo. "LRU. Universidad y poderes públicos». Ponencia presentada en la Conferencia "Los objetivos de la Universidad ante el nuevo siglo». Universidad de Salamanca, noviembre 1997. www.crue.org

PEREZ, D. y otros. «Expresión gráfica en la ingeniería. Introducción al Dibujo Industrial». Editorial Prentice Hall. Madrid 1998. 1a edición. ISBN 84-8322-139-X

REAL ACADEMIA DE LA LENGUA ESPAÑOLA. «Diccionario de la lengua española». 20a edición. 1984. ISBN-84-239-4778-5

ROBEY, Daniel y otros. "Information technology and organizational learning: a review and assessment of research» Accounting, Management and Information Technologies. Volume 10, Issue 2, pag. 125-155. Abril 2000. 
RODRÍGUEZ DE ABAJO, y otros. «Normalización del dibujo industrial». Editorial Donostiarra. San Sebastián 1993. ISBN 84-7063-181-0

SANGRÀ, Albert, y otros. "Projecte astrolabi. 2on informe de l'observatori sobre la implantació i l'ús de les tecnologies de la informació i comunicació a l'ensenyament no universitari.» UOC. IN3 Edu Lab. Fundació Jaume Bofill. Barcelona 2000.

SANGRÀ, Albert. «Enseñar y aprender en la virtualidad». Educar (revista del Departament de Pedagogia Aplicada de la UAB) no 28, 2001, SIN 0211-819-X.

SANVISENS, Alexandre. Presentación del libro «La comunicació visual» (Fernández, Federico y J. Ma Monguet). Edicions de la Universitat Politècnica de Catalunya. 2a edición. 1985. ISBN 84-7653-000-5.

SARTORI, Giovani. «Homo Videns. La sociedad teledirigida». Ed. Taurus. Madrid 1998.

SCHMIDT. «Geometría descriptiva con figuras estereoscópicas». Editorial Reverte. Barcelona 1986. ISBN-84-291-5135-4

SCOTT, Rachael y otros. "Managing technological change in education - what lessons can we all learn?». Computers \& Education. Volume 26, Issues 1-3, pag. 131134. Abril 1996.

SUÁREZ, Benjamín. "La Sociedad del Conocimiento: una revolución en marcha». Presentación en la Universidad de les Illes Balears. 8 de mayo de 2003. biblioteca. uam.es/documentos/Jornadas_REBIUN

SUÁREZ, Javier y otros. "Nuevas tecnologías en la enseñanza virtual a través de la red» XIV INGEGRAF. Santander. Junio 2002. http://departamentos.unican.es/ digteg/ingegraf/cd/xivcongreso.html

TAYLOR, J. «Fifth generation distance education». 25/02/2003. www.icde.org

TERCEIRO, José. «Sociedad digital. Del homo sapiens al homo digitalis». Alianza Editorial. Madrid 1996.

TERCEIRO, José. Entrevista en Ciberpaís de 3 de agosto 2000. Página 9. 
THOMAS, Gregory P. «Conceptualisation, development and validation of an instrument for investigating the metacognitive orientation of science classroom learning environments: the metacognitive orientation learning environment scale - science (moles-s)». Learning Environments Research. Volume 6. pag. 175-197. 2003.

ULBRICHT, Vania Ribas y otros. "Caminhando no tempo com a geometria» Ponencia presentada XIV Congreso Internacional de Ingeniería Gráfica. Santander. Junio 2002. http://departamentos.unican.es/digteg/ingegraf/cd/xivcongreso.html

WEDEMEYER. "Learning at the Back-door». Madison: University of Wisconsin. 1981.

\section{Bibliografía congresos}

ALIAGA Maraver, José Juan; Casati, María Jesús; Rúa, José Jaime. Implantación de metodologías activas basadas en la materialización mediante maquetas de proyectos de ingeniería. 20 INGEGRAF. Valencia 2008.

ALONSO, Ángela; de Cos, Javier; Ortega Fernández, Francisco; García, Rubén; Bello, Antonio. Detección, diferenciación y digitalización automática de cubiertas vegetales en entornos urbanos a través de imágenes en espectro visible e infrarrojo. 20 INGEGRAF. Valencia 2008.

ALPISTE Penalba, Francesc; Brigos Hermida, Miguel; Fernández Sánchez, Joaquín. Entorno virtual de aprendizaje Web de soporte a la asignatura de Oficina Técnica. IV CIDUI. Barcelona 2006.

ALPISTE Penalba, Francesc; Torner Ribé, Jordi; Brigos Hermida, Miguel. Evaluación de la satisfacción de los estudiantes en un entorno semi-presencial de aprendizaje. XV CUIEET. Valladolid 2007.

ALPISTE Penalba, Francesc; Brigos Hermida, Miguel. Oficina técnica. Web de soporte a la coordinación de la asignatura. XII CUIEET. Barcelona 2004.

ÁLVAREZ Peñín, Pedro Ignacio; López Brugos, J.A.; García Díaz, R.P.; Suárez Quirós, J. Reflexiones sobre la evolución de la enseñanza asistida por computador a través de los congresos de EGI y sobre sus posibilidades futuras. X INGEGRAF. Málaga 1988. 
ÁLVAREZ Peñín, P.I.; Charro Hernández, M.E.; García Díaz, R.P.; Suarez Quirós, J. Análisis de la utilización de las NNTT en la ETSII de Gijón. Actas del VIII Congreso Universitario de Innovación Educativa en las Enseñanzas Técnicas. ISBN 84-7585402-8. Donostia 2000.

ÁlVAREZ Peñín, Pedro Ignacio; Pando Cerra, Pablo; García Díaz, Rafael. Análisis del rendimiento de un programa de CAD-3D modular orientado al autoaprendizaje. XIX INGEGRAF. Perugia 2007.

ÁlVAREZ Peñín, Pedro Ignacio; Pando Cerra, Pablo; García Díaz, Rafael; Pérez Morales, Máximo. Entorno multimedia para uso docente en materias de expresión gráfica. XVIII INGEGRAF. Barcelona 2006.

ÁlVAREZ Peñín, P.I.; López Brugos, J.A.; García Díaz, R.; Suárez Quirós, J. Reflexiones sobre la evolución de la enseñanza asistida por computador a través de los congresos de EGI y sobre sus posibilidades futuras. X INGEGRAF. Málaga 1998.

ALVAREZ-MOZOS, J.; Perez, A.; Crespo, J.J.; Marcelino, S.; Adaptación de la asignatura Técnicas de representación de Ingenieros Agrónomos al Espacio Europeo de Educación Superior. XXI INGEGRAF - XVII ADM. Lugo 2009.

AYALA, D; Franquesa, M; Joan, R; Pérez, LI.; Pla, N; Puig, A; Solano, L; Soto, A; Tost, D; Vigo, M; Vila, S; Vilaplana J. La docència d'informàtica en estudis no informàtics. XI CUIEET. Vilanova i la Geltrú 2003.

BENITO, J.A. Análisis de la dedicación horaria del alumno de fase selectiva del plan de estudios 95 en la EUETIB. XI CUIEET. Vilanova i la Geltrú 2003.

BERMÚDEZ Rodríguez, F.; Lapaz Castillo, J.L.; Marqués Calvo, J.; Povill Cartoixà, D.; Morón Tarifa, M.; Voltas i Aguilar, J. Aplicación de las tecnologías de la información y las comunicaciones en la enseñanza de la expresión gráfica. XI INGEGRAF. Logroño 1999.

BERMÚDEZ Rodríguez, F.; Lapaz Castillo, J.L.; Marqués Calvo, J.; Morón Tarifa, M.; Povill Cartoixà, D.; Voltas Aguilar, J. Utilización de las nuevas tecnologías de la información y de las comunicaciones en las asignaturas de carácter semi-presencial. XII INGEGRAF. Valladolid 2000.

BLANCO Caballero, M; Martín Panero, A; Prádanos del Pico, R; Rodríguez Ovejero, Q; Sanz Arranz, J; Parra Gonzalo, E; San Martín Ojeda, M; Serrano Sanz, J. Estudio 
del sistema diédrico mediante un tutorial multimedia. XVII INGEGRAF - ADM. Sevilla 2005.

BRIGOS Hermida, Miguel; Alpiste Penalba, Francesc; Torner Ribé, Jordi. Análisis crítico de resultados y planteamiento de mejoras como consecuencia de la adaptación de la Asignatura de Expresión Gráfica en la Ingeniería al EEES. XV CUIEET. Valladolid 2007.

BRIGOS, Miguel; Torner, Jordi; Alpiste, Francesc; Fernández, Joaquín; García, Andrés; Farrerons, Oscar. Estrategias en la generación de contenidos para formación Presencial - Online. XVIII CUIEET. Santander 2010.

BUSTINZA Esparta, Jorge; Fernández Villegas, Antonio; Bustinza Esparta, Javier. Una propuesta para la integración de aplicaciones telemáticas en la enseñanza de la geometría descriptiva. IX INGEGRAF. Bilbao 1997.

CALLEJERO Cornao, Bernardino; García Hernández, César. Entorno didáctico multimedia para el aprendizaje del programa de modelado Solid Designer. XIV INGEGRAF. Santander 2002.

CAMIÑA Catalá, Carlos; Ballester Sarriás, Enrique. ¿Aprendes o te examinas?: evaluación de competencias versus evaluación de conocimientos. XVI CUIEET. Cádiz 2008.

CAMIÑA Catalá, Carlos; Ballester Sarriás, Enrique. Bolonia año cero: la renovación metodológica. XVIII CUIEET. Santander 2010.

CAÑAS, Ignacio; Bayod, Carlos; Velilla, Cristina; de San Antonio, Carlos. Pensamiento Crítico para el Pensamiento Gráfico. XIX INGEGRAF. Perugia 2007.

CAPELLA, Juan V.; Ors, Rafael. Hacia la integración en el Espacio Europeo de Educación Superior: nuevo diseño de la asignatura «redes industriales de computadores». XI CUIEET. Vilanova i la Geltrú 2003.

CAPÓ Vicedo, Josep; Expósito Langa, Manuel; Tomás Miquel, José. Metodología docente en la asignatura Gestión de Sistemas Avanzados de Fabricación. III CIDUI. Girona 2006.

CARRERA, Enric; Alpiste, Francesc; Massana, Eulalia; Fernández, Joaquín; Monguet, Josep Ma. Una experiencia de enseñanza no presencial y entrono multimedia en la UPC. II CIDUI. Tarragona 2002. 
CARRETERO Díaz, A; Martínez Muneta, M.L.; Félez Mindán, J.; Cabanellas Becerra, J.M.; Maroto Ibáñez, J.; Alvarez García, R. Enseñanza de Ingeniería Gráfica Asistida por Internet. XI INGEGRAF. Logroño 1999.

CASTELLÀ, Josep M.; Viñas, Judit. Metodología y organización del tiempo de aprendizaje en el crédito ECTS. V CIDUI. Lleida 2008.

CODINA, Xavier. Pasado, presente y futuro de la informatización de la docencia de técnicas de representación gráfica. XI INGEGRAF. Logroño 1999.

CONTERO González, M.; Vergara Monedero, M. La especificación VRML 2.0 y su aplicación en la docencia de la expresión gráfica. IX INGEGRAF. Bilbao 1997.

CORBELLA Barrios, David. Experiencias de innovación pedagógica en la expresión gráfica en la ingeniería. VI CUIEET. Las Palmas 1998.

CRUZ, A.; Blanco, A.; Escalante, M.; Rivas, A. Resultados de una experiencia de aprendizaje virtual en alumnos universitarios. III CIDUI. Girona 2006.

DEL CANTO, Pablo; Gallego, Isabel; López, José Manuel; Mora, Javier; Reyes, Angélica; Rodríguez, Eva; Sanjeevan, Kanapathipillai; Santamaría, Eduard; Valero, Miguel. Evaluación entre compañeros: Como lo hacemos en nuestros cursos de programación de ordenadores. VI CIDUI. Barcelona 2010.

DÍAZ Blanco, Ignacio José; Fernández Villegas, Antonio; López Vázquez, José Antonio; Souto López, José Ramón. Experiencia metodológica en la materia de Expresión Gráfica en la ingeniería técnica en diseño industrial. XIII ADM - XV INGEGRAF. Italia 2003.

FARRERONS Vidal, Oscar; Monguet Fierro, Josep Ma . De los departamentos de expresión gráfica a los laboratorios multimedia. XI CUIEET. Vilanova i la Geltrú 2003.

FANDIÑO Patiño, Santiago; Rodríguez Huertas, Rosa; Gámez Mellado, Antonio; Marín Trechera, Luis. Estrategias de evaluación del trabajo del alumno usando TIC. Actas del XIV Congreso Universitario de Innovación Educativa en las Enseñanzas Técnicas. Oviedo 2006.

FERREIRO Prieto, Juan Ignacio; Pérez del Hoyo, Raquel; Esclapés Jover, Francisco Javier. Sistema b-learning para la enseñanza aprendizaje de expresión gráfica. V CIDUI. Lleida 2008. 
FONT Andreu, Jordi; Hernández Abad, Francisco; Ochoa Vives, Manuel; Hernández Abad, Vicente; López Membrilla, Manel. Experiencia en asignaturas de Expresión Gráfica en proyectos interdisciplinares. XII INGEGRAF. Valladolid 2000.

FONT Andreu, Jordi; Hernández Abad, Francisco; Ochoa Vives, Manuel; Hernández Abad, Vicente. Integración del Diseño Asistido y las TIC en la Ingeniería Gráfica. XIX INGEGRAF. Perugia 2007.

FUENTE Fernández, J.; Pérez Manso, A; Santos Pera, J.A.; Lecubarri Alonso, I. Implantación y adaptación del modelo de liderazgo situacional a la enseñanza en el área de expresión gráfica. 20 INGEGRAF. Valencia 2008.

GARCÍA Almirall, I. Proyecto de informatización de la docencia de Técnicas de Representación Gráfica en la ETSEIB. XI INGEGRAF. Logroño 1999.

GARCIA-GARCIA, María Jesús. Competencias, troncalidad y propuesta de asignaturas en Expresión Gráfica y Geomática para los nuevos Planes de Estudios de la universidad. XXI INGEGRAF - XVII ADM. Lugo 2009.

GARCÍA Garrido, J.; García Castelló, E.; Rodríguez López, A.D.; Laguarda Miró, N.; Pascual Garrido, J. El profesorado universitario y la reforma. Algunas cuestiones pendientes. XIII CUIEET. Maspalomas 2005.

GARCÍA González, Alfonso J.; Troyano Rodríguez, Yolanda. La figura del profesor tutor universitario en el Espacio Europeo de Educación Superior. V CIDUI. Lleida 2008.

GAZO Cervero, A; González-Sánchez, J.L; García Rodríguez, P.; Sánchez Figueroa, F. Elaboración de material docente multimedia para su difusión a través de Internet. VII CUIEET. Huelva 1999.

GIL Molina, Pilar; Elizalde Alcayaga, Luis Mari; Amiama Ibarguren, José Francisco; Bernarás Iturrioz, Elena; Garaizar Arenaza, José Miguel; Monzón González; Francisco Javier. El profesorado universitario ante las propuestas de cambio. Cuatro equipos docentes del campus de Gipuzkoa ante los retos del EEES. V CIDUI. Lleida 2008.

GÓMEZ-ELVIRA González, Miguel Ángel; Puerta Romero, Francisco; De San Antonio Gómez, Carlos; Pascual De La Fuente, José Luis. Evolución de la asignatura de Dibujo Técnico en la Escuela Técnica Superior de Ingenieros Agrónomos de Madrid. 
X INGEGRAF. Málaga 1998.

GÓMEZ Galán, José. Aplicaciones didácticas y educativas de las tecnologías RIV en entornos telemáticos. XIII INGEGRAF. Badajoz 2001.

GRIFUL i Ponsati, Eulàlia; Gibert i Pedrosa, Jaume. Un Segon Cicle semipresencial en Escola Tècnica Superior Enginyeria Industrial de Terrassa. II CIDUI. Tarragona 2002.

GRIÓN, María. Cambios profundos en la expresión gráfica: nuestros primeros pasos. XIII INGEGRAF. Badajoz 2001.

GUTIÉRREZ DE RAVÉ Agüera, E; Mármol Benavente; Fernández Pozuelo, S.; Montero Albiol, R.; Hidalgo Fernández, R. Aplicación de la animación por ordenador a la docencia del dibujo industrial. X INGEGRAF. Málaga 1998.

HERNÁNDEZ Abad, F.; Monguet Fierro, J. Mạ; Ochoa Vives, M.; Hernández Abad, V.; Font Andreu, J. Infraestructura y espacios virtuales para el desarrollo de la enseñanza a distancia. XIII ADM - XV INGEGRAF. Italia 2003.

HERNÁNDEZ Abad, F.; Hernández Abad, V.; Ochoa Vives, M.; Font Andreu, J.; Farré Desongles, C.; Rodríguez García, F. Desarrollo de una Aplicación Didáctica Interactiva en Ingeniería. XI INGEGRAF. Logroño 1999.

HERNÁNDEZ Vázquez, Jesús Ma; Fernandes Rodrigues, Mạ Helena. Adaptación al EEES de una asignatura teórico-práctica. IV CIDUI. Barcelona 2006.

HERRERO de Lucas, Luis Carlos; González González, Mạ Luisa; Acebes Arconada, Luis Felipe; Fernando Velázquez, Ma Luisa; Martín Bravo, Ma Ángeles; Mozo Ruiz, Ismael; Pardo Seco, Fernando; Quintano Pastor, Carmen. Hacia una nueva realidad docente: adaptación al EEES de la titulación de ingeniería técnica industrial, en la Escuela Universitaria Politécnica de Valladolid. V CIDUI. Lleida 2008.

HERVADA Sala, Carme; Jaén Fernández, Carles; Quintela Cortés, Jesús M. Ingeniería electrónica industrial: una experiencia en el desarrollo práctico de los créditos ECTS en la EUETIT (UPC). XIII CUIEET. Maspalomas 2005.

JIMÉNEZ, F. Retos, dificultades y posibilidades de la implantación de una metodología docente vinculada al sistema de créditos ECTS en el área de expresión gráfica en la ingeniería. XIII CUIEET. Maspalomas 2005. 
JIMÉNEZ, Felipe; Fernández, Consuelo; Pérez, Francisco; Leo, Teresa J.; Navarro, Emilio; Arraiza, Paz; Barrera, Paula; Lozano, Carlos. Rediseño de asignaturas para su impartición en formato semipresencial o a distancia. XVI CUIEET. Cádiz 2008.

LAPAZ Castillo, José Luis; Voltas i Aguilar, Jordi. Nuevos enfoques en la docencia del CAD y la normalización eléctrica. XIV INGEGRAF. Santander 2002.

LAPAZ Castillo, José Luis. Experiencia docente en el rediseño de la asignatura de economía española, incluida en los estudios de ingeniería en organización industrial. I CIDUI. Barcelona 2000.

LLORENS, M.; Ballester, E.; Gámiz, D.; Bertrán, E.; Tobías, S.; Galiano, F. El proceso de autoevaluación de la EUETIB. VI CUIEET. Las Palmas 1998.

LÓPEZ DE HERRERA, Juan C.; Gómez-Elvira González, Miguel A; Rojas Sola, José I. Representación Gráfica de la evolución en las almazaras, entre 1850 y 1950, mediante técnicas de dibujo asistido por ordenador. XVI INGEGRAF. Zaragoza 2004.

LORCA Hernando, Pedro José; Merino Egea, Manuel; Recio Díaz, M. Mar; Ocaña López, Rosa; Vicario López, José. Sustitución de las herramientas tradicionales de dibujo por el CAD en las asignaturas de expresión gráfica. XVII INGEGRAF - ADM. Sevilla 2005.

MARÍN Granados, MD.; Gutiérrez Ariza, FJ.; García Ceballos, MāL.; Mora Segado, P. La Enseñanza Asistida por Ordenador como recurso eficaz en el proceso enseñanza-aprendizaje. XII INGEGRAF. Valladolid 2000.

MARTín Gutiérrez, Jorge; Martín Dorta, Norena; Saorín Pérez, José Luis; Acosta González, Montserrat. Campus virtual en la docencia de expresión gráfica en la ingeniería en la universidad de La Laguna. XVIII INGEGRAF. Barcelona 2006.

MARTín Lorenzo, Gerardo; Suárez Rivero, José Pablo; García Domínguez, Melchor. Laboratorio Virtual para el Estudio y Aprendizaje de Mecanismos en la Ingeniería. VIII CUIEET. ISBN 84-7585-402-8. Donostia 2000.

MARTínEZ Muneta, M.L.; Romero Rey, G.; Félez Mindán, J. El proyecto WEBD: aplicación de los gráficos WEB3D en la ingeniería. XVI INGEGRAF. Zaragoza 2004.

MARTíNEZ Sentana, Alberto; Sentana Gadea, Irene. Evolución en la enseñanza del dibujo técnico mecánico en las enseñanzas técnicas. X CUIEET. Valencia 2002. 
MATEO Carballo, F.; Llorente Geniz, J; Sánchez Jiménez, F.J.; Reina Valle, R.; Fernández de la Puente, A. Docencia de Modelado Tridimensional mediante herramientas de animación asistida por ordenador. XII INGEGRAF. Valladolid 2000.

MEDEIROS Filho, Dante Alves; Cintra, Jorge Pimentel. Ordenadores en la enseñanza y aprendizaje de ingeniería. XIII INGEGRAF. Badajoz 2001.

MERINO Egea, M.; Fernández Martín, L. Comunicación multimedia: curvas cicloidales. IX INGEGRAF. Bilbao 1997.

MERINO Egea, Manuel; Martín García, Jesús; Corbella Ribes, David; Recio Díaz, Mạ Mar; Ocaña López, Rosa; Vicario López, José; Narbón Prieto, Julián. Nuevas expectativas tutoriales y didácticas en un entorno de red. X CUIEET. Valencia 2002.

MINGUEZ Gabiña, Rikardo; Muniozguren Colindres, Javier; Arias Coterillo, Agustín; Barrenetxea Apraiz, Lander; Sierra Uria, Egoitz. Proyecto universidad-empresa: diseño de nueva gama de Putters mediante ingeniería inversa. XVIII INGEGRAF. Barcelona 2006.

MORATO Moreno, M. Dos años de experiencias con la enseñanza reglada del Dibujo Asistido por Ordenador. VII CUIEET. Huelva 1999.

MORENO Cazorla, R. Nuevas tecnologías de la información y las comunicaciones en el ámbito docente de la Expresión Gráfica: EI CAD como punto de partida y no como disciplina complementaria. XII INGEGRAF. Valladolid 2000.

MOREU de Cózar, Belén; Moreu Jalón, Eduardo. Reflexión sobre Expresión Gráfica en el Espacio Europeo. 20 INGEGRAF. Valencia 2008.

ORERO Giménez, Alejandro; Criado Fernández, Mar; García Cabeza, Camilo. El uso de las TIC en la formación: el caso ARFO. VIII CUIEET. ISBN 84-7585-402-8. Donostia 2000.

ORIOZABALA Brit, José Antonio; Garmedia Mujika, Mikel; Galarraga Astibia, Roberto; Albisua, Joaquín. Experiencias de EAO en el aula. XI INGEGRAF. Logroño 1999.

ORTEGA Arceo, José Miguel; Urraza Digón, Guillermo; Doria Iriarte. Competencias en dibujo de ingeniería industrial demandadas por las empresas del País Vasco y acciones de mejora propuestas en respuesta al EEES. 20 INGEGRAF. Valencia 2008. 
PALLISERA Díaz, Maria; Carretero Torres, Reyes. Implicación de la Facultad de Educación y Psicología en la mejora de la docencia y la reforma de los planes de estudios. V CIDUI. Lleida 2008.

PASCUAL Albarracín, Esther; Prieto Alberca, Manuel; Sondesa Freire, Ma Dolores. Generalización del teorema de Desargues. XIV INGEGRAF. Santander 2002.

PELLEJERO Salaberria, I; Mongelos Oquiñena, MB; Gurruchaga Vázquez, JM; Galarraga Astibia, R; Garmendia Mujika, M; Oriozabala Brit, JA. Sistema Multimedia aplicado a la mejora del proceso enseñanza-aprendizaje en el estudio de las Bombas Hidráulicas. VIII CUIEET. ISBN 84-7585-402-8. Donostia 2000.

PÉREZ Rojas, Luis; González Gutiérrez, Leo Miguel; Zamora Rodríguez, Ricardo; Sánchez Sánchez, Juan Miguel. Aportaciones sobre la implantación del Plan Bolonia. Un giro copernicano para los alumnos. XVIII CUIEET. Santander 2010.

PORTILLO Franquelo, Pedro; Guerrero Strachan, Jesús; López López, Antonio. Calidad, creatividad, fantasía e imaginación; las notas de una nueva dimensión de la expresión gráfica. X INGEGRAF. Málaga 1998.

RAJADELL Carreras, Manel; Astals Coma, Francesc. Las enseñanzas semipresenciales: la experiencia de la ETSI de Terrassa. VIII CUIEET. ISBN 84-7585-402-8. Donostia 2000.

RAMÍREZ Vallvey, Jorge; Morciego García, Carlos. Programa de dibujo para la ingeniería eléctrica. XVI INGEGRAF. Zaragoza 2004.

RAMOS Barbero, B; García Maté, E; Caro Rodríguez, J.L. Técnicas multimedia aplicadas a la docencia de Dibujo Técnico Industrial. VII CUIEET. Huelva 1999.

REBOLLO Castillo, Fco. Javier; Álvarez Martínez, Pedro. Desarrollo de una propuesta metodológica para evaluar la docencia de la asignatura Sistemas de Información Geográfica basada en el modelo de Rasch. XXI INGEGRAF - XVII ADM. Lugo 2009.

RODRÍGUEZ Villagrá, María; Martínez Muneta, María Luisa; Marquez, J.J.; Carretero Díaz, Antonio. Ayuda al aprendizaje: la inyectora virtual. 20 INGEGRAF. Valencia 2008.

ROJAS Sola, José Ignacio; Jordá Albiñana, Begoña; San Antonio Gómez, Carlos de; Manzano Agugliaro, Francisco. Evaluación de competencias en Expresión Gráfica. XVII CUIETT. Valencia 2009. 
ROJAS Sola, José Ignacio. Utilización de la Plataforma ILIAS 3.0 en la Experiencia Piloto de Implantación del EEES a la docencia de la Expresión Gráfica. XVII CUIEET. Valencia 2009.

SÁNCHEZ Jiménez, J; Mateo Carballo, F; Fernández de la Puente, A; Reina Valle, R.; Llorente Geniz, J. Los planes de estudios de Ingeniero Técnico en Diseño Industrial. Análisis comparativo. XII INGEGRAF. Valladolid 2000.

SÁNCHEZ, J.A.; Torrent, M.; Blanqué, B.; Perat, I. Adaptación de las enseñanzas técnicas a los ECTS. XIV CUIEET. Oviedo 2006.

SÁNCHEZ Sánchez, J.M. La evaluación continua documentada. VI CUIEET. Las Palmas 1998.

SANGRÀ, Albert; Guàrdia, Lourdes; Bellot, Andreu. ¿Pueden las innovaciones tecnológicas mejorar la docencia universitaria? I CIDUI. Barcelona 2000.

SENTANA Gadea, Irene; Sentana Cremades, Eloy; Serrano Cardona, Canuel; Tomás Jover, Roberto; Pigem Boza, Ricardo; Gomez Gabaldón, Arquímedes; Perez Carrion, Mạ Teresa; Diaz Ivorra, Ma Carmen; Ferreiro Prieto, Ignacio; Poveda Pérez, José Luis; Martinez Sentana, Alberto. Estudio para el diseño de contenidos de geometría para ingenieros. XVI INGEGRAF. Zaragoza 2004.

SENTANA Gadea, Irene; Sentana Cremades, Eloy; Gutiérrez Diego, Yolanda; Poveda Pérez, José Luís. El desafío de la ingeniería gráfica ante el nuevo sistema universitario del siglo XXI. 20 INGEGRAF. Valencia 2008.

SENTANA Gadea, Irene; Ferreiro Prieto, Ignacio; Tomás Jover, Roberto; Díaz Ivorra, M-Carmen. Nueva metodología en la docencia en ingeniería química. X CUIEET. Valencia 2002.

SERRANO Cardona, Manuel; Pérez Carrión, Teresa. Percepción espacial y dibujo técnico. Método de autoformación del alumnado de las escuelas técnicas basado en los indicadores de la tercera dimensión. IX INGEGRAF. Bilbao 1997.

SOLÉ Gustems, Miquel. Adaptación de los créditos ECTS a l'Escola Universitària d’Enginyeria Tècnica Industrial d'Igualada. XI CUIEET. Vilanova i la Geltrú 2003.

SUÁREZ Quirós, J.; Rubio García, R.; Gallego Santos, R.; Martín González, S. «Gráficos por computador»: una experiencia de formación on-line en el campus virtual compartido del grupo G9. XII CUIEET. Barcelona 2004. 
SUÁREZ Quirós, Javier; García Díaz, R.P.; Álvarez Peñín, P.I.; Gallego Santos, R. Nuevas tecnologías en la enseñanza virtual a través de la red. XIV INGEGRAF. Santander 2002.

TARDíO Monreal, E.; Fernández Sora, A.; Agustín Hernández, L; Sánchez-Lafuente Lahulla, F. Sistema automatizado de gestión y control académicos en el entorno de una asignatura de expresión gráfica en la ingeniería. XII INGEGRAF. Valladolid 2000.

TORNER Ribé, Jordi; Brigos Hermida, Miguel; Alpiste Penalba, Francesc. Diseño curricular adaptado al EEES para la asignatura de Expresión Gráfica en la Ingeniería. XV CUIEET. Valladolid 2007.

TORTAJADA, I; Brusola, F; Rubió, C. Objetos de aprendizaje aplicados a la asignatura de gestión de los procesos de color. XVII CUIEET. Valencia 2009.

TRONCOSO Saracho, José C; Alonso Rodríguez, José A. Medios didácticos aplicables en la enseñanza del Dibujo. VII CUIEET. Huelva 1999.

UBIETO Artur, Pedro; García Hernández, César; Callejero Cornao, Bernardino; Cebollada Pras, Fernando; Fernández Sora, Alberto; Ibáñez Carabantes, Pedro. Entorno de simulación didáctico de una Ingeniería Técnica Industrial. 20 INGEGRAF. Valencia 2008.

URRAZA Digón, G.; Ortega Arceo, J.M. Participación del alumno para definir un plan de mejora en el aprendizaje de la asignatura de expresión gráfica y DAO. Actas del VI CIDUI. Barcelona 2010.

VALDERRAMA, Fernando; Icarán, Eva; Castaño, Enrique. Diseño y planificación de materias en el EEES: una experiencia de formación del profesorado de la Universidad Europea de Madrid. V CIDUI. Lleida 2008.

VICARIO López, José; Corbella Barrios, David. Aplicación del dibujo tridimensional a la enseñanza de la geometría del espacio o geometría descriptiva. X CUIEET. Valencia 2002.

VILLAR Ribera, Ricardo; Hernández Abad, Francisco. La Geometría Descriptiva de Monge. Una visión multimedia. XIII ADM - XV INGEGRAF. Italia 2003.

ZULUETA Pérez, Patricia; Delgado Urrecho, Javier; Geijo Barrientos, José Manuel. Análisis de los recursos y actividades propios de la plataforma virtual MOODLE, 
para su utilización como apoyo a la docencia presencial de expresión gráfica en la ingeniería. XXI INGEGRAF - XVII ADM. Lugo 2009.

ZURITA de la Vega, Eduardo; Tato Sánchez del Valle, Patricia. Formación a través de plataformas virtuales. 20 INGEGRAF. Valencia 2008.

\section{Bibliografía referenciada}

ALLEN, MW. «Michael Allen's Guide to E-learning». John Wiley \&Sons, 2002.

BANGERT, A.W. «Peer Assessment: A Win-Win Instructional Strategy for Both Students and Teachers» J. Cooperation \& Collaboration in College Teaching, Vol. 10 no 2. Pag 77.

CAMIÑA, C. El PIE y el proceso de enseñanza-aprendizaje en la UPV. Libro jornadas sobre la docencia en la UPV. Ed. SPUPV, Valencia 1998.

CASHIN, WE; Downey, RG. Using Global studing rating items for summative evaluation, Journal of Educational Psychology 84 (4) 1992, pp 563-572.

COHEN, PA. Student ratings of instruction and student achievement, Review of Educational Research 51 (3) 1981 pp 281-309.

DEBORAH, B; Kaurman, F; Richard, F. Accountig for individual effort in cooperative learning teams. J. Engr. Education, 89(2), 133-140 (2000).

DUVAL, E; Hodgins, W. A LOM Research Agenda, WWW2003 Conference, 20-24 May 2003, Budapest, Hongary. http://www.cs.kuleuven.ac.be/ erikd/PRES/2003/ www2003/www2003-paper.pdf

GARCÍA, M.J; Terrón, M.J; Blanco, Y. IV Jornadas Internacionales de Innovación Universitaria, Diseño y evaluación de competencias en las ingenierías de Telecomunicación, Madrid 2007.

GARDNER, Howard. Multiple approaches to understanding. In C.M. Reigeluth (Ed.). Instructional-design theories and models: A New paradigm of instructional theory. Mahwah, NJ: Lawrence Erlbaum Associates, Inc. 1999. 
GUZMÁN, A; Núñez, G. «Virtual Learning Spaces in Distance Education: Tools for the Eva Project» International Journal Expert Systems with Applications (Special Issue), Pergamon Press, 1998.

ILIAS. http://www.ilias.de/docu/goto_docu_cat_581.html

JONASSEN, D.H.; Peck, K.L. y Wilson, B.G. (1999). Learning with Technology: A constructivist Perpective. Upper Saddle, Nueva Jersey: Merrill, Prentice Hall.

KATHY V. Writing instructional objectives. PhD, CLS (NCA), NAACLS Board of Directors.

KEARSLEY, Greg \& Shneiderman Ben, «Engagement Theory: A framework for technology - based teaching and learning. http://home.sprynet.com/ gkearsley/engage.htm

L'ALLIER, J. Frame of Reference: NETg's Map to the Products, Their Structure and Core Beliefs. NETG (1997). http://www.netg.com/research/whitepapers/frameref.asp

MANDEL, Arnaldo; Simon, Inre; Delyra, Jorge L. Informação: computação e comunicação. Revista USP, n.35, pag.10-45, set./out./nov. 1997.

MOON J. Linking Levels, Learning Outcomes and Assessment criteria: the Design of Programmes and Modules in Higher Education. Unpublished paper, Staff Development Unit, University of Exeter. 2000.

NELSON, L. M. (in press). «Collaborative problem solving». In C. M. Reigeluth (Ed.), Instructional-design theories and models: A new paradigm of instructional theory. Mahwah, NJ: Lawrence Erlbaum Associates.

NÚÑEZ, G. «Tecnologías avanzadas de información para soportar el aprendizaje: el proyecto EVA». Proc. Ff the Int. Simposium on Information Technologies for Learning, DF, Mexico, 1997.

PUIG Adam, P. Curso de Geometría Métrica. Tomo I y II. Biblioteca Matemática, Madrid, 1952.

REIGELUTH, C. «Elaborating the elaboration theory». Educational Technology Research \& Development, 40(3), 1992, pp. 80-86.

WILEY, D. The Instructional Use of Learning Objets. Bloomington, IN: Agency for Instructional Technology, (2002). 


\section{ACRónimos}

ABET Accreditation Board for Engineering Technology

ACET Associació Catalana d'Enginyers de Telecomunicació

ACM Association for Computing Machinery

ACUP Associació Catalana d'Universitats Públiques

ADI Aplicación Didáctica Interactiva

ADM Andalucía Digital Multimedia

ADM Associazione Nazionale Disegno di Machine

AENOR Asociación Española de Normalización y Certificación

AFNOR Association Française de Normalisation

AGUR Agència de Gestió d'Ajuts Universitaris i de Recerca (DURSI)

AICRE Asesoramiento para la Introducción del Crédito Europeo

AIDIT Agència d'Acreditació d'Investigació, Desenvolupament i Innovació Tecnològica

AIP Ateliers Inter-établissements de Productique

ALE Asignatura Libre Elección

ANECA Agencia Nacional de Evaluación de la Calidad y Acreditación

AQU Agència per a la Qualitat del Sistema Universitari de Catalunya

ARP Address Resolution Protocol

ARPANET Advanced Research Projects Agency Network

ASCC Automatic Sequence Controlled Calculator

BDC Biblioteca Digital de Catalunya

BINAC Binary Automatic Computer

BOE Boletín Oficial del Estado 
BSI British Standards Institution

CAD Computer Aided Design

CAE Computer Aided Engineering

CAM Computer Aided Manufacturing

CAPD Comisión Académica y Publicaciones Docentes (EGE-UPC)

CATIA Computer Aided Three-dimensional Interactive Application

CBUC Consorci de Biblioteques Universitàries de Catalunya

CD Compact Disc

CDIO Conceive Design Implement and Operate (MIT)

CDITI Conferencia de Directores Escuelas de Ingeniería Técnica Industrial

CD-ROM Compact Disc - Read Only Memory

CEIB Consorci Escola Industrial de Barcelona

CEN Comité Européen de Normalisation

CENT Centro de Educación de las Nuevas Tecnologías (Univ. Jaume I)

CESAER Conference of European Schools for Advanced Engineering Education and Research

CETIB Col-legi d'Enginyers Tècnics Industrials de Barcelona

CEU Catedrático de Escuela Universitaria

CGQ Comisión Gestión de la Calidad (SAGIQ. EGE-UPC)

CIDEM Centro de Información y Desarrollo Empresarial (GenCat)

CIDUI Congreso Internacional de Docencia Universitaria e Innovación

CIM Computer Integrated Manufacture

CINDA Centro Interuniversitario de Desarrollo

CITT Comisión Investigación y Transferencia de Tecnología (EGE-UPC)

CLUSTER Consortium Linking Universities of Science and Technology for Education and Research

CNGP Comisión Nuevos Grados y futuros Posgrados (EGE-UPC)

CNRS Centre National de la Recherche Scientifique (Institut National Polytechnique, Grenoble)

COEIC Col.legi d'Enginyers Industrials de Catalunya

CPU Central Processing Unit

CRT Cathode Ray Tube

CRUE Conferencia de Rectores de las Universidades Españolas

CSGQ Comisión del Sistema de Gestión de la Calidad (EUETIB)

CSTIC Centre de Suport a les TIC (EUETIB)

CTT Centro de Transferencia de Tecnología (UPC)

CU Catedrático de Universidad

CUDU Càtedra UNESCO de Direcció Universitària (UPC)

CUIEET Congreso Universitario de Innovación Educativa en las Enseñanzas Técnicas 
DAO Diseño Asistido por Ordenador / Dibujo Asistido por Ordenador

DEAN Deans and European Academics Network

DEHAES Grupo de Investigación en Habilidades Espaciales

DFM Diseño para Facilidad de Manufactura

DIN Deutsches Institut für Normung

DIUE Departament d'Innovació, Universitats i Empresa (Generalitat Cat.)

DNA Deustcher Normenausschus

DPI Dots Per Inch

DURSI Departament d'Universitats, Recerca i Societat de la Informació (Generalitat de Catalunya)

DVST Direct View Storage Tube

EAC Enseñanza Asistida por Computador

EADTU European Association of Distance Teaching University

EAO Enseñanza Asistida por Ordenador

ECC Electronic Control Corporation

ECTS European Credit Transfer System

ECUK Engineering Council United Kingdom

EDEN European Distance and E-Learning Network

EduLab Laboratorio de Innovación Educativa (UOC)

EEES Espacio Europeo de Educación Superior

EEI Escola d'Enginyeria de Igualada (UPC, adscrita)

EET Escola d'Enginyeria de Terrassa (UPC)

EFQM European Foundation for Quality Management

EFQUEL European Foundation for Quality in e-Learning

EFTA European Free Trade Association

EGE Expressió Gràfica a l'Enginyeria (UPC)

EGI Expresión Gráfica en la Ingeniería

EITAM Escuela de Ingenieros Técnicos Aeronáuticos de Madrid (UPM)

EMUNI Euro-Mediterranean University

ENQA European Association for Quality Assurance in Higher Education

EPSC Escola Politècnica Superior de Castelldefels (UPC)

EPSEM Escola Politècnica Superior d'Enginyeria de Manresa (UPC)

EPSEVG Escola Politècnica Superior d'Enginyeria de Vilanova i la Geltrú (UPC)

EPUF Euromed Permanent University Forum

EQAR European Quality Assurance Register for Higher Education

ESOs European Standards Organizations

ETSEIAT Escola Tècnica Sup. Enginyeries Industrial Aeronàutica Terrassa

ETSEIB Escola Tècnica Superior d'Enginyeria Industrial de Barcelona (UPC)

ETSEIT Escola Tècnica Superior d'Enginyeria Industrial de Terrassa (UPC) 
ETSID Escuela Técnica Superior de Ingeniería del Diseño (UPV)

ETSIIG Escuela Técnica Superior de Ingeniería Industrial de Gijón

ETSIIM Escuela Técnica Superior de Ingeniería Industrial de Madrid (UPM)

ETSIN Escuela Técnica Superior de Ingeniería Naval de Madrid (UPM)

ETSITM Escuela Técnica Superior Ingeniería Telecomunicación Madrid (UPM)

EUA European University Association

EUCEN European Association for University Life Long Learning

EUETIB Escola Universitària d'Enginyeria Tècnica Industrial Barcelona (UPC)

EUETIT Escola Universitària d'Enginyeria Tècnica Industrial Terrassa (UPC)

EUITIB Escuela Universitaria Ingeniería Técnica Industrial Bilbao (UPV/EHU)

EUITIM Escuela Universitaria Ingeniería Técnica Industrial de Madrid (UPM)

EUNIS European University Information Systems

EUOOT Escola Universitària d'Òptica i Optometria de Terrassa (UPC)

EUPM Escola Universitària Politècnica de Manresa (UPC)

EUPMT Escola Universitària Politècnica de Mataró (UPC, adscrita)

EUPVG Escola Universitària Politècnica de Vilanova i la Geltrú (UPC)

EURACERT European eAccessibility Certification

EVA Entorno/Espacio Virtual de Aprendizaje

FAlIE Federación de Asociaciones de Ingenieros Industriales de España

FMS Flexible Manufacture Systems

FTP File Transfer Protocol

GATT General Agreement on Tariffs and Trade

GIDEN Grupo de Innovación Docente especialidad Electrónica Industrial de la Universidad de Valladolid

GIG Grupo de Ingeniería Gráfica y Simulación (UPM)

GRAVIR Graphisme, Vision et Robotique (Universidad de Grenoble)

GUI Graphical User Interface (Interfaz Gráfica de Usuario)

GUNI Global University Network for Innovation

HD-DVD High Definition Digital Versatile Disc

HTTP Hyper Text Transfer Protocol

IA Inteligencia Artificial

IBM International Business Machines

ICAI Escuela Técnica Superior de Ingeniería (Pontifica de Comillas)

ICDE International Council for Open and Distance Education

ICE Instituto de Ciencias de la Educación

ICT Information and Communications Technology (Trinity College, Dublin)

IEEE Institute for Electrical and Electronic Engineering

IG Ingeniería Gráfica

IMM Multimedia Interactivo Online 
INGEGRAF Asociación Española de Ingeniería Gráfica

IJIDeM International Journal on Interactive Design and Manufacturing

INRIA Institut National de Recherche en Informatique et en Automatique (Grenoble)

INSIDE Innovación en Sistemas para el Diseño y la Formación en la Ingeniería (UPC)

IP Internet Protocol

ISA Instrumentation Society of America

ISO International Organization for Standardization

ITACA Instituto de Aplicaciones en Tecnologías de la Información y las Comunicaciones Avanzadas (UPC)

LAM Laboratori d'Aplicacions Multimèdia (UPC)

LAN Local Area Network

LGEFRE Ley General de Educación y de Financiación de la Reforma Educativa

LLP Programa de Aprendizaje Permanente (Comisión Europea)

LMS Learning Management System (gestión proc. enseñanza-aprendizaje)

LOU Ley Orgánica de Universidades

LRU Ley de Reforma Universitaria

LSI Lenguajes y Sistemas Informáticos (departamento UPC)

LUC Llei d'Universitats de Catalunya

MEC Ministerio de Educación y Ciencia

MECD Ministerio de Educación, Cultura y Deporte

MIT Massachusetts Institute of Technology

MODID-3D Modelo Didáctico de Diédrico en 3D

MOODLE Modular Object Oriented Dynamic Learning Environment

MVSMA Marco para la Verificación, el Seguimiento, la Modificación y la Acreditación de títulos oficiales (AQU)

NASA National Aeronautics and Space Administration

NNTT Nuevas Tecnologías

OA Objeto de Aprendizaje

OAPEE Organismo Autónomo Programas Educativos Europeos

OCDE Organización para la Cooperación y el Desarrollo Económico

PAE Proceso Aprendizaje-Enseñanza

PAP Programa de Aprendizaje Permanente (Comisión Europea)

PARC Palo Alto Research Center (Xerox)

PAS Personal Administración y Servicio

PATUPC Plan de Acción Tutorial UPC

PAU Pruebas de Acceso a la Universidad

PC Pensamiento Crítico 


$\begin{array}{ll}\text { PC } & \text { Personal Computing / Ordenador Personal } \\ \text { PDA } & \text { Personal Digital Assistant } \\ \text { PDCA } & \text { Plan, Do, Check, Act (Planificar, Hacer, Verificar, Actuar) } \\ \text { PDI } & \text { Personal Docente Investigador } \\ \text { PG } & \text { Pensamiento Gráfico } \\ \text { PICA } & \text { Préstec Interbibliotecari Consorciat i d'Accés } \\ \text { PIXEL } & \text { Picture Element (Elemento de Imagen) } \\ \text { POP } & \text { Post Office Protocol }\end{array}$

PRIMECA Pôles de Ressources Informatiques pour la MECAnique

QAA Quality Assurance Agency for Higher Education (Reino Unido)

RA Realidad Aumentada

RAM Random-Access Memory

RECyT Repositorio Español de Ciencia y Tecnología

RD Real Decreto

RITA Revista Iberoamericana de Tecnologías de Aprendizaje

RIV Realidad Infovirtual

RMEI Réseau Méditerranéen des Écoles d'Ingénieurs

SETE Student's Evaluation of Teaching Effectiveness

SGIQ Sistemas de Garantía Interna de la Calidad

SI $\quad$ Sociedad de la Información

SIG Sistema de Información Geográfica

SIGGRAPH Special Interest Group on Graphics

SMTP Simple Mail Transfer Protocol

TCP Protocolo de Control de Transmisión

TEU Titular de Escuela Universitaria

TIC / TIC's Tecnologías de la Información y la Comunicación

TIME Top Industrial Managers for Europe

TRG Técnicas de Representación Gráfica

TU Titular de Universidad

UAB Universidad Autónoma de Barcelona

UB Universidad de Barcelona

UdG Universidad de Girona

UdL Universidad de Lleida

UE Unión Europea

UEM Universidad Europea de Madrid

UIC Universidad Internacional de Catalunya

UMTS Universal Mobile Telecommunications System

UNED Universidad Nacional de Educación a Distancia

UNESCO United Nations Educational, Scientific and Cultural Organization 
UNI Ente Nazionale Italiano di Unificazione

UNIVAC Universal Automatic Calculator

UOC Universitat Oberta de Catalunya

UPC Universitat Politècnica de Catalunya

UPF Universidad Pompeu Fabra (Barcelona)

UPM Universidad Politécnica de Madrid

UPV Universidad Politécnica de Valencia

UPV/EHU Universidad del País Vasco / Euskal Herriko Unibertsitatea

URL Universidad Ramón Llull (Barcelona)

URV Universidad Rovira i Virgili (Tarragona-Reus)

US User Satisfaction

UVic Universitat de Vic (Barcelona)

UWEM Unified Web Evaluation Methodology (EURACERT)

VLE Virtual Learning Environment

VRML Virtual Reality Modeling Language

WAI Web Accessibility Initiative

WAN Wide Area Network

WCAG Web Content Accessibility Guidelines

XCT Xarxa de Centres Tecnològics (Generalitat de Catalunya) 
